Uma ferramenta baseada em aspectos para apoio ao teste funcional de programas Java 
SERVIÇO DE PÓS-GRADUAÇÃO DO ICMC-USP

Data de Depósito: 20 de janeiro de 2005

Assinatura:

\title{
Uma ferramenta baseada em aspectos para apoio ao teste funcional de programas Java
}

\author{
André Dantas Rocha
}

Orientador: Prof. Dr. Paulo Cesar Masiero

Dissertação apresentada ao Instituto de Ciências Matemáticas e de Computação - ICMC/USP, como parte dos requisitos para obtenção do título de Mestre em Ciências Ciências de Computação e Matemática Computacional.

USP - São Carlos

Janeiro/2005 
Aos meus pais, Lucia e Aroldo 


\section{Agradecimentos}

Inicialmente a Deus, por todos os momentos de força e esperança.

À minha família, em especial à minha mãe Lucia e ao meu pai Aroldo, que sempre acreditaram em mim e foram educadores, companheiros e exemplos de vida. Obrigado pelo carinho, amor, incentivo e força.

Aos meus irmãos Henrique e Liana e ao meu sobrinho Rodrigo por todo o carinho, ainda que à distância.

À minha namorada e companheira Cris, que sempre me apoiou, incentivou, ajudou e que, sobretudo, teve a paciência de suportar as diversas vezes que não estive com ela para trabalhar nesta dissertação. Seu apoio foi fundamental, muito obrigado pelo seu carinho e compreensão.

Ao meu orientador, Prof. Dr. Paulo Cesar Masiero, pelo profissionalismo, orientação, confiança, incentivo e paciência durante este trabalho. Sua experiência e sugestões foram essenciais.

Ao Prof. Dr. José Carlos Maldonado, pela ajuda e sugestões ao longo de todo o meu mestrado.

Ao Prof. Dr. Adenilso Simão, pela sua colaboração e disponibilidade, incluindo as diversas horas dedicadas, e inúmeras sugestões ao trabalho.

Aos demais professores do grupo de Engenharia de Software: $\operatorname{Prof}^{\mathrm{a}}$. Dr ${ }^{\mathrm{a}}$. Rosely Sanches, Prof $^{\mathrm{a}}$. Dr ${ }^{\mathrm{a}}$. Renata P. M. Fortes e Prof ${ }^{\mathrm{a}}$. Dr ${ }^{\mathrm{a}}$. Rosana T. V. Braga.

A todos do LABES e àqueles considerados amigos do LABES, pelas horas de descontração, alegria e incentivo: Adenilso, Tati, André Luís, Auri, Simone, Débora, Maris, Tânia, Ellen, Sandra Fabbri, Rosângela, Marco, Rogério Garcia, Lu, Richard, Andrea, Reginaldo, Erika, Lisandra, Edilson, Valter, Juliana, Bira, Camila, Otávio (obrigado pela sugestão para o nome da ferramenta), Sandro KLB, Fabiano, Antonielly, Marcelo, Darley, Paula, Stanley, Kicho. E a todos amigos de todos os outros laboratórios.

À minha amiga Erika, em especial, pelas caronas, disposição para ajudar, sugestões e acima de tudo pela amizade. Ao Bira pela amizade e parceria durante todo o mestrado, além da ajuda e disponibilidade constantes. Aos dois pela enorme ajuda durante a última semana do mestrado.

Aos meus amigos da Bahia, em especial a Gerson, que me incentivou a fazer o mestrado.

A todos funcionários, professores e alunos que participaram e colaboraram de alguma maneira na realização deste trabalho.

Ao CNPq, pelo apoio financeiro. 
Você vê as coisas e se pergunta: por quê? Mas eu sonho com coisas que jamais existiram e me pergunto: por quê não?

George Bernard Shaw 


\section{Sumário}

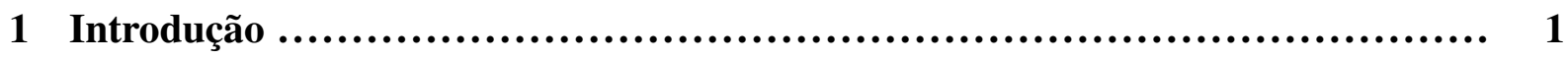

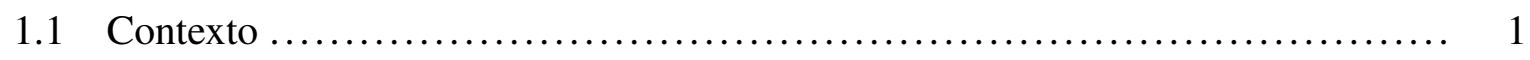

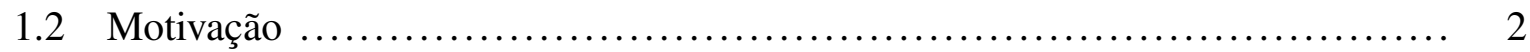

1.3 Objetivos................................................... 3

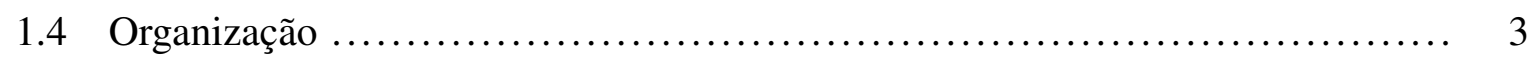

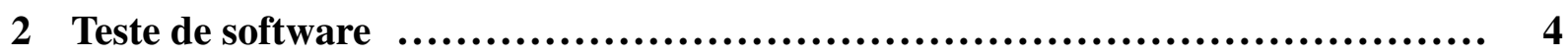

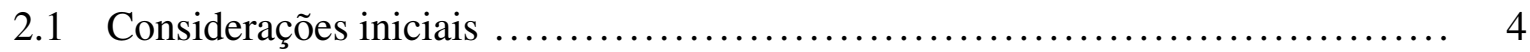

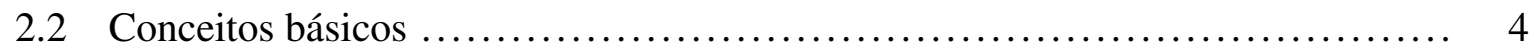

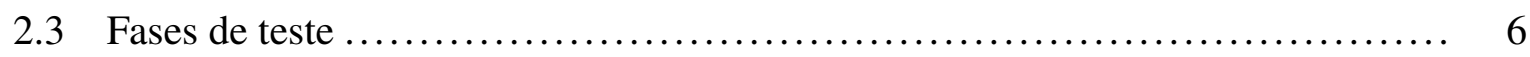

2.3.1 Teste de unidade ........................................... 6

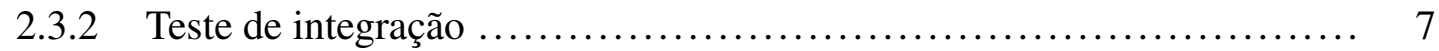

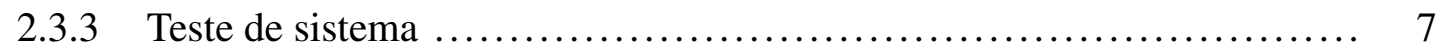

2.4 Técnicas e critérios de teste..................................... 7

2.4.1 Técnica funcional .......................................... 8

2.4.1.1 Particionamento de Equivalência ........................ 8

2.4.1.2 Análise de Valor-limite............................. 10

2.4.1.3 Teste Funcional Sistemático $\ldots \ldots \ldots \ldots \ldots \ldots \ldots \ldots \ldots \ldots \ldots, 11$

2.4.1.4 Grafo de Causa-efeito .............................. 13

2.4.1.5 Invariantes, Pré e Pós-condições....................... 15

2.4.2 Técnica estrutural............................................. 16

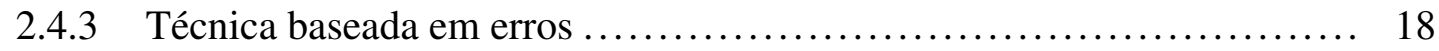

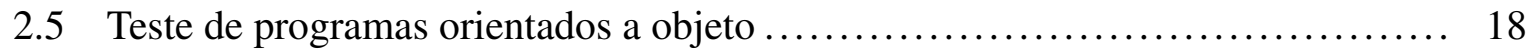

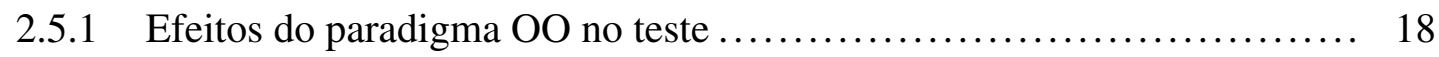


2.5.2 Fases do teste de programas orientados a objeto.................... 19

2.5.3 Técnicas do teste de programas orientados a objeto ................ 20

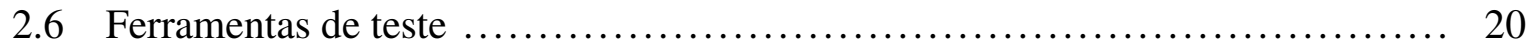

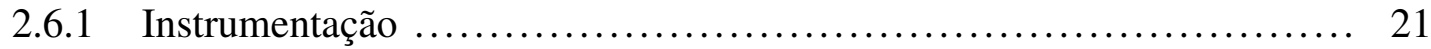

2.6.2 Ferramentas para teste funcional de programas Java $\ldots \ldots \ldots \ldots \ldots \ldots .22$

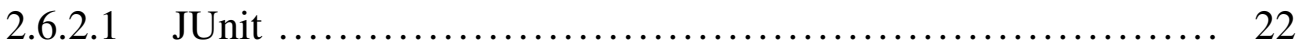

2.6.2.2 Jtest $\ldots \ldots \ldots \ldots \ldots \ldots \ldots \ldots \ldots \ldots \ldots \ldots \ldots \ldots \ldots \ldots \ldots \ldots \ldots \ldots \ldots \ldots \ldots \ldots, 23$

2.6.2.3 TestComplete ...................................... 24

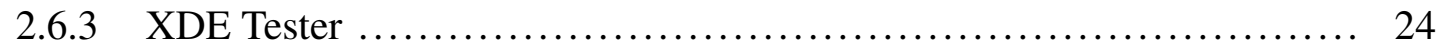

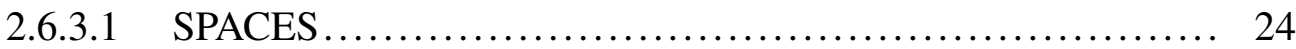

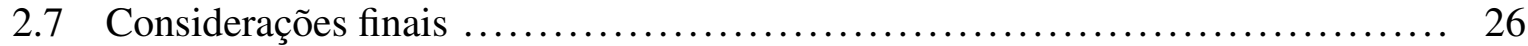

3 Programação Orientada a Aspectos $\ldots \ldots \ldots \ldots \ldots \ldots \ldots \ldots \ldots \ldots \ldots \ldots \ldots \ldots \ldots \ldots \ldots \ldots \ldots \ldots, 27$

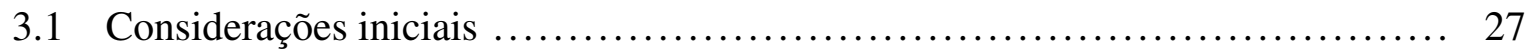

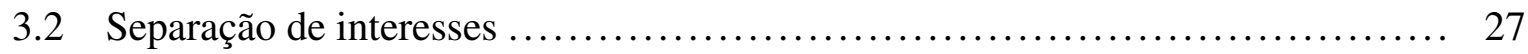

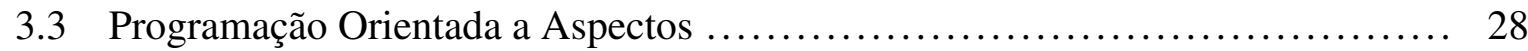

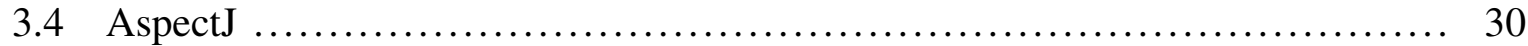

3.4.1 Pontos de junção ............................................ 31

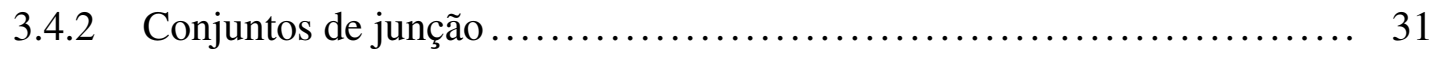

3.4.2.1 Operadores e caracteres coringas para conjuntos de junção.... 33

3.4.3 Adendos ................................................... 34

3.4.4 Declarações inter-tipos ...................................... 35

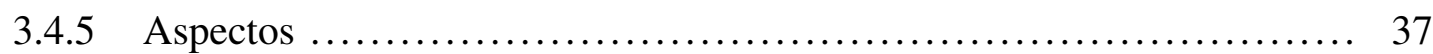

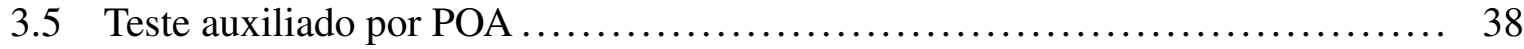

3.5.1 Imitações virtuais de objetos ................................. 38

3.5.2 Teste embutido em componentes de software $\ldots \ldots \ldots \ldots \ldots \ldots \ldots \ldots \ldots, 41$

3.5.3 Framework para teste de integração ............................ 43

3.5.4 Aspecto abstrato de teste ................................... 44

3.5.5 Verificação de padrões de código ............................. 46

3.5.6 Teste de invariantes, pré e pós-condições ......................... 47

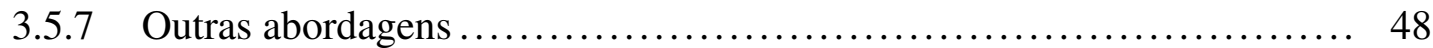

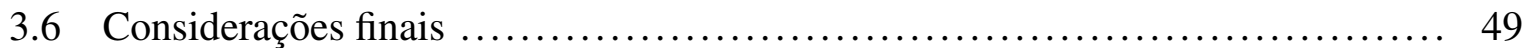




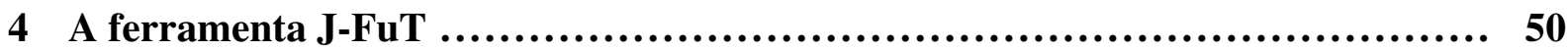

4.1 Considerações iniciais ................................................. 50

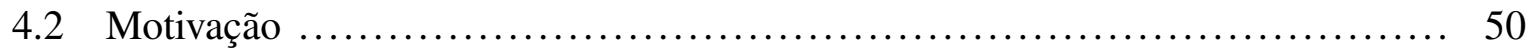

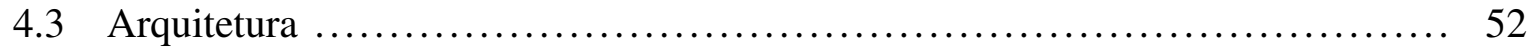

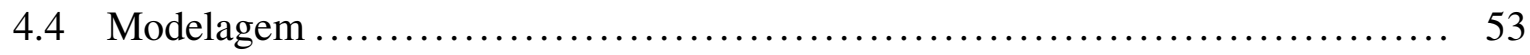

4.4.1 Conceitos básicos ............................................. 53

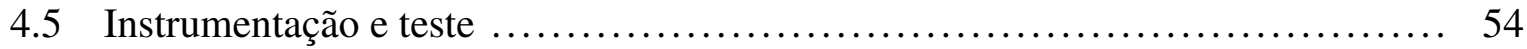

4.5.1 Aspectos elaborados para o teste de uma aplicação .................... 57

4.5.2 Regras para construção dos aspectos de teste ........................ 58

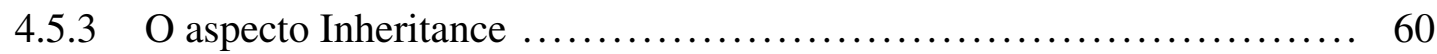

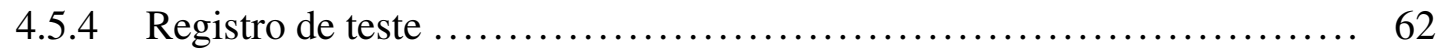

4.6 Análise dos dados ................................................... 63

4.6.1 Estratégias de análise ........................................ 64

4.6.1.1 Estratégia "invalidar casos de teste" ...................... 67

4.6.1.2 Estratégia "primeiros válidos" ............................ 67

4.6.1.3 Estratégia "otimizar casos de teste" ....................... 68

4.6.1.4 Estratégia "otimizar requisitos de teste" ................... 70

4.7 Considerações finais ...................................................... 72

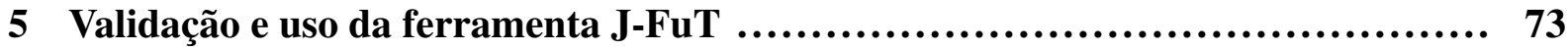

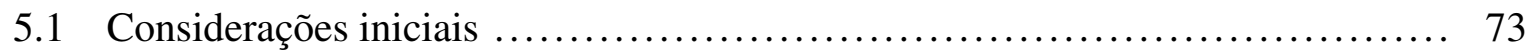

5.2 Testes executados durante o desenvolvimento da ferramenta J-FuT ............. 73

5.3 A aplicação VendingMachine ........................................... 74

5.3.1 Especificação da aplicação VendingMachine .......................... 74

5.3.2 Implementação e requisitos de teste para a aplicação VendingMachine ... 75

5.4 Teste da aplicação VendingMachine ..................................... 76

5.4.1 Visão geral do processo de teste utilizando a J-FuT ................... 76

5.4.2 Criação do projeto de teste .......................................... 77

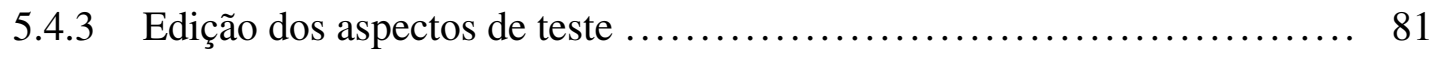

5.4.4 Execução dos casos de teste ...................................... 83

5.4.5 Análise de cobertura ............................................ 85

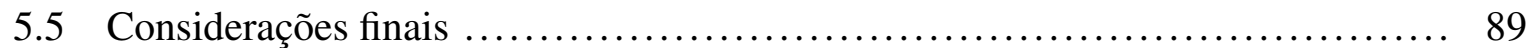




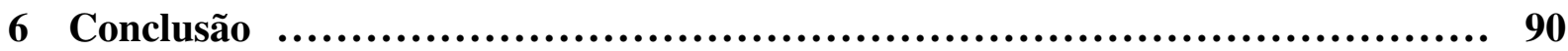

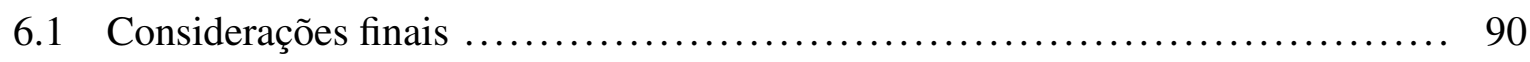

6.2 Contribuições ................................................... 90

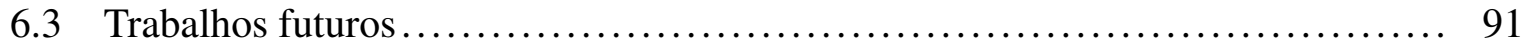

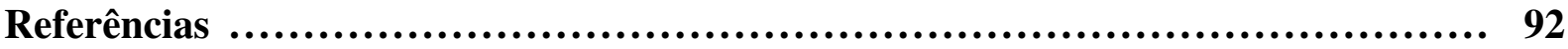

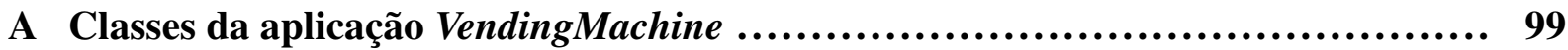

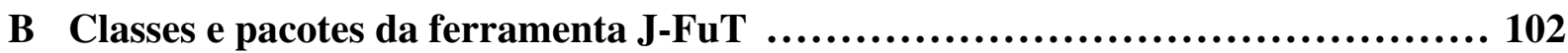




\section{Lista de Figuras}

2.1 Grafo de causa-efeito - Símbolos básicos ........................... 13

2.2 Grafo de causa-efeito - Símbolos de restrição.......................... 14

2.3 Grafo de causa-efeito do comando SendFile - adaptado de Nursimulu e Probert

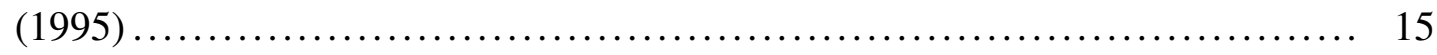

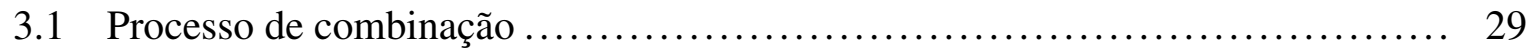

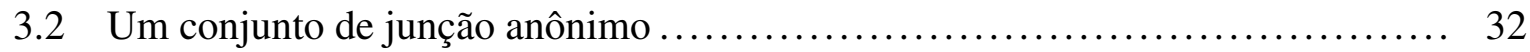

3.3 Um conjunto de junção nomeado .................................. 33

3.4 Adendo para verificação do saque .................................. 35

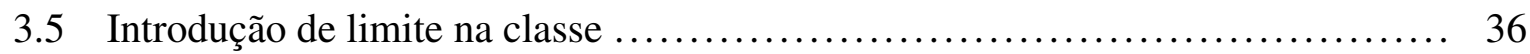

3.6 Introdução de herança na classe Conta ............................... 37

3.7 Exemplo de um aspecto (adaptado de AspectJ Team (2003))................ 38

3.8 Diagrama de classes - adaptado de Monk e Hall (2002) .................... 39

3.9 Objetos imitadores - adaptado de Monk e Hall (2002) .................... 40

3.10 Objetos imitadores virtuais - adaptado de Monk e Hall (2002) .............. 40

3.11 Classe e aspecto de teste - adaptado de Bruel et al. (2003) ................. 41

3.12 Introdução de atributos - adaptado de Bruel et al. (2003) .................... 41

3.13 Introdução de método específico - adaptado de Bruel et al. (2003) ............. 42

3.14 Introdução de funções - adaptado de Bruel et al. (2003).................... 42

3.15 Conjuntos de junção e adendos- adaptado de Bruel et al. (2003) .............. 42

3.16 Classe testável - adaptado de Bruel et al. (2003) ......................... 43

3.17 Identificação de interação - adaptado de Mao e May (2004) .................. 44

3.18 Verificação de interação em um fluxo de controle - adaptado de Mao e May (2004) 44

3.19 Aspecto AspectoAbstratoTeste - adaptado de Wenner (2004) ............. 45

3.20 Verificação de escrita de atributos - adaptado de Isberg (2002) ............... 46 
3.21 Verificação de métodos fábrica - adaptado de Isberg (2002) .................. 46

3.22 Verificação de pré-condições - adaptado de AspectJ Team (2003) ............. 47

3.23 Verificação de asserções - adaptado de Isberg (2002)...................... 48

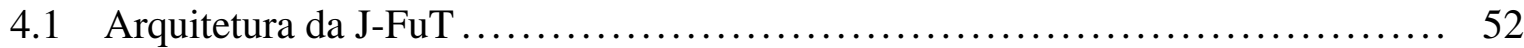

4.2 Classes básicas ..................................................... 53

4.3 Exemplo de configuração dos critérios de teste......................... 53

4.4 Classes e aspectos utilizados na instrumentação e teste ....................... 55

4.5 Aspecto Tracing ................................................... 56

4.6 Aspecto Instrumentation ...................................... 57

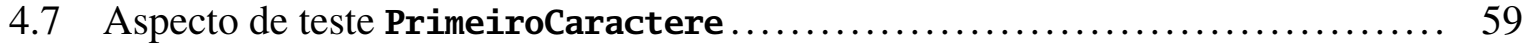

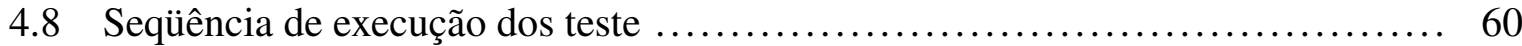

4.9 Aspecto Inheritance ................................................ 61

4.10 Aspecto PolicyEnforcement ....................................... 62

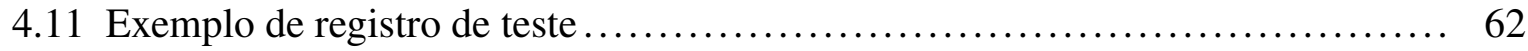

4.12 Representação dos requisitos de teste na J-FuT $\ldots \ldots \ldots \ldots \ldots \ldots \ldots \ldots \ldots \ldots \ldots \ldots$

4.13 Estratégias de análise de dados ..................................... 66

4.14 Algoritmo para otimização dos casos de teste $\ldots \ldots \ldots \ldots \ldots \ldots \ldots \ldots \ldots \ldots \ldots \ldots \ldots$

4.15 Algoritmo para otimização dos requisitos de teste $\ldots \ldots \ldots \ldots \ldots \ldots \ldots \ldots \ldots \ldots \ldots \ldots \ldots$

5.1 Classes da aplicação VendingMachine .................................. 75

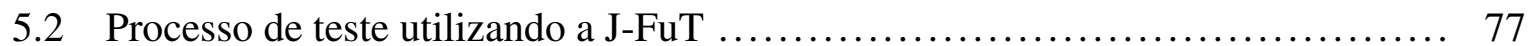

5.3 Primeira etapa para criação de um projeto de teste $\ldots \ldots \ldots \ldots \ldots \ldots \ldots \ldots \ldots \ldots \ldots \ldots$

5.4 Segunda etapa para criação de um projeto de teste .......................... 79

5.5 Criação de uma condição de entrada ....................................... 79

5.6 Criação de um requisito de teste...................................... 80

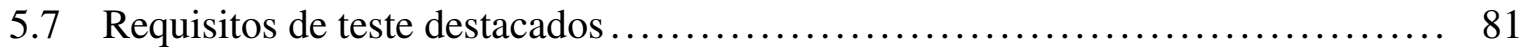

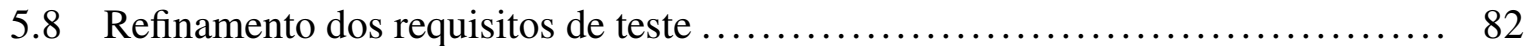

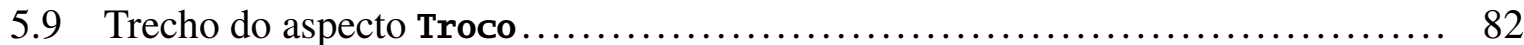

5.10 Teste da insuficiência de ingredientes ................................ 83

5.11 Aspecto MelhoriaTestabilidade................................... 84

5.12 Teste da insuficiência de ingredientes (simplificado) ........................ 84

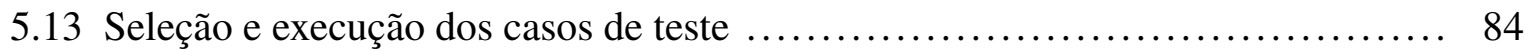

5.14 Cobertura inicial das operações utilizando o critério Particionamento de Equivalência e a estratégia "invalidar casos de teste" 
5.15 Cobertura inicial das condições de entrada da operação getRecipes utilizando o critério Particionamento de Equivalência e a estratégia "invalidar casos de teste" 86

5.16 Cobertura final das operações utilizando o critério Particionamento de Equivalência e a estratégia "invalidar casos de teste"

5.17 Cobertura das operações utilizando o critério Teste Funcional Sistemático e a estratégia "invalidar casos de teste"

5.18 Cobertura das operações utilizando o critério Teste Funcional Sistemático e a estratégia "otimizar requisitos de teste"

5.19 Relação entre casos e requisitos de teste 88

A.1 Classe Ingredient ................................................ 99

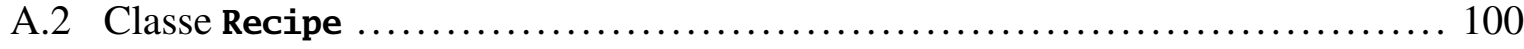

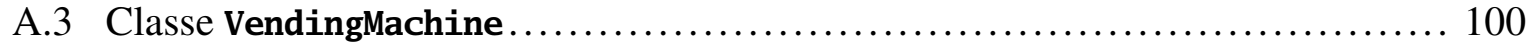

A.4 Classe InvalidCoinException ........................................ 101

A.5 Classe IngredientMissingException ................................ 101

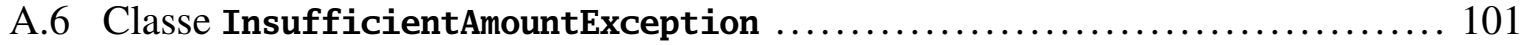

A.7 Classe UnknownRecipeException ................................... 101 


\section{Lista de Quadros}

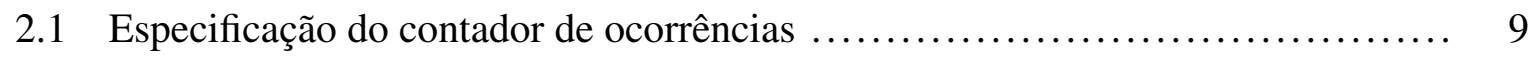

2.2 Classes de equivalência para o contador de ocorrências $\ldots \ldots \ldots \ldots \ldots \ldots \ldots \ldots \ldots . \quad 10$

2.3 Casos de teste para o contador de ocorrências ........................... 10

2.4 Valores-limite para o contador de ocorrências .......................... 11

2.5 Especificação do comando Sendfile - adaptado de Nursimulu e Probert (1995) .. 14

2.6 Causas para o comando Sendfile - adaptado de Nursimulu e Probert (1995) ..... 15

2.7 Efeitos para o comando Sendfile - adaptado de Nursimulu e Probert (1995) ..... 15

2.8 Tabela de decisão do comando Sendfile ................................ 15

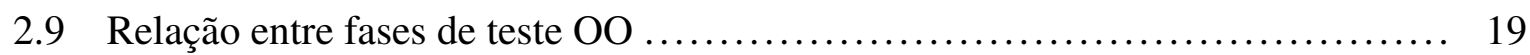

2.10 Comparativo entre as ferramentas de teste analisadas ..................... 25

3.1 Tipos de pontos de junção do AspectJ (AspectJ Team, 2003) .................. 32

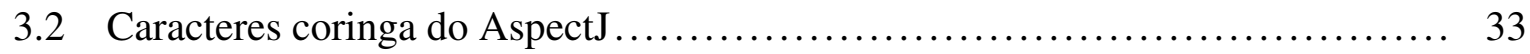

3.3 Exemplos de conjuntos de junção (AspectJ Team, 2003)...................... 34

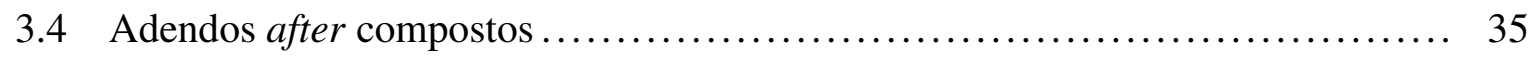

4.1 Nomes de marcadores para os critérios de teste ........................ 54

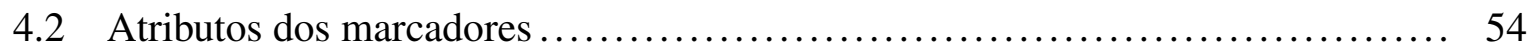

4.3 Métodos auxiliares definidos no aspecto Instrumentation ................. 59

4.4 Métodos auxiliares definidos no aspecto Tracing ....................... 60

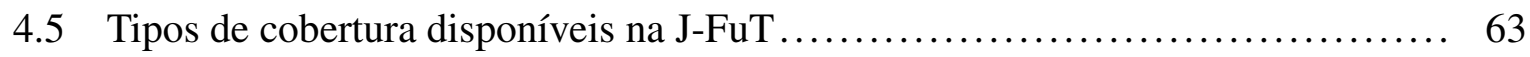

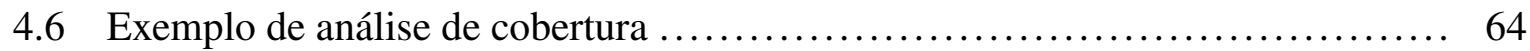

4.7 Exemplo de registro de execução.................................... 65

4.8 Aplicação da estratégia "invalidar casos de teste" ....................... 67

4.9 Aplicação da estratégia "primeiros válidos" ............................ 68

4.10 Aplicação da estratégia "otimizar casos de teste" ......................... 70 
5.1 Ingredientes disponíveis na VendingMachine .......................... 74

5.2 Receitas disponíveis na VendingMachine .............................. 74

5.3 Requisitos de teste para o método void insertCoin(int) $\ldots \ldots \ldots \ldots \ldots \ldots \ldots \ldots$

5.4 Requisitos de teste para o método Vector getRecipes() $\ldots \ldots \ldots \ldots \ldots \ldots \ldots \ldots$

5.5 Requisitos de teste para o método Recipe makeRecipe(String) ............ 77

5.6 Requisitos de teste para o método int returnChange() $\ldots \ldots \ldots \ldots \ldots \ldots \ldots \ldots . \ldots \ldots$ 


\section{Resumo}

A disponibilidade de ferramentas de teste de software propicia maior qualidade e produtividade para as atividades de teste. Diversas ferramentas têm sido propostas para o apoio ao teste estrutural, mas nota-se a falta de ferramentas que ofereçam suporte ao teste funcional e implementem os diversos critérios dessa técnica. Visando a preencher essa lacuna, uma ferramenta para apoio ao teste funcional de programas Java foi desenvolvida e é apresentada. A ferramenta apóia os principais critérios funcionais, tais como o Particionamento de Equivalência e Análise de Valor-limite, e oferece análise de cobertura baseada nos critérios da técnica funcional. A análise de cobertura é uma característica normalmente encontrada nas ferramentas que apóiam o teste estrutural, mas raramente disponível nas ferramentas que oferecem suporte ao teste funcional. O projeto da ferramenta é apresentado, no qual o conceito de separação de interesses é utilizado. A Programação Orientada a Aspectos é utilizada nas etapas de instrumentação e execução dos critérios de teste. O uso dessa técnica permite a separação clara entre o código de teste e o código do programa, assim como torna mais fácil a adição e remoção dos aspectos que implementam o teste, além de ser uma solução eficaz para o projeto da ferramenta. Um exemplo de uso da ferramenta é apresentado. 


\section{Abstract}

Availability of testing tools provides better quality and more productivity for the testing activities. Several tools have been proposed to support structural test, but there is a lack of tools to support functional testing and to implement the several criteria of this technique. Seeking to fill out this gap, a tool to support functional testing of Java programs was developed and is presented. The tool supports the main functional testing criteria, such as Equivalence Partitioning and Boundary-value Analysis, and offers coverage analysis based on the criteria of the functional technique. The coverage analysis is a characteristic found usually in the tools that support structural testing, but is rarely available in the tools that support functional test. The tool's design is presented in witch the concept of separation of concerns is used. Aspect-oriented Programming is used in the phases of instrumentation and execution of the testing criteria. The use of this technique allows a clear separation between the testing code and the program code and is an effective and elegant solution for this type of tool. Furthermore, it makes easy adding and removing the aspects that implement the tests. An example of the tool's use is presented. 


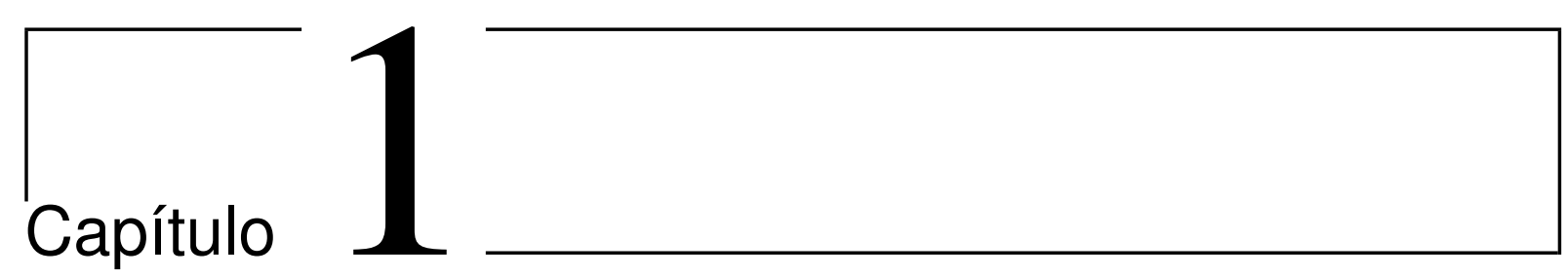

\section{Introdução}

\subsection{Contexto}

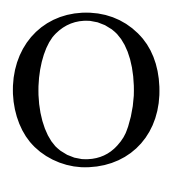

uso de sistemas baseados em computação em praticamente todas a áreas da atividade humana tem exigido o desenvolvimento de software com alto padrão de qualidade e produtividade. Nesse sentido, novos métodos e técnicas têm sido propostos pela disciplina de Engenharia de Software visando a produção de softwares de alta qualidade e baixo custo.

Ao longo do processo de desenvolvimento de software, mesmo com o uso de técnicas, métodos e ferramentas, erros no produto final ainda podem ocorrer. As atividades de Verificação, Validação e Teste (VV\&T) vêm sendo utilizadas ao longo do processo de desenvolvimento com o intuito de minimizar esses erros e riscos (MALDONADO et al., 2003). O teste de software encaixa-se no escopo dessas atividades e procura evidenciar a confiabilidade do software por meio da aplicação de técnicas e critérios de teste em fases distintas do seu ciclo de desenvolvimento.

Dentre as técnicas de teste utilizadas destaca-se a técnica funcional que, por basear-se na especificação do sistema, pode ser aplicada indistintamente em programas implementados sob diversos paradigmas de programação. O uso dessa técnica, assim como das demais técnicas de teste, normalmente é apoiado por ferramentas de teste, tendo em vista que a atividade de teste é custosa e propensa a erros. A utilização de ferramentas propicia maior qualidade e produtividade ao teste, no entanto ainda são poucas as ferramentas que implementam a técnica funcional utilizando os critérios de teste propostos pela comunidade especializada.

Além da aplicação das atividades de VV\&T, a Engenharia de Software tem buscado criar e adotar abordagens que auxiliem todo o ciclo de desenvolvimento (concepção, desenvolvimento 
e manutenção). Linguagens e técnicas de programação evoluíram nesse sentido e novos paradigmas foram criados e progressivamente absorvidos pela indústria. A Programação Orientada a Aspectos (POA) é uma técnica recente de programação que baseia-se no conceito da separação de interesses e oferece uma abordagem para o tratamento de interesses distintos, que nos paradigmas atuais encontram-se dispersos no código. A POA tem motivado pesquisas em diversas áreas da Engenharia de Software e já se encontram na literatura propostas para sua aplicação não apenas ao desenvolvimento, mas também às fases de engenharia de requisitos (RASHID et al., 2002), modelagem (SUZUKI; YAMAMOTO, 1999; STEIN; HANENBERG; UNLAND, 2002; CHAVEZ, 2004; BANIASSAD; CLARKE, 2004) e teste de programas (LESIECKI, 2002; ISBERG, 2002; MONK; HALL, 2002; BRUEL et al., 2003).

O uso da POA para apoio ao teste de software ainda encontra-se em seu estágio inicial, mas apesar de se tratar de um tema recente, já existem propostas que buscam unir os dois conceitos e apontam diversas possibilidades e benefícios dessa combinação. Nota-se no entanto, que essas propostas ainda encontram-se dissociadas de muitos dos conceitos que envolvem as técnicas e critérios de teste, enfatizando apenas os aspectos práticos dessa atividade.

\subsection{Motivação}

Teste de software é uma atividade trabalhosa e propensa a erros e, portanto, sua automatização representa uma premissa importante para o teste de programas. Nota-se que as ferramentas existentes em geral apóiam apenas a técnica estrutural e seus critérios, e o suporte ao teste funcional ainda é incipiente. As poucas ferramentas que oferecem algum auxílio à aplicação da técnica funcional normalmente não consideram os critérios de teste propostos pela comunidade de teste e geralmente enfatizam a geração de casos de teste ou o teste de interface. Além disso, a avaliação do progresso da atividade de teste é dificultada, pois essas ferramentas não implementam análise de cobertura segundo os requisitos funcionais.

O desenvolvimento de uma ferramenta que ofereça suporte aos critérios funcionais e efetue análise de cobertura segundo a técnica funcional apresenta-se como uma oportunidade de pesquisa. Além disso, o uso da POA nesse contexto, auxiliando a instrumentação e execução de critérios, traz benefícios à implementação da ferramenta e melhora os procedimentos de teste. Portanto o uso da POA para apoiar ferramentas de teste é uma área nova e promissora. Apesar de tratar-se de um assunto relativamente novo, as publicações existentes apontam para a viabilidade da pesquisa proposta. A pesquisa, por sua vez, segue uma das linhas de trabalho do Laboratório de Engenharia de Software do ICMC-USP, que possui experiência na definição e aplicação de técnicas e critérios de teste, condução de experimentos e desenvolvimento de ferramentas (DELAMARO, 1993; SUGETA, 1999; SIMÃO, 2000; VINCENZI, 2004). 


\subsection{Objetivos}

O objetivo geral deste trabalho é investigar o uso da POA para auxílio ao teste funcional de software de programas desenvolvidos na linguagem Java e estudar as aplicações dessa técnica para a instrumentação de programas, execução do teste e análise dos resultados. Também são objetivos deste trabalho desenvolver uma ferramenta de apoio ao teste funcional que ofereça suporte aos principais critérios funcionais utilizando o ferramental provido pela POA e incorpore o conceito de análise de cobertura para o teste funcional.

\subsection{Organização}

Esta dissertação está organizada em seis capítulos dois apêndices. Neste capítulo foram apresentados o contexto em que se insere o trabalho, as motivações para o seu desenvolvimento e os seus objetivos. Nos próximos dois capítulos apresenta-se a Revisão Bibliográfica: no Capítulo 2 introduz-se o teste de software, seus conceitos básicos, técnicas, fases e critérios. Aborda-se com mais profundidade o teste funcional, já que neste trabalho será enfatizada essa técnica. No Capítulo 3 apresenta-se os conceitos principais da Programação Orientada a Aspectos e discutem-se algumas abordagens existentes para o uso da POA no teste de software. Atenção especial é dada à sintaxe da linguagem AspectJ, uma vez que essa é a linguagem utilizada neste trabalho.

No Capítulo 4 é apresentada a ferramenta J-FuT (Java Functional Testing), desenvolvida no escopo deste trabalho, e todas as decisões relativas à sua modelagem. Além disso, são descritas em detalhe sua arquitetura e implementação. No Capítulo 5 são apresentadas a validação e uso da ferramenta e alguns exemplos utilizados para o seu teste, dos quais um é detalhado. No Capítulo 6 são apresentadas as contribuições desta pesquisa e trabalhos futuros. O Apêndice A contém os esqueletos das classes utilizadas no exemplo detalhado e no Apêndice B encontra-se a hierarquia de classes e pacotes da J-FuT. 


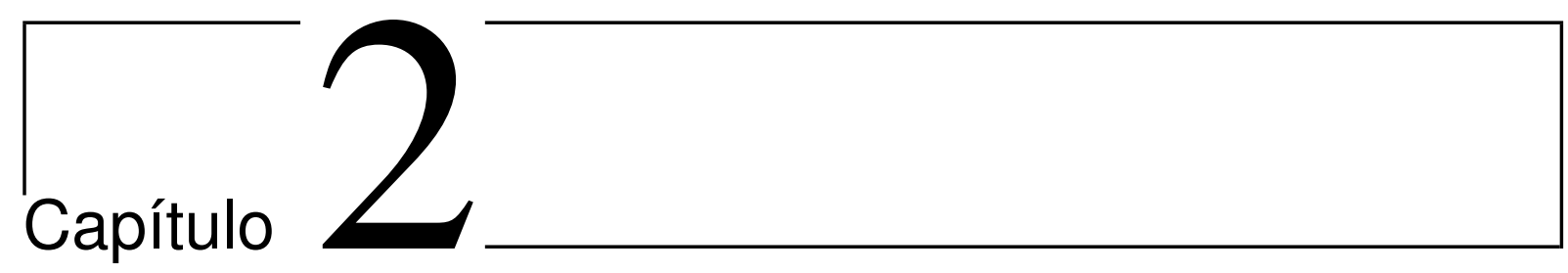

\section{Teste de software}

\subsection{Considerações iniciais}

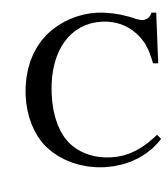

onsiderando-se o objetivo deste trabalho, que envolve investigar como as técnicas e construções da Programação Orientada a Aspectos podem ser utilizadas no contexto de teste de software, introduz-se neste capítulo o teste de software e apresentam-se os pontos principais dessa atividade. Inicialmente, na Seção 2.2, são apresentados os conceitos básicos e a importância do teste na Engenharia de Software. Em seguida, na Seção 2.3, descrevem-se as diversas fases de teste. As principais técnicas e critérios de teste são apresentadas na Seção 2.4, na qual enfatiza-se a técnica funcional, por essa estar diretamente envolvida com o escopo deste trabalho. A Seção 2.5 é dedicada ao teste de programas Orientados a Objeto. Por fim, na Seção 2.6, aborda-se a automatização da atividade de teste.

\subsection{Conceitos básicos}

O processo de desenvolvimento de software envolve uma série de atividades nas quais, apesar das técnicas, métodos e ferramentas empregadas, erros no produto ainda podem ocorrer. Assim, a atividade de teste mostra-se relevante para a identificação e eliminação de erros que persistem (MALDONADO et al., 2003). Teste de software diz respeito à análise dinâmica do programa e consiste na execução do produto com o intuito de revelar a presença de erros. $\mathrm{O}$ teste de software envolve quatro etapas que geralmente devem ser executadas durante o próprio processo de desenvolvimento de software: planejamento de testes, projeto de casos de teste, execução de testes (e coleta dos resultados) e avaliação dos resultados coletados. 
As quatro etapas mencionadas geralmente realizam-se em três fases de teste: teste de unidade, de integração e de sistema. No teste de unidade verifica-se a menor unidade do software - o componente ou módulo de software - tentando descobrir erros de lógica e implementação (em cada módulo, separadamente). No teste de integração a preocupação é com os erros de interface (quando os diversos módulos são compostos para criar o programa). Por fim, no teste de sistema identificam-se características do software que não estão em conformidade com a sua especificação.

O propósito do teste de software é encontrar erros (MYERS, 1979) e, desta forma, um teste bem sucedido é aquele que possui casos de teste que levam a falhas do programa. Assim, deve-se procurar, nas diversas fases do teste, criar conjuntos de casos de teste com potencial para revelar o máximo de defeitos existentes no programa sem perder de vista que o custo e o esforço gastos devem ser minimizados.

O padrão IEEE 610.12-1990 (IEEE Standards Board, 1990) distingue diversos termos utilizados no contexto de teste de software: Defeito (fault) - um passo, processo ou definição de dados incorreto; Engano (mistake) - uma ação humana que produz um resultado incorreto; Erro (error) - diferença entre o valor computado, observado ou medido e o valor real; Falha (failure) - um resultado incorreto. De forma geral, erros são classificados em dois tipos (MALDONADO et al., 2003): computacionais e de domínio. Um erro computacional ocorre quando a computação é incorreta, porém a sequiência de comandos (caminho) executada é igual à esperada. O erro de domínio, por sua vez, acontece quando o caminho executado é diferente do esperado (um caminho errado é selecionado). Neste trabalho, os termos engano, defeito e erro são referenciados como erro (causa) e o termo falha (consequiência) referencia-se a um comportamento incorreto do programa.

No domínio de teste, um caso de teste consiste em um par ordenado $(d, S(d))$ em que $d \in D$ (domínio de entrada) e $S(d)$ é a saída esperada. O oráculo é representado pelo testador (ou algum outro mecanismo) e decide, dentro de limites de tempo e dificuldade razoáveis, o veredicto do teste (se os valores de saída estão corretos para aquelas entradas) (MALDONADO et al., 2003). O teste de software apresenta diversas limitações (HOWDEN, 1987; NTAFOS, 1988; HARROLD, 2000; HETZEL, 1988) e, de forma geral, diversos problemas são indecidíveis: a equivalência entre dois programas; se sequiências de comandos (do mesmo programa ou não) computam a mesma função e se um caminho de um programa é executável ou não (um caminho é executável se para algum conjunto de dados de entrada ele é exercitado). Considera-se que um programa, com um determinado domínio de entrada, é correto em relação a uma especificação se o programa se comporta adequadamente para quaisquer itens desse domínio. Programas que se comportam de acordo com o esperado para o mesmo domínio de entrada são ditos equivalentes.

Como comenta Myers (1979), de forma geral é impraticável ou até impossível encontrar todos os erros de um software e a atividade de teste não pode mostrar a corretitude de um 
dado programa, por questões de tempo e custo. Assim, dois importantes aspectos devem ser considerados: a seleção dos dados de teste e a decisão de que um programa foi suficientemente testado. Um conjunto de dados de teste deve ser grande o suficiente para oferecer uma medida satisfatória de confiança, porém não tão grande que torne impraticável a atividade de teste. Portanto, encontrar o conjunto adequado de elementos a serem usados no teste é um ponto crucial na atividade de teste (HETZEL, 1988; ANDRIOLE, 1986).

Critérios de teste guiam o testador na avaliação da suficiência do teste e indicam como os casos de teste devem ser selecionados e avaliados para aumentar as possibilidades de se encontrar erros. Como esclarece Andriole (1986), por meio de um critério de teste escolhem-se elementos representativos do domínio funcional. Esse critério deve refletir a descrição funcional ou estrutural do programa. Critérios distintos são utilizados nas diversas fase de teste e, desta forma, a definição e adequação dos critérios devem ser conduzidas em função de cada uma dessas fases.

\subsection{Fases de teste}

O teste de software obedece a estratégias e normalmente é executado em fases, de forma incremental e complementar. Segundo Pressman (2002), uma estratégia de teste fornece um roteiro que descreve os passos a serem conduzidos como parte do teste, sendo que esse inicia-se em nível de componente e prossegue em direção à integração de todo o sistema. Basicamente, são três as fases de teste: unidade, integração e sistema.

\subsubsection{Teste de unidade}

Uma unidade é um componente de software que não pode ser subdividido (IEEE Standards Board, 1990). Assim, de acordo com a abordagem adotada, classes, métodos, sub-rotinas ou procedimentos de um programa de computador podem ser considerados unidades. No teste de unidade investigam-se erros dentro da fronteira do módulo e para isso são necessárias implementações que façam chamadas ao módulo em teste ou sejam utilizadas por ele. A essas duas implementações dá-se os nomes respectivamente de módulos pseudocontroladores (drivers) e módulos pseudocontrolados (stubs) (PRESSMAN, 2002).

O módulo pseudocontrolador é responsável por receber os dados de teste, passá-los para a unidade que está sendo testada, obter os resultados produzidos e apresentá-los ao testador. O módulo pseudocontrolado, por sua vez, substitui a unidade que é chamada pelo módulo testado, emulando o comportamento dessa unidade com o mínimo de computação ou manipulação de dados. 
Os testes de unidade desempenham papel fundamental nos métodos ágeis (BECK et al., 2001) e atualmente são apoiados por diversas ferramentas como o JUnit (GAMMA; BECK, 2002), que oferece auxílio ao teste de unidade de programas Java.

\subsubsection{Teste de integração}

Durante o teste de integração realizam-se testes que procuram encontrar erros associados a interfaces. O objetivo é, a partir dos módulos testados no nível de unidade, construir a estrutura de programa que foi determinada pelo projeto. O teste de integração é classificado em dois tipos: incremental e não incremental (PRESSMAN, 2002).

Na integração não-incremental todos os módulos são combinados antecipadamente e o programa completo é testado. Na abordagem incremental o software é construído e testado em blocos e as interfaces têm maior probabilidade de serem testadas completamente, o que facilita o isolamento e a correção de erros. Na integração incremental podem-se utilizar duas estratégias: descendente (top-down) ou ascendente (bottom-up).

- Integração descendente: a integração é iniciada no módulo de controle principal e os módulos são integrados de cima para baixo ao longo da hierarquia de controle. Módulos pseudocontrolados devem ser criados para simular os módulos ainda não integrados;

- Integração ascendente: inicia-se a construção e os testes com os módulos localizados nos níveis mais baixos da estrutura do programa. Módulos pseudocontroladores são utilizados para executar chamadas aos módulos que estão sendo testados.

\subsubsection{Teste de sistema}

No teste de sistema verifica-se a integração de todos os elementos que compõem o sistema e o seu funcionamento. O teste de sistema consiste de uma série de testes de diferentes tipos cuja finalidade principal é exercitar todo o software. Testes de recuperação, segurança, estresse e desempenho são alguns dos tipos de teste de sistema (PRESSMAN, 2002).

\subsection{Técnicas e critérios de teste}

Técnicas de teste fornecem diretrizes para projetar testes que exercitam a lógica interna dos componentes do software, assim como seus domínios de entrada e saída (PRESSMAN, 2002). A aplicação de testes segue diversas técnicas, que oferecem perspectivas diferentes e abordam diferentes classes de erros, e que portanto devem ser utilizadas de forma complementar. As várias técnicas propostas diferenciam-se pela origem das informações utilizadas para estabelecer 
os requisitos e critérios de teste, podendo-se citar as técnicas funcional, estrutural e baseada em erros.

Há basicamente duas categorias de teste: teste baseado em especificação e teste baseado em programa (HOWDEN, 1987). Seguindo-se essa classificação pode-se enquadrar o teste funcional na primeira categoria, enquanto que as técnicas estrutural e baseada em erros enquadram-se na segunda.

\subsubsection{Técnica funcional}

Na técnica funcional (caixa-preta) os requisitos são estabelecidos a partir da especificação do software, e sua estrutura não é necessariamente considerada. De acordo com Ostrand e Balcer (1988), o objetivo do teste funcional é encontrar discrepâncias entre o comportamento atual do sistema e o descrito em sua especificação. Assim, consideram-se apenas as entradas, saídas e estado do programa e o testador não tem necessariamente acesso ao código fonte do software.

Nesse tipo de teste procura-se descobrir erros relacionados a quatro categorias (PRESSMAN, 2002): funções incorretas ou omitidas; erros de interface; erros de estrutura de dados ou de acesso a dados externos; erros de comportamento ou desempenho e, por fim, erros de iniciação e término. No teste caixa-preta pode-se citar os seguintes critérios: Particionamento de Equivalência, Análise de Valor-Limite, Teste Funcional Sistemático e Grafo de Causa-Efeito.

\subsubsection{Particionamento de Equivalência}

No critério Particionamento de Equivalência divide-se o domínio de entrada do programa em classes de dados, dos quais os casos de teste são derivados (PRESSMAN, 2002). Neste critério a divisão é feita em classes de equivalência válidas e inválidas e busca-se produzir casos de teste que cubram diversas classes de erro e que ao mesmo tempo reduzam o total de casos necessários.

O particionamento do domínio de entrada deve ser feito de forma que para cada classe de equivalência, qualquer um dos seus elementos seja representativo de toda a classe e dessa forma o programa em teste se comporte da mesma maneira, independentemente do elemento escolhido na classe. Assim, se um caso de teste de uma determinada classe de equivalência revela um erro, qualquer outro caso de teste nessa classe deve revelar o mesmo erro. A definição das classes de equivalência é um processo heurístico, no entanto, algumas diretrizes podem ser adotadas (MYERS, 1979):

- Se a condição de entrada é uma gama de valores, identificam-se uma classe válida e duas inválidas. Por exemplo, se a condição impõe que “x deve estar entre 1 e 99", identificam- 
se "x entre 1 e 99" como classe válida e "x menor que 1" e "x maior que 99" como classes inválidas;

- Se uma determinada quantidade de itens de entrada é especificada, identificam-se uma classe válida e duas inválidas. Por exemplo, se na entrada "o total de itens varia entre 1 e 4 ", identificam-se "quantidade de itens entre 1 e 4 " como classe válida e "nenhum item" e "quantidade de itens maior que 4" como classes inválidas;

- Se a entrada corresponde a um conjunto de valores que recebem tratamento diferente pelo programa, identificam-se uma classe válida para cada elemento do conjunto e uma classe inválida, para elementos não contidos no conjunto. Por exemplo, se a entrada deve ser "aprovado" ou "cancelado", identificam-se uma classe válida para cada um desses valores e uma classe inválida, contendo um valor que não faz parte do conjunto, como "bloqueado";

- Se a condição de entrada especifica uma situação do tipo "deve ser", identificam-se uma classe de equivalência válida e uma inválida. Por exemplo, se na entrada "o separador de decimais deve ser uma vírgula", identificam-se uma classe válida "o separador é uma vírgula" e uma inválida "o separador não é uma vírgula";

- Se, por algum motivo, os elementos contidos em uma classe de equivalência não são manipulados de forma idêntica pelo programa, a classe de equivalência deve ser dividida em classes de equivalência menores.

O critério Particionamento de Equivalência exige que seja implementado um conjunto mínimo de casos de teste para exercitar as classes de equivalência válidas e um caso de teste individual para cada classe inválida. A exigência de um caso de teste específico por classe de equivalência inválida se faz necessário pois a verificação de algumas condições de entrada pode mascarar ou anular a verificação de outras. Por exemplo, supondo um método escreve(linha, coluna), no qual o parâmetro linha varia entre 0 e 4 e o parâmetro coluna varia entre 0 e 9 . Um caso de teste com uma entrada $(6,10)$, que expressa duas condições errôneas (linha e coluna inválidas), provavelmente não exercitaria a checagem da coluna e assim a segunda condição não seria avaliada.

No Quadro 2.1 encontra-se a especificação de um programa que analisa um texto e contabiliza o total de ocorrências de uma determinada palavra.

Quadro 2.1: Especificação do contador de ocorrências

\begin{tabular}{|l|l|}
\hline Entrada & $\begin{array}{l}\text { Texto a ser analisado e palavra a ser localizada. O texto e a palavra } \\
\text { devem conter ao menos um caractere cada. Além disso, a palavra a ser } \\
\text { localizada não deve conter caracteres em branco. }\end{array}$ \\
\hline Saída & $\begin{array}{l}\text { Retorna o total de ocorrências da palavra no texto (zero ou mais) ou }-1 \\
\text { em caso de erro. }\end{array}$ \\
\hline
\end{tabular}


Uma classe de equivalência representa um conjunto de estados válidos ou inválidos para uma condição (restrição) de entrada descrita na especificação, e a sua identificação é feita particionando-se cada condição de entrada em um ou mais grupos. Como descrito anteriormente, essa divisão leva à criação de dois tipos de classe: válidas (entradas válidas para o programa) e inválidas (demais entradas). Utilizando a especificação do Quadro 2.1 é possível identificar condições de entrada referentes ao tamanho do texto, tamanho da palavra e existência da palavra no texto. Além disso, a existência de caracteres em branco na palavra também deve ser considerada. As classes de equivalência derivadas para este exemplo encontram-se descritas no Quadro 2.2 e os casos de teste no Quadro 2.3.

Quadro 2.2: Classes de equivalência para o contador de ocorrências

\begin{tabular}{|l|c|c|}
\hline Condição de entrada & Classe válida & Classe inválida \\
\hline Tamanho do texto $\left(T_{t}\right)$ & $T_{t}>0(\mathrm{a})$ & $T_{t}=0(\mathrm{~b})$ \\
\hline Tamanho da palavra $\left(T_{p}\right)$ & $T_{p}>0(\mathrm{c})$ & $T_{p}=0(\mathrm{~d})$ \\
\hline Palavra contém espaço(s) em branco & Não (e) & Sim (f) \\
\hline Palavra existe no texto & Sim (g) & - \\
& Não (h) & - \\
\hline
\end{tabular}

Quadro 2.3: Casos de teste para o contador de ocorrências

\begin{tabular}{|c|c|c|}
\hline Entrada & Saída & Classes exercitadas \\
\hline 'Instituto de Ciências Matemáticas e de Com & 2 & $\mathrm{a}, \mathrm{c}, \mathrm{e}, \mathrm{g}$ \\
\hline 'Instituto de Ciências Matemáticas e de Computação', 'da' & 0 & $\mathrm{a}, \mathrm{c}, \mathrm{e}, \mathrm{h}$ \\
\hline '’, 'de' & -1 & $\mathrm{~b}$ \\
\hline 'Instituto de Ciências Matemáticas e de Computação’, ‘’ & -1 & $\mathrm{~d}$ \\
\hline 'Instituto de Ciências Matemáticas e de Computação’, 'de ' & -1 & $\mathrm{f}$ \\
\hline
\end{tabular}

A estratégia adotada pelo particionamento de equivalência, na qual qualquer membro da classe é representativo de toda a classe, não impõe tratamento especial aos limites das classes, que são elementos importantes do particionamento e devem ser examinados de forma distinta. Além disso, nesse critério o domínio de saída não é considerado para elaboração dos casos de teste. Dessa forma, algumas classes de defeitos podem não ser relevadas e o critério portanto não é muito forte. Essas duas limitações são consideradas pelo critério de Análise de ValorLimite.

\subsubsection{Análise de Valor-limite}

Grande parte dos erros tende a ocorrer nas fronteiras do domínio de entrada (PRESSMAN, 2002; MYERS, 1979). O critério de Análise de Valor-limite complementa o Particionamento de Equivalência por meio de casos de teste que exercitam os valores limítrofes. Valores-limite referem-se a situações que ocorrem dentro de uma classe de equivalência, diretamente acima ou abaixo dela. Nesse critério o domínio de saída do programa também é particionado e auxilia na derivação dos casos de teste, que por sua vez devem ser escolhidos em cada uma das bordas das classes. Algumas diretrizes podem ser utilizadas nesse critério: 
- Se uma condição de entrada especifica uma gama de valores, devem ser escritos casos de teste para os extremos dessa gama e para suas proximidades (ex., se os valores válidos forem números reais entre entre -1.0 e 1.0, deve-se testar -1.0, 1.0, -1.001, 1.001);

- Valores de saída também devem ser particionados e devem ser escritos casos de teste que exercitem seus extremos (ex., se o programa produz como resultado um número inteiro que varia entre 0 e 25 , devem ser escritos casos de teste que façam o programa produzir esses dois extremos e, se possível, um valor negativo e outro maior que 25);

- Se a condição de entrada especifica um número de valores, devem ser desenvolvidos casos de teste para o número mínimo e máximo de valores e suas proximidades (ex., se o tamanho da entrada varia de 1 a 4 números, deve-se testar o tamanho da entrada sendo 0 , $1,4$ e 5$)$;

- De forma semelhante, os valores de saída devem ser analisados e casos de teste devem ser elaborados para testar seus limites e vizinhanças (ex., se um programa calcula de 1 a 3 valores, deve-se criar casos de teste que levem ao cálculo de $0,1,4$ e, se possível, 5 valores).

O Quadro 2.4 apresenta possíveis casos de teste que utilizam o critério de Análise de Valorlimite para o contador de ocorrências especificado na Seção 2.4.1.1.

Quadro 2.4: Valores-limite para o contador de ocorrências

\begin{tabular}{|l|l|c|} 
Descrição & \multicolumn{1}{|c}{ Entrada } & Saída \\
\hline Texto igual a palavra & 'Padrões', 'Padrões' & 1 \\
\hline Apenas um ocorrência da palavra & 'Padrões de Projeto', ‘Projeto' & 1 \\
\hline Texto com comprimento mínimo & 'A', ‘A' & 1 \\
\hline Palavra maior que texto & 'Projeto', ‘Padrões de Projeto' & -1 \\
\hline Palavra vizinhas & 'São Padrões Padrões', 'Padrões' & 2 \\
\hline Palavra no início do texto & 'Padrões de Projeto', 'Padrões' & 1 \\
\hline Palavra no fim do texto & 'São Padrões', 'Padrões' & 1 \\
\hline
\end{tabular}

\subsubsection{Teste Funcional Sistemático}

O Teste Funcional Sistemático (LINKMAN; VINCENZI; MALDONADO, 2003) é uma variante mais forte do Particionamento de Equivalência que leva em consideração os domínios de entrada e saída, segundo um conjunto bem definido de regras. Uma vez que o particionamento da entrada e saída é efetuado, esse critério exige que sejam exercitados ao menos dois casos de teste em cada partição, uma vez que a utilização de apenas um valor pode mascarar erros coincidentes. Como descrevem os autores, um exemplo desse tipo de erro pode ser ilustrado por um programa que recebe um número inteiro como entrada e deve retornar seu valor ao quadrado. Utilizando o valor 2 como entrada, uma saída igual a 4 não permite distinguir entre $(2+2)$ e $(2 * 2)$. Nota-se que a escolha de apenas um valor, como sugerido pelo Particionamento de 
Equivalência, não é suficiente nesse caso e a seleção de um segundo valor nessa partição ajuda a minimizar o problema.

Além disso, o Teste Funcional Sistemático exige a avaliação dos valores limites e de suas proximidades, e oferece regras para facilitar a identificação dos casos de teste. Nessas regras são descritos que tipos de dados devem ser selecionados para variados tipos de função, domínios de entrada e de saída, o que pode conduzir à seleção de um ou mais casos de teste, de acordo com o programa que está sendo testado. Algumas dessas regras estão descritas a seguir, maiores detalhes podem ser obtidos em (LINKMAN; VINCENZI; MALDONADO, 2003).

Valores numéricos: devem ser tratados como descrito abaixo:

- Domínio de entrada

- Valores discretos: testar cada um;

- Gama de valores: para cada gama, testar extremidades e um valor no seu interior.

- Domínio de Saída

- Valores discretos: gerar cada um;

- Gama de valores: para cada gama, gerar cada extremidade e ao menos um valor no seu interior.

Casos especiais: diferentes tipos de valores devem estar na entrada e serem gerados na saída, como por exemplo um espaço em branco, que pode ser considerado como zero em um campo numérico. Casos desse tipo devem ser considerados individualmente, ainda que pertençam a uma gama de valores.

Valores ilegais: valores que representam entradas inválidas devem ser incluídos no caso de teste, de forma a assegurar que o software os rejeite corretamente. Além disso, é necessário verificar se valores inválidos foram gerados na saída (o que não deve ocorrer).

Números reais: apesar da checagem de extremidade para valores reais não ser exata, ela deve ser incluída no caso de teste. Para isso deve ser definida uma precisão aceitável e números reais muito pequenos e o valor zero devem ser testados.

Arrays: cada valor do array deve ser testado. Além disso, o tamanho do array deve ser testado para os valores mínimos, máximos e intermediários para todas as dimensões, em todas combinações.

Strings: textos devem ser checados com comprimento variável (incluindo comprimento zero) e validade de cada caractere, de acordo com a regra de validação específica (se existir). 


\subsubsection{Grafo de Causa-efeito}

Ao contrário dos critérios apresentados anteriormente, o Grafo de Causa-efeito combina as condições de entrada para a geração de casos de teste, tendo em vista que a combinação dos dados de entrada pode denunciar erros não revelados pelo Particionamento de Equivalência ou Análise de Valor-Limite. O total de combinações dessas condições pode ser muito grande, e dessa forma, o grafo de causa-efeito busca auxiliar na escolha de um conjunto de casos de teste, assim como apontar para ambigüidades ou dados incompletos na especificação (MYERS, 1979).

O grafo de causa-efeito é uma notação gráfica para descrever relacionamentos lógicos entre causas e efeitos em uma especificação de software, principalmente aquelas que descrevem regras do negócio. Uma causa representa uma condição de entrada ou uma classe de equivalência das condições de entrada, enquanto um efeito diz respeito a uma condição de saída ou a uma mudança no estado do sistema (PARADKAR; TAI; VOUK, 1997; MYERS, 1979). A representação gráfica do grafo em questão é feita conectando-se as causas e efeitos (representados como variáveis booleanas) conforme uma notação própria.

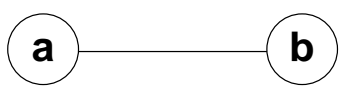

Identidade

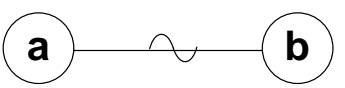

Negação

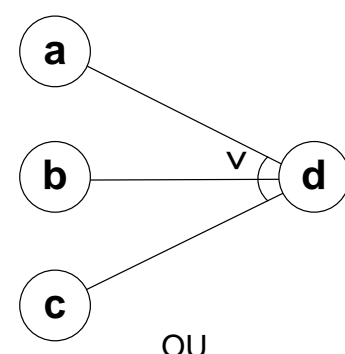

OU

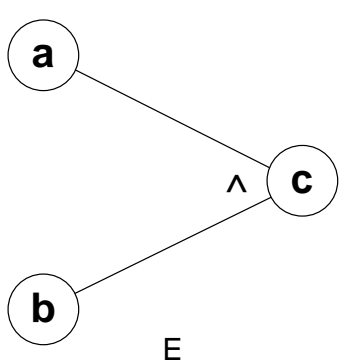

E

Figura 2.1: Grafo de causa-efeito - Símbolos básicos

Os símbolos básicos utilizados na notação encontram-se na Figura 2.1. Cada nó possui um valor 0 ou 1, representando a ausência ou presença de um estado, respectivamente. A função identidade declara que se $a$ possui valor $1, b$ também será 1 . A função negação declara que se $a$ é $1, b$ é 0 . A função $O U$ declara que se $a$ ou $b$ ou $c$ é $1, d$ também será 1 . A função $E$ declara que se $a$ e $b$ forem $1, c$ será 1 . As funções $E$ e $O U$ podem ter qualquer número de argumentos (MYERS, 1979).

O processo de derivação dos casos de teste proposto por Myers (1979) pode ser resumido em três etapas:

1. Identificação das causas e efeitos: causas e efeitos são identificados a partir de palavras ou frases da especificação que descrevem condições de entrada, saída ou mudança no estado do sistema. Cada causa ou efeito recebe uma numeração única; 
2. Dedução dos relacionamentos lógicos e restrições: a especificação é analisada e transformada em um grafo booleano ${ }^{1}$ no qual as causas e efeitos são representados por nós (e representam valores binários), enquanto arcos descrevem a ligação lógica entre os elementos. Restrições são adicionadas ao grafo por meio de notações especiais (Figura 2.2), e descrevem combinações não possíveis entre causas e efeitos;

3. Construção da tabela de decisão e casos de teste: As condições de estado do grafo são rastreadas e o grafo é convertido em uma tabela de decisão. Cada coluna na tabela representa um caso de teste.

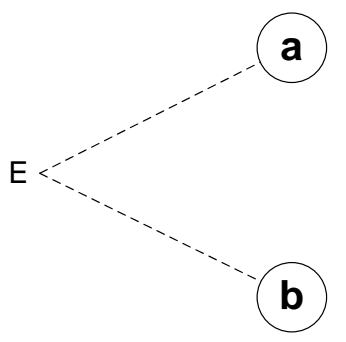

Exclusivo

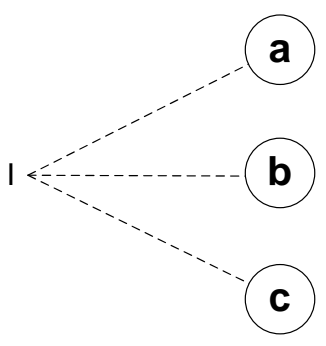

Inclusivo

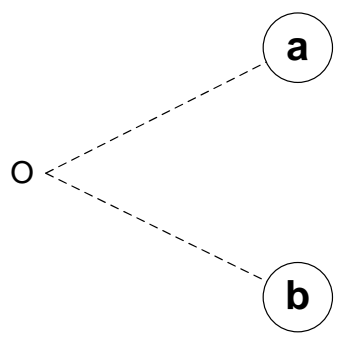

Um e apenas um

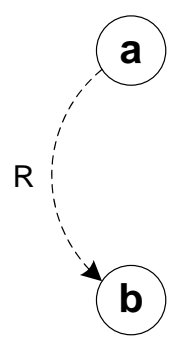

Exigência

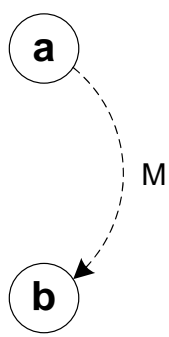

Máscara

Figura 2.2: Grafo de causa-efeito - Símbolos de restrição

Na Figura 2.2 são apresentados os símbolos que representam restrições no grafo de causaefeito. A restrição $E$ declara que no máximo um elemento pode ter valor 1 ( $a$ ou $b$ ). A restrição $I$ declara que ao menos um elemento deve ter valor 1 ( $a, b$ ou $c$ ). A restrição $O$ declara que apenas um dos elementos pode ter valor $1(a$ ou $b)$. A restrição $R$ declara que para $a$ ter valor 1 , $b$ deve ser 1 . A restrição $M$ declara que se $a$ é 1 , o efeito $b$ é forçado para 0.

No Quadro 2.5 encontra-se a especificação do comando Sendfile para envio de arquivos de um usuário para um servidor (NURSIMULU; PROBERT, 1995). A análise da especificação permite identificar as causas e efeitos e atribuir-lhes uma numeração, conforme apresentado nos Quadros 2.6 e 2.7.

Quadro 2.5: Especificação do comando Sendfile - adaptado de Nursimulu e Probert (1995)

\begin{tabular}{|l|l|}
\hline Entrada & $\begin{array}{l}\text { O comando Sendfile possui três argumentos: o primeiro argumento deve } \\
\text { ser um arquivo existente no diretório raiz do remetente, o segundo, o } \\
\text { nome do servidor destino e o último, o código do usuário }\end{array}$ \\
\hline Saída & $\begin{array}{l}\text { Se todos os argumentos estiverem corretos o arquivo é enviado, caso } \\
\text { contrário o remetente recebe uma mensagem de erro }\end{array}$ \\
\hline
\end{tabular}

O grafo resultante pode ser visto na Figura 2.3. Como descrito anteriormente, cada nó possui associado um valor booleano (0 ou 1). O nó 10 representa o resultado do and lógico $(\wedge)$ entre as três condições de entrada (causas) e o seu valor determina os efeitos sobre o sistema.

\footnotetext{
${ }^{1} \mathrm{O}$ grafo de causa-efeito é um circuito lógico com uma notação simplificada (MYERS, 1979)
} 
Quadro 2.6: Causas para o comando Sendfile - adaptado de Nursimulu e Probert (1995)

\section{Causas}

1. O primeiro argumento é o nome de um arquivo existente no diretório raiz do remetente

2. O segundo argumento é o nome do servidor de arquivos destino

3. O terceiro argumento é o código do usuário
Quadro 2.7: Efeitos para o comando Sendfile - adaptado de Nursimulu e Probert (1995)

\section{Efeitos}

100. O arquivo é enviado

101. O remetente recebe uma mensagem de erro

Um valor verdadeiro leva ao envio do arquivo, pois a relação de identidade entre os nós 10 e 100 faz com que o último também possua valor verdadeiro. Um valor falso, por sua vez, leva ao efeito 101 e uma mensagem de erro é exibida.

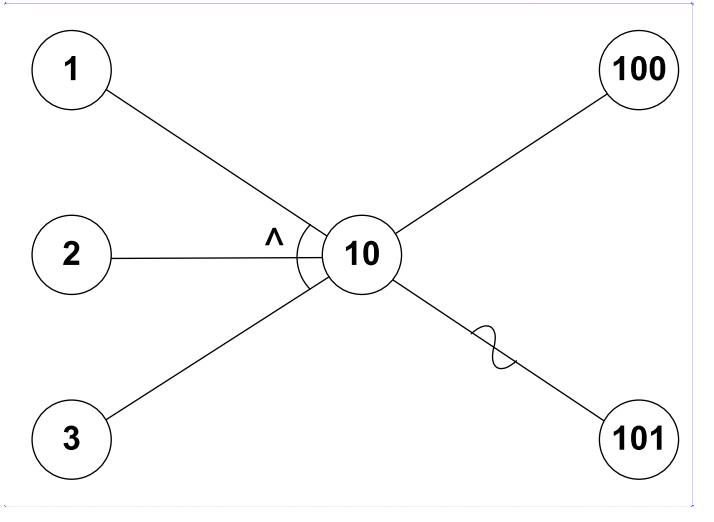

Quadro 2.8: Tabela de decisão do comando Sendfile

Figura 2.3: Grafo de causa-efeito do comando SendFile - adaptado de Nursimulu e Probert (1995)

\begin{tabular}{|l|c|c|c|c|c|c|c|c|c|}
\multicolumn{1}{c|}{} & \multicolumn{10}{c|}{ Casos de teste } \\
\hline \multirow{3}{*}{ Causas } & $\mathbf{1}$ & 1 & 0 & 1 & 0 & 0 & 1 & 1 & 0 \\
& 2 & 1 & 0 & 0 & 1 & 0 & 1 & 0 & 1 \\
& 3 & 1 & 0 & 0 & 0 & 1 & 0 & 1 & 1 \\
\hline \multirow{2}{*}{ Efeitos } & $\mathbf{1 0 0}$ & 1 & 0 & 0 & 0 & 0 & 0 & 0 & 0 \\
& $\mathbf{1 0 1}$ & 0 & 1 & 1 & 1 & 1 & 1 & 1 & 1 \\
\hline
\end{tabular}

A partir do grafo pode ser construída a tabela de decisão (Quadro 2.8). As combinações das possíveis causas e efeitos definem os casos de teste, representados nas oito colunas. Assim, tomando como exemplo a primeira coluna (111 10) tem-se um caso de teste em que as três causas são verdadeiras (111), ou seja, o arquivo existe no remetente, o nome do servidor destino é válido e o código do usuário é válido. O efeito esperado é que o arquivo é enviado. Isso é representado pelo valor 1 , enquanto o valor 0 especifica que o segundo efeito não deve ser ativado (o remetente recebe uma mensagem de erro).

\subsubsection{Invariantes, Pré e Pós-condições}

Projeto por Contrato (Design by Contract) (MEYER, 1992, 1997) é uma técnica de projeto OO cujo objetivo é melhorar a confiança no software. Nessa técnica especifica-se de forma precisa o relacionamento entre cada rotina cliente e cada rotina fornecedora do serviço por meio de contratos.

Contratos definem obrigações entre as partes componentes, assim como os resultados do seu relacionamento, e são implementados por meio de mecanismos denominados assertivas. As assertivas podem ser de três tipos: 
- Pré-condições: obrigações que o cliente deve cumprir para chamar o componente externo (fornecedor do serviço) corretamente;

- Pós-condições: resultados esperados após a execução do componente externo;

- Invariantes: condições que devem permanecer inalteradas após a execução do componente externo.

Uma assertiva corresponde a uma expressão booleana, analisada em um ponto específico da execução do programa e que deve sempre ser verdadeira. Uma falha na assertiva geralmente indica erro no software. Assim, uma violação de uma pré-condição indica a existência de defeito na função cliente (função chamadora). Uma violação de uma pós-condição, por sua vez, aponta defeito no provedor do serviço (função chamada).

A técnica funcional apresenta características importantes, que facilitam sua utilização. Como requer apenas a especificação do software para derivar os requisitos de teste, essa técnica pode ser aplicada indistintamente em programas procedimentais ou orientados a objetos. Além disso, os testes podem ser criados logo no início do processo de desenvolvimento e sua especificação é independente de uma implementação em particular.

No entanto, como os critérios funcionais são baseados apenas na especificação, eles não garantem que partes críticas ou essenciais do software foram cobertas, o que dificulta a quantificação dessa atividade. Além disso, o teste caixa-preta está sujeito às inconsistências existentes na própria especificação, que em geral é feita de forma descritiva e informal. Essas características dificultam a automação dos critérios dessa técnica.

\subsubsection{Técnica estrutural}

$\mathrm{Na}$ técnica estrutural (caixa-branca) os requisitos são estabelecidos com base na implementação do programa e a estrutura e os detalhes do código são considerados para derivar os casos de teste. Nessa técnica, caminhos lógicos e condições do software são testados e o estado do programa pode ser examinado em diversos pontos (PRESSMAN, 2002). De forma geral, os critérios dessa técnica utilizam uma representação de programa conhecida como Grafo de Fluxo de Controle - GFC ${ }^{2}$ (MALDONADO et al., 2003).

Um grafo de fluxo de controle é um grafo dirigido que possui um único nó de entrada e um único nó de saída. Para a construção de um grafo desse tipo, o programa alvo é divido em diversos blocos distintos de comandos, que possuem duas características: (a) seus comandos são executados de forma atômica, ou seja, uma vez que o primeiro comando do bloco é executado, todos os demais são executados seqüencialmente; (b) não existe desvio de execução para

\footnotetext{
${ }^{2} \mathrm{O}$ grafo de fluxo de controle também é denominado grafo de programa
} 
nenhum comando dentro do bloco. A conexão entre os blocos é feita por intermédio de arcos que indicam os possíveis fluxos de controle entre os blocos.

Os critérios estruturais baseiam-se em diferentes conceitos e componentes de programas para derivar os requisitos de teste. De forma geral, os critérios da técnica estrutural são três (MALDONADO et al., 2003; MALDONADO; FABBRI, 2001):

- Baseados em fluxo de controle: utilizam apenas características do controle de execução do programa (comandos ou desvios) para determinar quais estruturas são necessárias. Os critérios mais conhecidos são (NTAFOS, 1988):

- Todos-Nós: cada bloco do programa deve ser executado por pelo menos um caso de teste;

- Todos-Arcos: cada aresta do grafo de programa deve ser executada por pelo menos um caso de teste;

- Todos-Caminhos: todos os caminhos do programa devem ser executados. Este critério é, em geral, impraticável porque o total de caminhos existentes pode ser muito grande.

- Baseados em fluxo de dados: utilizam informações do fluxo de dados para derivar os requisitos de teste. Neste critério são exploradas associações entre pontos do programa em que é atribuído um valor a uma variável (definição) e pontos onde esse valor é referenciado (uso), em um caminho livre de definição (um caminho onde nenhuma outra atribuição é feita a essa variável). De forma geral, esses critérios utilizam um GFC estendido, em que são adicionadas informações do conjunto de variáveis definido e usado em cada nó ou arco (VINCENZI et al., 2003a; MALDONADO; FABBRI, 2001). Nessa classe destacam-se dois critérios (MALDONADO et al., 2003):

- Todos-Usos: todas as associações entre uma definição de variável e seus subseqüentes usos devem ser exercitadas por pelo menos um caminho no qual a variável não é redefinida;

- Potenciais-Usos: para todo nó $i$ e para toda variável $x$, para a qual existe uma definição em $i$, que pelo menos um caminho livre de definição com relação à variável (c.r.a) $x$ do nó $i$ para todo nó e para todo arco possível de ser alcançado a partir de $i$ por um caminho livre de definição c.r.a. $x$ seja exercitado.

- Baseados na complexidade: utilizam informações sobre a complexidade do programa para derivar os requisitos de teste. Um dos critérios conhecidos dessa classe é o Critério de McCabe, que utiliza a complexidade ciclomática para derivar os requisitos de teste. Basicamente, esse critério define um conjunto de caminhos independentes no programa e 
os testes que devem ser realizados para garantir que todos os comandos sejam executados pelo menos uma vez (PRESSMAN, 2002).

\subsubsection{Técnica baseada em erros}

$\mathrm{Na}$ técnica baseada em erros, os requisitos são estabelecidos por meio dos erros típicos encontrados durante o processo de desenvolvimento de software. Semeadura de Erros e Análise de Mutantes são dois critérios típicos desta classe (MALDONADO et al., 2003).

- Semeadura de Erros: erros são inseridos artificialmente no programa durante o teste. Após a execução do teste, verifica-se, entre os erros encontrados, quais são naturais e quais são artificiais. Por meio da proporção entre os tipos de erros descobertos tem-se, teoricamente, uma indicação do número de erros naturais ainda existentes no programa;

- Análise de Mutantes: baseia-se na hipótese de que erros são introduzidos nos programas como pequenos desvios sintáticos que alteram a semântica do programa e o conduzem a um comportamento incorreto. Assim, por meio de um conjunto de programas gerados a partir do programa em teste (mutantes) busca-se obter um conjunto de casos de teste que revele diferenças de comportamento entre o programa e seus mutantes (DEMILLO et al., 1987; MALDONADO et al., 2003).

\subsection{Teste de programas orientados a objeto}

Apesar de ter surgido no fim dos anos sessenta como uma alternativa à programação procedimental, apenas na década de noventa o paradigma da Orientação a Objetos foi adotado de forma efetiva. A abordagem OO propõe um novo modelo para o desenvolvimento de programas no qual a estrutura do software é, inerentemente, desacoplada. Como descreve Pressman (2002), no paradigma OO o domínio do problema é caracterizado como um conjunto de objetos que possuem propriedades e comportamentos específicos e se comunicam por meio de mensagens.

\subsubsection{Efeitos do paradigma $O O$ no teste}

Embora tenha trazido generalidade, flexibilidade, robustez e produtividade ao desenvolvimento de programas, o novo paradigma não reduziu a incidência de defeitos no software ou a necessidade do teste. Ao invés disso, os novos conceitos da Orientação a Objetos - encapsulamento, herança, polimorfismo, acoplamento dinâmico, etc. - criam novos desafios ao teste de software (BINDER, 1999). 
O encapsulamento apresenta um obstáculo ao teste, pois limita a visibilidade do estado do objeto, fundamental para a atividade de teste. De acordo com Binder (1999), embora o encapsulamento não contribua diretamente para a ocorrência de erros, ele dificulta a leitura ou alteração do estado de um objeto. A herança, por sua vez, leva ao re-teste, pois as subclasses podem funcionar em contextos diferentes da classe pai e dessa forma precisam ser testadas (BARBEY; STROHMEIER, 1994).

O polimorfismo e o acoplamento dinâmico permitem que um objeto exiba diferentes comportamentos, o que leva a um aumento significativo do número de caminhos de execução. $\mathrm{O}$ polimorfismo também dificulta o teste de programas OO. Cada possível acoplamento é uma computação única, e o fato de diversos acoplamentos funcionarem corretamente não implica que todos funcionarão (BINDER, 1999).

De forma geral, os conceitos e técnicas aplicados ao teste de programas procedimentais podem ser aproveitados para o teste de programas OO, porém a ênfase e a efetividade das várias técnicas diferem nessa nova abordagem.

\subsubsection{Fases do teste de programas orientados a objeto}

Assim como o teste de programas tradicionais, o teste de programas OO segue três fases: unidade, integração e sistema. Uma classe define um conjunto de dados (atributos) e operações que agem sobre esses dados (métodos) e, de forma geral, pode ser considerada como sendo a menor unidade a ser testada (PRESSMAN, 2002). Assim, o teste de unidade refere-se ao teste da classe, enquanto o teste de integração corresponde ao teste inter-classes.

Harrold e Rothermel (1994), no entanto, consideram o método como a unidade do teste OO e propõem três níveis para o teste de classes: teste do método individualmente (intra-método), equivalente ao teste de unidade de programas procedimentais; teste de diversos métodos da mesma classe (inter-método), equivalente ao teste de integração de programas procedimentais; e por fim, teste entre classes.

Os testes de sistema são executados logo após os testes de integração e, por basearem-se na técnica funcional, não apresentam diferenças consideráveis em relação à abordagem escolhida ou ao teste de programas procedimentais. No Quadro 2.9 (VINCENZI, 2004) encontra-se uma síntese das fases de teste de acordo com a abordagem utilizada para a menor unidade (método ou classe).

Quadro 2.9: Relação entre fases de teste $O O$

Menor unidade: método Menor unidade: classe

\begin{tabular}{|l|l|l|}
\hline Fase & Tipo de Teste & Tipo de Teste \\
\hline Unidade & Intra-método & Intra-método, Inter-método, Intra-classe \\
\hline Integração & Inter-método, Intra-classe, Inter-classe & Inter-classe \\
\hline Sistema & Toda a aplicação & Toda a aplicação \\
\hline
\end{tabular}




\subsubsection{Técnicas do teste de programas orientados a objeto}

Como descrito anteriormente, técnicas e critérios de teste buscam fornecer uma abordagem sistemática para a condução da atividade de teste, e atualmente diversas iniciativas têm estendido as técnicas e critérios utilizadas no teste de programas procedimentais para o teste de programas $\mathrm{OO}$. Identificam-se abordagens que utilizam critérios funcionais e baseados em máquinas de transição de estado (baseados em especificação), assim como estruturais e baseados em erro (baseados em programa).

De forma geral, os critérios funcionais podem ser aplicados no teste OO, tendo em vista o fato de basearem-se somente na especificação (OFFUTT; IRVINE, 1995). Por outro lado, diversos critérios de teste vêm sendo desenvolvidos com o intuito de validar o aspecto comportamental de programas OO. No entanto, como comenta Vincenzi (2004), a grande maioria dos trabalhos concentra-se na geração de casos de teste a partir do comportamento dinâmico dos objetos.

Segundo Binder (1996), nem sempre os testes baseados em sequiências de estados ou mensagens são suficientes. Nesse sentido, esse autor propõe o teste modal de classes, no qual as diferenças de comportamento das classes (modalidade das classes) são utilizadas para indicar qual a melhor estratégia para selecionar casos de teste, tendo em vista que diferentes tipos de erros podem ocorrer em cada modalidade. Uma outra estratégia de teste é a Flateened Regular Expression - FREE descrita por Binder (1999), que consiste de um framework conceitual que possibilita o desenvolvimento de conjuntos de casos de teste de unidade, integração e sistema para o teste de software OO.

Em relação à técnica estrutural, pode-se citar o trabalho desenvolvido por Harrold e Rothermel (1994), que estenderam o critério de fluxo de dados para classes. Os autores descrevem nesse trabalho que os critérios de fluxo de dados destinados ao teste de programas procedimentais (HARROLD; SOFFA, 1989; RAPPS; WEYUKER, 1985) podem ser utilizados para teste de métodos individuais e de métodos que interagem dentro de uma mesma classe. Para o teste de métodos acessíveis de fora da classe uma nova representação - grafo de fluxo de controle de classe - foi desenvolvida, a partir da qual associações inter-método e intra-classe podem ser derivadas. Vincenzi et al. (2003a) também têm investigado o uso de critérios de fluxo de controle e de dados no teste de programas $\mathrm{OO}$, especificamente a análise estática de programas Java diretamente a partir do seu código objeto (Java bytecode).

\subsection{Ferramentas de teste}

Devido à crescente complexidade dos softwares, a utilização de ferramentas de teste visando a automatização desempenha papel fundamental na aplicação de critérios de teste. Sem o apoio de uma ferramenta, a atividade de teste torna-se trabalhosa, propensa a erros e limitada 
a programas simples. A utilização de ferramentas de teste também facilita a adoção de critérios de teste pela industria e a condução de estudos empíricos com vistas a comparar diversos critérios de teste existentes (VINCENZI, 2004).

Além disso, como descreve Binder (1999), a automatização permite verificação rápida e eficiente das correções de defeitos, agiliza o processo de depuração, permite a captura e análise dos resultados de teste de forma consistente e facilita a execução de testes de regressão, nos quais os casos de teste podem ser reutilizados para revalidação do software após modificação.

Em geral as ferramentas utilizam o conceito de cobertura para medir (em porcentagem) o quanto um critério foi satisfeito em relação aos seus requisitos. Coberturas de nós, arcos e definições-uso constituem alguns exemplos utilizados pela ferramentas. A análise de cobertura permite identificar áreas do programa não exercitadas por um conjunto de casos de teste e dessa forma avaliar a qualidade desse conjunto. Além disso por meio da análise de cobertura é possível medir o progresso do teste e decidir quando finalizar essa atividade.

Existem diversas iniciativas na direção de automatizar o teste de software, tanto procedimental quanto orientado a objetos. O Laboratório de Engenharia de Software do ICMC-USP possui tradição no desenvolvimento de ferramentas para apoiar diversas técnicas de teste (DELAMARO, 1993; SUGETA, 1999; SIMÃO, 2000; VINCENZI et al., 2003b).

\subsubsection{Instrumentação}

A utilização de ferramentas no teste de software normalmente envolve uma etapa na qual se realiza a instrumentação do programa em teste. A instrumentação consiste em inserir código auxiliar no programa que está sendo testado, o que permite ao testador observar o comportamento do programa e obter informações ou medidas referentes à sua execução. Essas informações permitem conhecer, por exemplo, o estado do sistema e os métodos que foram executados durante o teste da aplicação e dessa forma, fornecem subsídios para avaliar a adequação dos casos de teste utilizados. A instrumentação pode ser realizada em tempo de compilação ou dinamicamente, quando o código de instrumentação é inserido/removido durante a execução do programa.

Especificamente em relação a linguagem Java, ferramentas como JIE (TROMER, 1999) permitem a instrumentação diretamente sobre o código fonte, por meio da introdução de comandos (ou anotações) de instrumentação em locais específicos. A instrumentação do código fonte possui um nível maior de abstração, pois é feita no nível da linguagem de programação. No entanto, além de exigir a disponibilidade do código, esse tipo de abordagem leva à manutenção de dois códigos fontes: um instrumentado e outro não.

Protocolos como o Guaraná (OLIVA, 1998) utilizam uma abordagem distinta, baseada em implementações modificadas da JVM (Java Virtual Machine) com o objetivo de oferecer recursos de instrumentação dinâmica via reflexão computacional. Apesar de não necessitar do 
código fonte, a modificação da JVM diminui a versatilidade de teste do software, uma vez que o programa a ser testado deverá ser executado na máquina virtual modificada, obrigatoriamente.

Uma terceira abordagem é a utilizada por ferramentas como Javassist (CHIBA, 2004), BCEL (DAHM, 2002) e JOIE (COHEN; CHASE; KAMINSKY, 2003), que permitem manipulação do bytecode Java e introdução de código de instrumentação por meio da inserção de instruções de baixo nível. A instrumentação do bytecode, por sua vez, apesar de eliminar os problemas citados anteriormente, muitas vezes exige o conhecimento da estrutura do bytecode e portanto não é muito intuitiva.

\subsubsection{Ferramentas para teste funcional de programas Java}

Nesta seção são apresentadas, a título de ilustração, algumas ferramentas (comerciais ou não) para teste funcional de programas Java, por serem essas a técnica de teste e linguagem de programação adotadas nesta pesquisa. As ferramentas foram escolhidas principalmente a partir de pesquisas na Internet e suas descrições baseiam-se na documentação fornecida por cada fabricante ou utilização das versões de avaliação disponíveis nos respectivos sites. É importante salientar que apenas o suporte à técnica funcional é avaliado, não sendo consideradas outras características existentes nas ferramentas.

\subsubsection{JUnit}

O JUnit (GAMMA; BECK, 2002) é um framework para apoio ao teste de unidade, que contém classes e métodos específicos para declaração e checagem de asserções em Java. Casos de teste são elaborados estendendo-se a classe abstrata TesteCase e implementando-se os métodos de teste desejados. Os métodos de teste possuem nome iniciado com o prefixo test e implementam os casos de teste. Geralmente esses métodos utilizam asserções disponíveis na API (Application Program Interface) do JUnit para verificar se o teste foi bem sucedido (métodos iniciados com prefixo assert).

Além disso, o framework possui dois métodos especiais que facilitam a configuração do teste. O método setUp é executado antes de cada método de teste ser disparado e portanto deve ser utilizado para estabelecer uma configuração inicial padrão. Normalmente nesse método são criados os objetos que serão utilizados pelos métodos de teste. O método tearDown, por sua vez, executa após cada método de teste e é utilizado para configurar o final da execução.

A execução dos métodos de teste é feita por meio de reflexão. Os métodos existentes na classe descendente de TestCase são executados e o resultado apresentado em um relatório de teste, que consiste em um sumário no qual são exibidos os casos de teste que passaram ou falharam. O formato desse relatório pode ser configurado por meio de classes específicas 
do framework. O JUnit disponibiliza uma versão gráfica e outra via linha de comando para execução dos casos de teste e exibição do relatório do teste.

Apesar de permitir a especificação e execução automática de casos de teste, o JUnit não oferece análise de cobertura ou utiliza qualquer técnica específica de teste. Assim, diversas propostas têm estendido esse framework com o intuito de aproveitar suas facilidades e inserir novos requisitos, necessários às ferramentas de teste.

\subsubsection{Jtest}

A ferramenta Jtest (Parasoft Corporation, 1997) oferece apoio à verificação de padrões de codificação e ao teste de unidade, e opera diretamente sobre o código fonte (que deve, portanto, estar disponível). No teste de unidade os casos de teste são gerados e executados automaticamente pela ferramenta a partir da análise da classe em teste. Os casos de teste são gerados no JUnit, e são construídos de forma que exercitem cada um dos métodos da classe com uma grande variedade de entradas, maximizando a cobertura da classe. Os dados de entrada permitidos para cada método são especificados no comentário do método, utilizando uma sintaxe própria de Projeto por Contrato. Caso não haja contrato especificado, qualquer valor poderá ser gerado como entrada, inclusive um valor nulo.

Durante uma sessão de teste, o testador pode modificar os casos de teste gerados ou acrescentar novos casos de teste. A documentação da ferramenta sugere que essa abordagem seja utilizada para o teste funcional, em que os casos de teste gerados devem ser alterados para verificar se as interfaces públicas da classe operam como esperado. Os requisitos dessas interfaces podem ser especificados por meio de Projeto por Contrato em comentários no código fonte, como descrito no parágrafo anterior.

A Jtest disponibiliza informações sobre a cobertura de métodos e classes, segundo a ótica do teste estrutural. A cobertura de um método é calculada como a relação entre as linhas de código do método executadas e o total de linhas correspondente. A cobertura da classe, por sua vez, consiste na relação entre o total de métodos cobertos e o total de métodos da classe.

Nota-se que a ferramenta Jtest não implementa claramente a noção de teste funcional e são necessários esforços complementares para esse fim, uma vez que não são apoiados os conceitos principais dessa técnica. Além disso, o procedimento de cálculo de cobertura (em função de linhas de código), não possui significado para o teste funcional, no qual muitas vezes não se dispõe da implementação do programa e os requisitos de teste derivam apenas de sua especificação. 


\subsubsection{TestComplete}

TestComplete (AutomatedQA Corp., 1999) é uma ferramenta que oferece apoio ao teste de programas implementados em diversas linguagens, incluindo Java. Para o teste de aplicações Java, o testador deve inserir comandos especiais nas classes em teste (o que implica em disponibilidade do código fonte) e criar um script para a sua execução. Também devem ser indicados os métodos em teste, sendo que apenas os métodos que não possuem parâmetros nem retorno podem ser testados.

O TestComplete utiliza o lançamento de exceções para verificar o (in)sucesso na execução de um método. Assim, o lançamento de uma exceção indica uma falha no método em teste, enquanto o não lançamento indica que o método teve sucesso na sua execução. O relatório de teste (denominado Test Log) exibe todos os métodos executados em uma estrutura hierárquica, na qual é possível visualizar os métodos que passaram e os que falharam.

Apesar de se propor ao teste funcional, a ferramenta implementa apenas verificações de exceções e o teste de interface (UI Testing), utilizando a técnica de gravação e reprodução. Nessa técnica, as interações do usuário com o programa em teste são capturadas em arquivos de script, que podem ser alterados posteriormente. A TestComplete não oferece análise de cobertura diretamente, sendo necessária a integração com outra ferramenta do mesmo fabricante (que fornece cobertura apenas em função dos requisitos estruturais). Além disso, a ferramenta não utiliza qualquer critério do teste funcional.

\subsubsection{XDE Tester}

O XDE Tester (Rational Corp., 2002) é uma ferramenta para teste funcional de programas Java. Sua principal característica consiste da capacidade de gravar scripts e posteriormente reproduzi-los, de forma semelhante ao TestComplete. A XDE Tester permite que sejam definidos pontos de verificação para checar que uma certa ação ocorreu ou verificar o estado de um objeto. Após a execução de um script de teste, é exibido um relatório contendo os pontos de verificação cadastrados e o resultado de sua execução.

Além de não implementar análise de cobertura, a ferramenta não utiliza o conceito de classes de equivalência ou valores-limite e o teste funcional é limitado à observação dos estados dos objetos.

\subsubsection{SPACES}

SPACES (BARBOSA et al., 2004) é uma ferramenta para teste funcional de componentes. A ferramenta oferece suporte para geração, execução e análise dos resultados de teste e, para ser utilizada, exige a disponibilidade de diversos diagramas do modelo UML (Unified Modeling 
Language), descritos em um arquivo XMI (XML Metadata Interchange). Os dados contidos nesse arquivo - diagrama de classes, restrições OCL (Object Constraint Language), diagrama de casos de uso e diagramas de seqüencia - são utilizados para derivação dos casos de teste.

A SPACES é formada por cinco módulos. O Seletor de Casos de Teste permite que o usuário selecione os casos de teste que serão executados. Os casos de teste exercitam as funcionalidades dos casos de uso, derivadas do modelo UML. O Gerador de Oráculo utiliza as restrições OCL para gerar os oráculos para cada caso de teste selecionado, convertendo as restrições que definem pré e pós condições em fragmentos de código Java, utilizados posteriormente para a geração dos casos de teste.

O módulo Seletor de Dados de Teste determina valores de entrada para os casos de teste utilizando técnicas que permitem identificar as partições estabelecidas pelas condições expressas em OCL. O Gerador de Código de Teste, por sua vez, utiliza a informação produzida pelos módulos descritos anteriormente para gerar o código de teste, no qual para cada funcionalidade é gerada uma classe de teste no formato JUnit, contendo um método de teste para cada caso de teste selecionado. O último módulo, denominado Empacotador, agrupa todas as classes de teste em um novo componente responsável pela execução e análise dos casos de teste.

Os conceitos de classe de equivalência e valor-limite são utilizados apenas internamente pela ferramenta, durante a derivação dos dados de teste, quando são identificadas as classes de equivalência e os valores-limite a partir das pré e pós-condições OCL. O testator, portanto, não tem acesso a essas informações, a não ser a partir do código de teste gerado.

Quadro 2.10: Comparativo entre as ferramentas de teste analisadas

\begin{tabular}{|l|c|c|c|c|c|}
\hline Característica & JUnit & Jtest & TestComplete & XDE Tester & SPACES \\
\hline Geração de casos de teste & & $\checkmark$ & & & $\checkmark$ \\
\hline Execução de casos de teste & $\checkmark$ & $\checkmark$ & $\checkmark$ & $\checkmark$ & $\checkmark$ \\
\hline Especificação de classes de equivalência & & & & & \\
\hline Especificação de valores-limite & & & & & $\checkmark$ \\
\hline Especificação de pré e pós-condições & & $\checkmark$ & & & $\checkmark$ \\
\hline Análise de cobertura & & $\checkmark$ & & $\checkmark$ & \\
\hline Teste de interface & & & $\checkmark$ & $\checkmark$ & \\
\hline
\end{tabular}

No Quadro 2.10 é exibida uma comparação entre as ferramentas analisadas, enfatizando características importantes do teste funcional. Nota-se que nenhuma das ferramentas mostradas contempla todas as características desejáveis, e as características Especificação de classes de equivalência e Especificação de valores-limite não têm suporte. Apesar das ferramentas Jtest e SPACES possuírem características semelhantes, é importante salientar que a ferramenta SPACES implementa essas características segundo a ótica do teste funcional, enquanto a Jtest apresenta uma abordagem semelhante à técnica estrutural.

Além das ferramentas descritas anteriormente, pode-se citar diversas outras com finalidades específicas. O teste caixa-preta para interfaces gráficas é apoiado por ferramentas como Abbot (WALL, 2002), jfcUnit (CASWELL; ARAVAMUDHAN; WILSON, 2002) e PGUIRobot (CALDER, 
2000), enquanto o teste de pré e pós condições na técnica de Projeto por Contrato, é apoiado por ferramentas como iContract Plus (HELLESOY; QUIROZ, 2001) e jContractor (KARAORMAN; ABERCROMBIE, 2002).

Por basear-se na especificação do software e não exigir necessariamente o conhecimento da sua implementação, o teste funcional representa uma importante técnica de teste de software. Essa técnica, no entanto, muitas vezes é relegada em razão da falta de ferramentas que forneçam apoio à aplicação dos seus critérios. Ainda que existam ferramentas que ofereçam algum suporte ao teste funcional, nota-se que, de forma geral, elas não utilizam as técnicas ou critérios difundidos pela comunidade de software e muitas vezes o teste funcional é tratado apenas como teste de interface. Além disso, nessas ferramentas a quantificação da atividade de teste é feita apenas em termos de cobertura de comandos ou funções e não de acordo com a especificação do software.

Evidencia-se assim a carência por ferramentas que forneçam apoio aos critérios funcionais descritos anteriormente e permitam avaliar a cobertura do teste funcional em relação a esses mesmos critérios. Essas características representam dois importantes requisitos que devem ser considerados no projeto de uma ferramenta para teste funcional, e são utilizados no desenvolvimento da ferramenta J-FuT, que é apresentada no Capítulo 4.

\subsection{Considerações finais}

Neste capítulo foi abordado o teste de software e sua importância no processo de desenvolvimento. Noções gerais sobre a atividade e conceitos básicos foram apresentados, assim como as fases, técnicas e principais critérios de teste. Atenção especial foi dada ao teste funcional, por sua relação com o tema desta pesquisa. Também foi apresentada uma breve introdução sobre ferramentas automatizadas para teste funcional de software.

No próximo capítulo aborda-se a Programação Orientada a Aspectos e seu uso no teste de software, completando a revisão bibliográfica deste trabalho. 


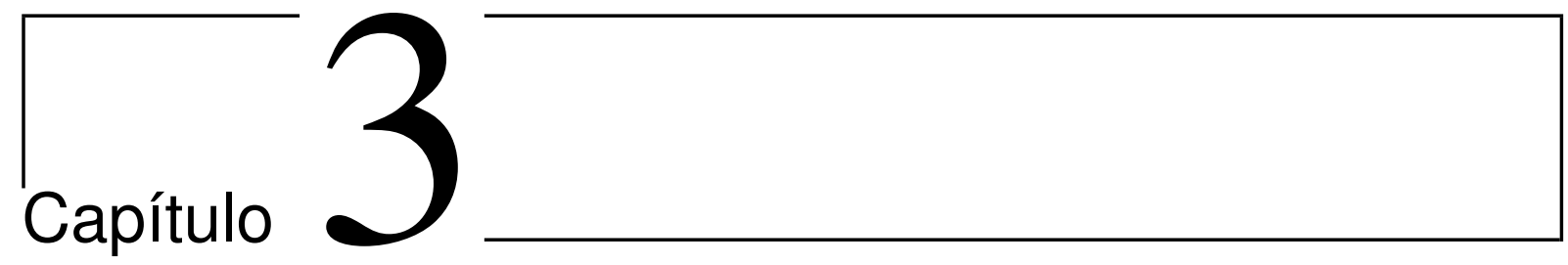

\section{Programação Orientada a Aspectos}

\subsection{Considerações iniciais}

$\mathrm{N}$

este capítulo é abordada a Programação Orientada a Aspectos (POA), completando o embasamento teórico necessário para compreensão desta pesquisa. O capítulo é organizado da seguinte forma: na Seção 3.2 descreve-se o conceito da separação de interesses, base para a compreensão da POA. A seguir, na Seção 3.3, introduz-se a Programação Orientada a Aspectos e seus conceitos básicos. A Seção 3.4 é dedicada ao AspectJ, uma linguagem geral para POA. Por fim, na Seção 3.5 é tratado o teste auxiliado por aspectos, e descritas algumas das abordagens existentes.

\subsection{Separação de interesses}

A separação de interesses (PARNAS, 1972; DIJKSTRA, 1976) é um conceito essencial na engenharia de software. De forma geral, a separação de interesses refere-se à habilidade de capturar e manipular apenas partes do software relativas a um conceito ou objetivo particular (OSSHER; TARR, 2000). Interesses constituem uma forma de dividir e organizar o software em partes manejáveis e compreensíveis e, teoricamente, a sua separação e tratamento individualizado leva à redução da complexidade do software e à melhoria de sua compreensão, além de facilitar a evolução.

Apesar de sua importância evidente, o conceito pregado pela separação de interesses ainda não foi alcançado em sua totalidade. Como comentam Ossher e Tarr (2000), interesses relevantes variam durante o ciclo de desenvolvimento e podem ser de diversos tipos e, portanto, contidos em dimensões distintas. A separação em uma dimensão de interesse privilegia alguns 
objetivos e atividades em detrimento de outros e, desta forma, nenhum critério de decomposição e integração é apropriado para todos os contextos e requisitos.

Todos os métodos modernos para o desenvolvimento de software oferecem algum suporte à separação de interesses por meio de mecanismos de composição e decomposição. No entanto, os formalismos existentes possuem mecanismos restritos de composição e decomposição e estes, por sua vez, dão suporte a apenas uma única dimensão de separação por vez, a chamada dimensão dominante (TARR et al., 1999). Exemplos deste tipo de abordagem (denominada "tirania da decomposição dominante") são classes (em linguagens $\mathrm{OO}$ ), funções (em linguagens funcionais) e regras (em sistemas baseados em regras) (OSSHER; TARR, 2000).

\subsection{Programação Orientada a Aspectos}

Ao longo das últimas décadas, a comunidade de desenvolvedores de software vem produzindo diversos paradigmas, com diferentes níveis de abstração. Nestas abordagens, todo o sistema é modelado e implementado tendo como base as unidades que fundamentam o paradigma, e desta forma apenas uma dimensão pode ser observada. No paradigma da Orientação a Objetos, por exemplo, o programa é modelado e decomposto em classes. As classes posteriormente são instanciadas sob a forma de objetos, que por sua vez, interagem para produzir o comportamento esperado do software.

Conforme discutido anteriormente, nem todos os interesses podem ser modularizados em uma única dimensão. Comunicação, persistência, depuração e controle de segurança são exemplos de interesses cujas implementações se espalham por diversos módulos do sistema, de forma transversal aos interesses funcionais. Esses interesses encontram-se dispersos em diversos objetos ou ainda em métodos distintos. Como explicam Kiczales et al. (1997), quando duas propriedades do programa devem ser compostas de forma distinta e ainda assim serem coordenadas, diz-se que elas se entrecortam. Os mecanismos tradicionais dão suporte a apenas um mecanismo de composição, e desta forma, o entrelaçamento acaba por levar ao aumento da complexidade e confusão no código. A Programação Orientada a Aspectos (POA) é uma técnica para lidar com esse problema.

A POA baseia-se no conceito de separação de interesses e busca identificar interesses que estão espalhados pelo código da aplicação e implementá-los como módulos separados (denominados aspectos). Essa abordagem permite que o projeto e a codificação sejam executados de maneira estruturada, refletindo a forma como o sistema é imaginado pelos seus projetistas (ELRAD et al., 2001). Segundo essa abordagem, cada uma das propriedades do software implementado pode se apresentar de duas formas distintas. Diz-se que uma propriedade é um componente se pode ser encapsulada de forma clara em um procedimento genérico (objeto, método, procedimento), permitindo fácil acesso e composição. De forma geral, componentes são 
interesses funcionais do sistema. Por outro lado, uma propriedade pode ser considerada um aspecto quando ela não pode ser encapsulada facilmente em um procedimento genérico. Assim, aspectos são propriedades que afetam o desempenho ou semântica do componente de forma sistemática (KICZALES et al., 1997).

O objetivo da POA é oferecer suporte para separação de componentes e aspectos por meio de mecanismos que possibilitem sua abstração e composição de forma a produzir o software (KICZALES et al., 1997). Tendo em vista que componentes e aspectos são construídos de forma disjunta, é necessário uni-los para que a aplicação final seja gerada. Isso é feito por meio de um processo denominado combinação (weaving), que pode ser conduzido de forma estática (sobre código fonte ou objeto) ou dinamicamente (durante a execução do programa). O processo é ilustrado na Figura 3.1.

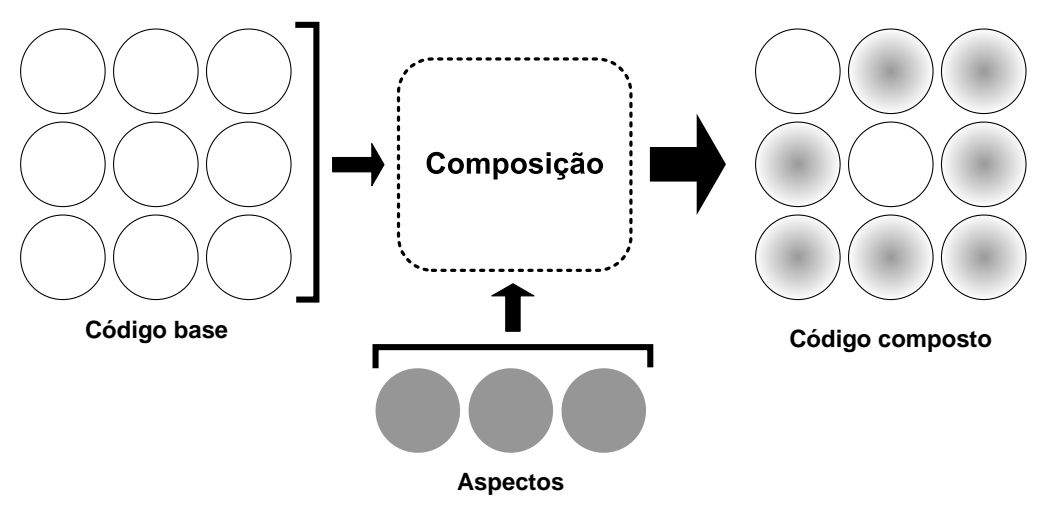

Figura 3.1: Processo de combinação

Existem atualmente implementações do conceito de aspectos para diversas linguagens. Existem basicamente dois tipos de linguagens orientadas a aspectos: as de propósito específico e as de propósito geral. Linguagens de propósito específico possuem um escopo restrito, e focam alguns tipos de problemas. Exemplos são as linguagens COOL e RIDL (LOPES, 1997) que modelam coordenação de threads e acesso remoto, respectivamente e $\mathrm{D}^{2} \mathrm{AL}$ (BECKER, 1998) que trata da especificação de objetos distribuídos.

Linguagens de propósito geral são utilizadas para a confecção de programas genéricos e normalmente são construídas a partir de linguagens de programação existentes, pela adição de novos construtores e operadores. Exemplos são o AspectC++ (SPINCZYK; GAL; SCHRODERPREIKSCHAT, 2002), que acrescenta aspectos à linguagem C++, AspectS (HIRSCHFELD, 2003), que estende o Smalltalk adicionando classes que implementam aspectos, AspectC\# (KIM, 2002), uma implementação da POA para linguagem C\# e AspectJ (KICZALES et al., 2001a), que estende a linguagem Java.

Em relação às implementações orientadas a aspectos utilizando Java, observa-se que enquanto o AspectJ utiliza um novo compilador que dá suporte a novas construções da linguagem, em outras propostas como JBoss AOP (BURKE, 2003) e AspectWerkz (BONÉR; VASSEUR, 
2002) os aspectos são implementados em Java "puro". Neste caso o processo de combinação é especificado por meio de arquivos XML (Extensible Markup Language) e a combinação pode ser feita dinamicamente, não sendo necessário um compilador específico.

Aspectos introduzem mais uma dimensão ao paradigma OO, representando geralmente requisitos não funcionais do software. Tarr et al. (1999) propõem a generalização do conceito de aspectos e sua extensão para diversas dimensões, nas quais cada uma modela um interesse. $\mathrm{O}$ Hyper/J (OSSHER; TARR, 2001), oferece suporte a esse tipo de abordagem - a separação multidimensional de interesses - e utiliza a linguagem Java em sua forma nativa.

Além das linguagens ilustradas, outras abordagens procuram modularizar interesses não funcionais, como os Filtros de Composição e a Programação Orientada a Assunto. Filtros de Composição são uma técnica da POA na qual diferentes aspectos são expressos em filtros de maneira declarativa, como especificações de mensagens de transformação. Assim, aspectos distintos podem ser expressos por meio de filtros e depois compostos sem a necessidade de geradores específicos. Nesta abordagem, cada mensagem recebida por ou enviada por um objeto está sujeita a avaliação e manipulação pelos filtros desse objeto (AKSIT et al., 1994; AKSIT; TEKINERDOGAN, 1998).

Na Programação Orientada a Assunto, por sua vez, interesses são tratados como assuntos, que podem operar separadamente sobre um determinado objeto, sem necessariamente conhecer os detalhes da sua associação com outros assuntos. Assuntos são instanciados e podem ser combinados para formar composições, que são construídas a partir de regras de combinação. Uma característica essencial desta abordagem é que novos assuntos podem ser acrescidos ao sistema sem perturbar seu funcionamento (HARRISON; OSSHER, 1993).

Na Seção seguinte é explorada a linguagem AspectJ, sendo mostradas suas construções básicas e exemplos de aplicação.

\subsection{AspectJ}

O AspectJ foi a primeira linguagem orientada a aspectos de propósito geral criada. O projeto da linguagem surgiu em 1997 no Xerox Palo Alto Research Center - PARC, sendo incorporado ao projeto Eclipse (IBM et al., 2001) em 2002. O AspectJ foi desenvolvido como uma extensão compatível com a linguagem Java, de forma a facilitar sua adoção por programadores dessa linguagem. No AspectJ os componentes são representados por classes Java e uma nova construção, denominada aspecto (aspect), é responsável por definir interesses que entrecortam a estrutura das classes (KICZALES et al., 2001a).

A linguagem possui mecanismos para implementação de dois tipos de entrecorte: dinâmico e estático. O entrecorte dinâmico permite que, em pontos específicos de execução do programa, 
seja definida uma implementação adicional ou alterado o comportamento padrão do software. O entrecorte estático, por sua vez, torna possível a adição de novas operações ou atributos em tipos existentes (esse mecanismo também é denominado declaração inter-tipos). A modularização dos interesses entrecortantes é feita por meio de pontos de junção (join points) e adendos (advices) (KICZALES et al., 2001b).

No AspectJ a combinação é executada em tempo de compilação, sobre bytecode ou código fonte Java. Uma vez executada a compilação, os aspectos estarão permanentemente incorporados ao software, não sendo possível alterar a combinação durante a execução do programa. De acordo com Hilsdale e Hugunin (2004), o processo de combinação segue duas etapas: na primeira o código Java e o código AspectJ são compilados em bytecode Java, instrumentado com informações sobre as construções do AspectJ (como adendos e conjuntos de junção, descritos posteriormente). Na segunda etapa o compilador utiliza essas informações para gerar as classes compostas (bytecode compatível com a especificação Java).

\subsubsection{Pontos de junção}

Pontos de junção (join points) são elementos essenciais para o projeto de qualquer linguagem Orientada a Aspectos (KICZALES et al., 2001b), e indicam locais específicos da execução do programa onde comportamentos adicionais poderão ser introduzidos. Segundo Kiczales et al. (2001a), pontos de junção podem ser considerados como os nós do grafo de chamada de um objeto em tempo de execução. Nesse grafo, por exemplo, os nós incluem locais onde um objeto recebe uma chamada de método e locais onde um atributo de um objeto é referenciado, enquanto as arestas representam as relações de fluxo de controle entre os nós. Os pontos de junção são classificados em diversos tipos, dependendo do local específico onde eles residem no programa. No Quadro 3.1 encontram-se os pontos de junção do AspectJ ${ }^{1}$.

\subsubsection{Conjuntos de junção}

Os conjuntos de junção (pointcuts) descrevem agrupamentos de pontos de junção e identificam pontos específicos no fluxo de execução do programa. Basicamente, essas construções definem expressões para construir tais agrupamentos. Além disso, em alguns casos, conjuntos de junção podem identificar contextos de execução, o que pode ser útil na implementação dos entrecortes. Como explicado anteriormente, uma vez que os pontos de junção tenham sido identificados, pode-se especificar regras de combinação envolvendo esses pontos.

Assim como acontece com dados e métodos na linguagem Java, em AspectJ é possível utilizar um especificador de acesso (público, privado, etc.) para um conjunto de junção, de forma a restringir seu acesso. Outra característica dos conjuntos de junção é que eles podem

\footnotetext{
${ }^{1}$ Neste trabalho é adotada a versão 1.2.1 do AspectJ
} 
Quadro 3.1: Tipos de pontos de junção do AspectJ (AspectJ Team, 2003)

\begin{tabular}{|l|l|}
\hline Tipo & Descrição \\
\hline Chamada de método ou construtor & $\begin{array}{l}\text { Um método ou um construtor de uma classe é chamado. Pon- } \\
\text { tos de junção deste tipo encontram-se no objeto chamador ou } \\
\text { possuem valor nulo (se a chamada é feita a partir de um mé- } \\
\text { todo estático) }\end{array}$ \\
\hline Execução de método ou construtor & $\begin{array}{l}\text { Um método ou construtor é chamado. Pontos de junção deste } \\
\text { tipo ocorrem no objeto chamado, dentro do contexto do mé- } \\
\text { todo }\end{array}$ \\
\hline Leitura de atributo & Um atributo de um objeto, classe ou interface é lido \\
\hline Escrita de atributo & Um atributo de um objeto ou classe é escrito \\
\hline Execução de tratador de exceção & Um tratador de exceção é invocado \\
\hline Iniciação de classe & $\begin{array}{l}\text { Iniciadores estáticos de uma classe (se existirem) são execu- } \\
\text { tados }\end{array}$ \\
\hline Iniciação de objeto & $\begin{array}{l}\text { Iniciadores dinâmicos de uma classe (se existirem) são exe- } \\
\text { cutados durante a criação do objeto, abrangendo desde o re- } \\
\text { torno da chamada ao construtor da classe pai até o retorno do } \\
\text { primeiro construtor chamado }\end{array}$ \\
\hline Pré-iniciação de objeto & $\begin{array}{l}\text { Pré-iniciadores de uma classe são executados, abrangendo } \\
\text { desde a chamada ao primeiro construtor até a chamada ao } \\
\text { construtor da classe pai }\end{array}$ \\
\hline Execução de adendo & Qualquer parte de um adendo é executada \\
\hline
\end{tabular}

ser nomeados. Conjuntos de junção nomeados são elementos que podem ser referenciados em diversos locais, o que os torna reusáveis (LADDAD, 2003). Conjuntos de junção anônimos, por sua vez, são definidos no local onde são utilizados, como parte de um adendo ou na definição de outro conjunto de junção. $O$ formato geral de um conjunto de junção anônimo é:

especificação do adendo: definição do conjunto de junção

Na definição do conjunto de junção escreve-se o código que identifica os pontos de junção que serão interceptados. A ação que será executada sobre esses pontos de junção é especificada por adendos, explicados posteriormente. Conjuntos de junção anônimos estão diretamente vinculados a um adendo, não podendo ser referenciados em outros locais.

before() : call(void Conta.saque(float)) || call(void Conta.deposito(float))

Figura 3.2: Um conjunto de junção anônimo

Na Figura 3.2 é apresentado um conjunto de junção composto (anônimo), no qual todas as chamadas aos métodos saque ou deposito, com parâmetro float e nenhum tipo de retorno são interceptadas. $\mathrm{O}$ termo before() refere-se ao adendo que está vinculado a este ponto de junção e será detalhado na próxima seção.

O formato geral de um conjunto de junção nomeado é mostrado a seguir. 
Diferentemente do conjunto de junção anônimo, em um conjunto de junção nomeado, além da definição do próprio conjunto de junção, especifica-se a restrição de acesso e obviamente seu nome. O nome será a referência para esse conjunto de junção, quando for desejável utilizá-lo novamente.

public pointcut operacao_saque() : call(void Conta.saque(float))

Figura 3.3: Um conjunto de junção nomeado

Na Figura 3.3 observa-se a definição de um conjunto de junção de nome operacao_saque, que seleciona chamadas a métodos cuja assinatura seja exatamente a descrita, ou seja, o método saque da classe Conta com um único parâmetro, do tipo float e nenhum retorno. Conjuntos de junção podem ser combinados para dar origem a conjuntos de junção mais complexos. Além disso, podem ser declarados como abstratos e definidos posteriormente nos aspectos descendentes, o que acrescenta flexibilidade ao seu uso.

\subsubsection{Operadores e caracteres coringas para conjuntos de junção}

Como comenta Laddad (2003), a funcionalidade de um conjunto de junção é expressa pela sua definição, que contém a sintaxe para identificação de pontos de junção específicos. O AspectJ utiliza caracteres coringa para construção de conjuntos de junção, com o objetivo de capturar pontos de junção com características comuns, que por sua vez podem estar espalhados pelos diversos módulos do software. A linguagem utiliza três caracteres coringa, descritos no Quadro 3.2.

Quadro 3.2: Caracteres coringa do AspectJ

\begin{tabular}{|c|l|}
\hline Caractere & Descrição \\
\hline$*$ & Qualquer número de caracteres, excluindo o caractere ponto (.) \\
\hline.. & Qualquer número de caracteres, incluindo qualquer número de caracteres ponto (.) \\
\hline+ & Qualquer subclasse ou subinterface de um tipo específico \\
\hline
\end{tabular}

O AspectJ também permite o uso de operadores unários e binários, além de parênteses, que podem ser utilizados para construir conjuntos de junção complexos a partir de expressões simples. Assim como na linguagem Java, o operador binário ! é usado para negação e os operadores unários | | e \&\& são usados como OU e E lógicos, respectivamente.

Conjuntos de junção podem ser definidos por meio das assinaturas explícitas de métodos (entrecorte baseado em nome) ou utilizando operadores e caracteres coringas (entrecorte baseado em propriedade) (KICZALES et al., 2001b). Assim como nos métodos, expressões regulares também podem ser utilizadas em construtores e atributos para filtrar pontos de junção. No Quadro 3.3 encontram-se exemplos desses tipos de expressões. 
Quadro 3.3: Exemplos de conjuntos de junção (AspectJ Team, 2003)

\begin{tabular}{|l|l|}
\hline Expressão & Descrição \\
\hline get(int Point .x) & Leitura do atributo x do tipo inteiro da classe Point \\
\hline set(!private $*$ Point .*) & Escrita de qualquer atributo não privado da classe Point \\
\hline call(public $*$ Figure $*(.))$. & Chamada a métodos públicos da classe Figure \\
\hline call(public $* *(.))$. & Chamada a qualquer método público de qualquer classe \\
\hline call(*.new(int, int)) & $\begin{array}{l}\text { Chamada a qualquer construtor de qualquer classe com } \\
\text { dois argumentos do tipo inteiro }\end{array}$ \\
\hline execution(**(..)) & $\begin{array}{l}\text { Execução de qualquer método de qualquer classe, inde- } \\
\text { pendente do retorno e de parâmetros }\end{array}$ \\
\hline execution(! static $* *(.))$. & $\begin{array}{l}\text { Execução de qualquer método não-estático de qualquer } \\
\text { classe }\end{array}$ \\
\hline
\end{tabular}

Conjuntos de junção apenas indicam locais do programa onde haverá interceptação. As operações que serão executadas em cada um desses locais são definidas pelos adendos, apresentados a seguir.

\subsubsection{Adendos}

Adendos (advices) são construções semelhantes a métodos, que definem comportamentos adicionais nos pontos de junção. Assim, esses elementos expressam as ações de entrecorte que serão executadas nos pontos de junção capturados por um conjunto de junção. O AspectJ define três tipos de adendo (KICZALES et al., 2001a; LADDAD, 2003):

- Adendo anterior (before): Um adendo anterior executa quando um ponto de junção é atingido, e antes de sua computação iniciar. Por exemplo, em uma chamada de método e antes do método iniciar sua execução;

- Adendo posterior (after): Um adendo posterior executa após a computação de um ponto de junção terminar. Por exemplo, depois do corpo do método ser executado e antes do controle retornar ao chamador;

- Adendo de contorno (around): Um adendo de contorno executa quando um ponto de junção é atingido, e possui controle explícito sobre a sua computação. Utilizando esse tipo de adendo é possível "contornar" a execução do ponto de junção, continuar a sua execução original ou induzir a ocorrência da sua execução em um novo contexto.

O formato geral de um adendo é:

declaração do adendo ([args]) : declaração do conjunto de junção \{corpo do adendo \}

A declaração do adendo define o tipo de adendo que será utilizado (before, after, around). A declaração do conjunto de junção, por sua vez, especifica o conjunto de junção sobre o qual 
o adendo atuará, seguindo a construção descrita anteriormente para conjuntos de junção. Por fim, o corpo do adendo contém o código do adendo e corresponde ao corpo de um método. No AspectJ adendos não possuem nome.

O adendo apresentado na Figura 3.4 verifica o valor do saldo sempre que o método saque da classe Conta é chamado. O saque só será executado se o valor não exceder o saldo da conta, caso contrário uma exceção será lançada.

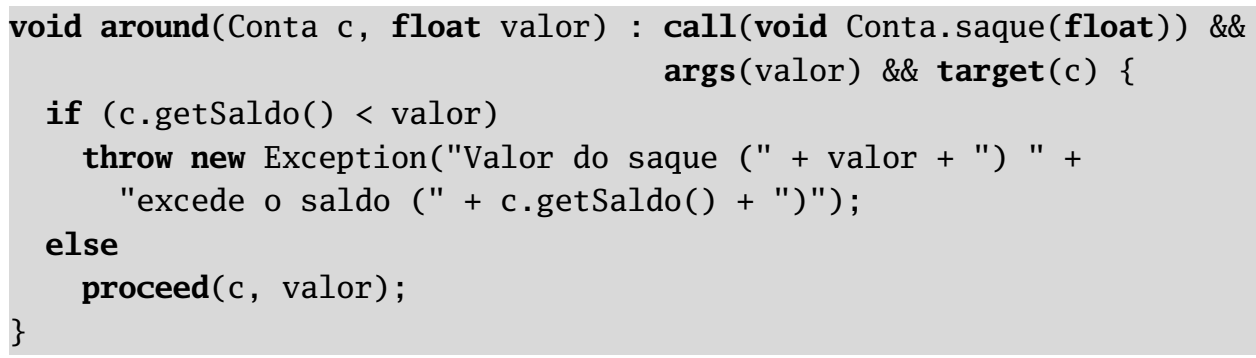

Figura 3.4: Adendo para verificação do saque

Como é possível observar, o adendo apresentado utiliza um conjunto de junção anônimo, ou seja, um conjunto de junção que só poderá ser utilizado por esse adendo. As primitivas args e target são responsáveis, respectivamente, pela captura do argumento que está sendo passado (valor) e do objeto que recebe a chamada ao método (c). Para implementar o interesse descrito foi utilizado um adendo do tipo around, que avalia se o método interceptado deve continuar sua execução ou não. Se o valor passado para o método saque for maior que o saldo da conta então uma mensagem será exibida e a execução do método será interrompida. Caso contrário, a instrução proceed prosseguirá a computação.

É importante perceber que a mesma verificação poderia ser feita utilizando um adendo do tipo before, mas nunca um do tipo after, uma vez que esse executa após a computação do ponto de junção. Adendos do tipo after, em especial, possuem construções compostas, que visam a explorar situações específicas no retorno do ponto de junção. No Quadro 3.4 são mostradas as outras construções da linguagem para adendos dessa categoria.

Quadro 3.4: Adendos after compostos

\begin{tabular}{|l|l|}
\hline Adendo & Descrição \\
\hline after() returning & Executada após a chamada ao ponto de junção retornar com sucesso \\
\hline after() throwing & Executada após a chamada ao ponto de junção retornar gerando uma exceção \\
\hline
\end{tabular}

\subsubsection{Declarações inter-tipos}

Declarações inter-tipos (inter-type declarations) são as construções que implementam entrecorte estático no AspectJ. Enquanto o entrecorte dinâmico modifica o comportamento de execução do programa, o entrecorte estático altera a estrutura estática dos tipos (classes, interfaces e outros aspectos) e seu comportamento em tempo de compilação. Existem diversos tipos 
de entrecorte estático: introdução de elementos, modificação de hierarquia de tipos, declaração de erros e avisos em tempo de compilação e suavização de exceção (LADDAD, 2003).

A introdução de elementos permite que atributos, constantes e métodos sejam adicionados às classes entrecortadas, alterando assim a sua estrutura original. Essa operação pode levar à quebra do encapsulamento, tendo em vista que a interface da classe pode vir a ser alterada. $\mathrm{O}$ aspecto Limite, apresentado na Figura 3.5, adiciona um novo atributo (limite) à classe Conta, assim como os métodos correspondentes para leitura (getLimite) e escrita (setLimite) desse atributo. Com a existência do novo atributo, é possível alterar o adendo que verifica a operação de saque (Figura 3.4), considerando agora o limite da conta.

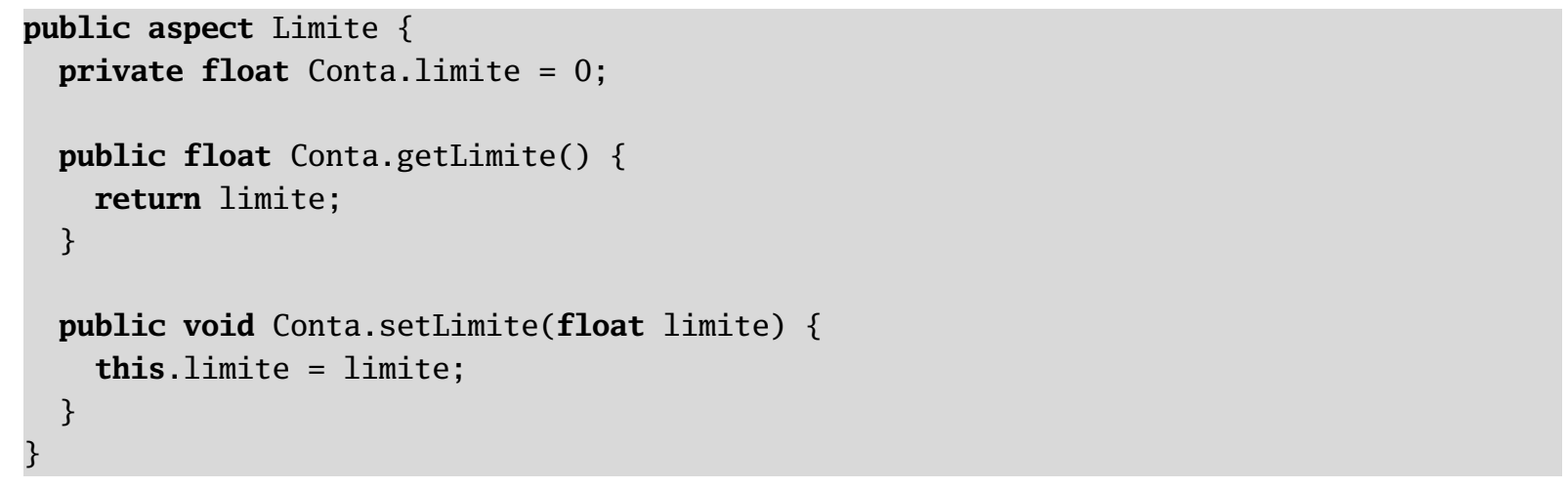

Figura 3.5: Introdução de limite na classe

Durante a combinação os elementos serão inseridos na classe original e, desta forma, estarão disponíveis normalmente, podendo ser utilizados pelo aspecto, pela própria classe ou por classes externas (no caso dos métodos e atributos públicos).

O AspectJ também permite a modificação da hierarquia de tipos, adicionando herança ou implementação de interfaces às classes entrecortadas. De forma semelhante à introdução de elementos, a hierarquia é alterada durante a combinação e os elementos contidos nas classes pai (ou nas interfaces) ficam disponíveis para as classes filhas. O formato geral de declaração de herança e de interface, é mostrado a seguir.

\section{declare parents : [expressão] extends | implements [classe ou lista de interfaces]}

Após o comando declare parents define-se uma expressão regular que aponta para os tipos que sofrerão mudança na hierarquia (a expressão é construída por meio de caracteres coringas e operadores lógicos do AspectJ). A seguir o tipo de herança é definido, usando-se palavras reservadas do Java para conotar herança de classe ou interface (extends e implements, respectivamente). A última declaração define a classe ou interfaces ancestrais.

No próximo exemplo (Figura 3.6) é ilustrada uma alteração na hierarquia da classe Conta. Uma nova classe é criada (ContaEspecial) contendo o método depositoCaderneta e, por meio 
do aspecto Heranca, uma herança é construída entre as duas classes. Após a combinação, instâncias da classe Conta conterão o método depositoCaderneta e poderão utilizá-lo normalmente.

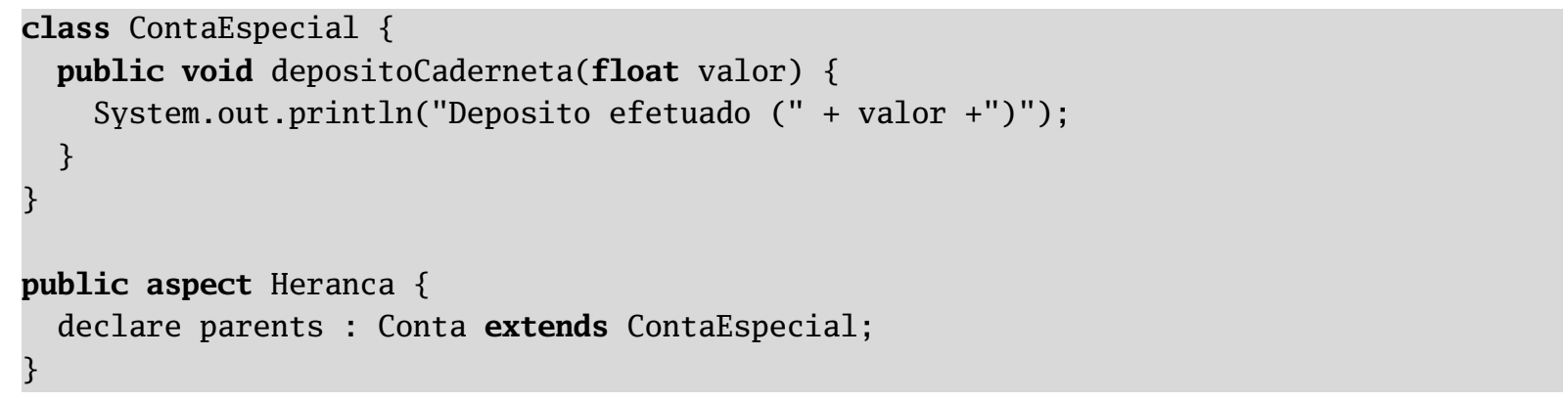

Figura 3.6: Introdução de herança na classe Conta

Além de introdução de elementos e modificação de hierarquia de tipos, é possível no AspectJ declarar avisos e erros em tempo de compilação e suavização de exceção. Por meio da declaração de avisos e erros é possível checar condições, emitir mensagens ou (no casos de falhas) interromper a compilação. A suavização de exceção, por sua vez, permite o "empacotamento" (wrapping) de exceções e seu tratamento separado.

\subsubsection{Aspectos}

Aspectos (aspects) são unidades de implementação de entrecorte, compostas por conjuntos de junção, declarações inter-tipo e adendos (KICZALES et al., 2001a). Além disso, aspectos podem conter construções Java "puras" como variáveis e métodos. Assim como classes, aspectos contém privilégio de acesso e podem herdar de outros aspectos (abstratos). Porém, diferentemente de classes, aspectos não podem ser instanciados pelo programador. As instâncias são criadas automaticamente quando o programa é executado.

Aspectos encapsulam todas as construções definidas pelo AspectJ e possuem estrutura semelhante à de objetos, como pode ser observado na Figura 3.7. O aspecto TratadorFalha consiste em uma declaração inter-tipo feita na classe Servidor, dois métodos escritos em Java "puro", uma definição de conjunto de junção e dois adendos.

Os aspectos devem obrigatoriamente definir locais de entrecorte com o objetivo de injetar interesses em objetos específicos, e por isso não podem existir sozinhos. Em geral, aspectos só possuem funcionalidade quando associados a classes. Objetos, por sua vez, constituem os componentes do AspectJ e normalmente representam unidades funcionais. 


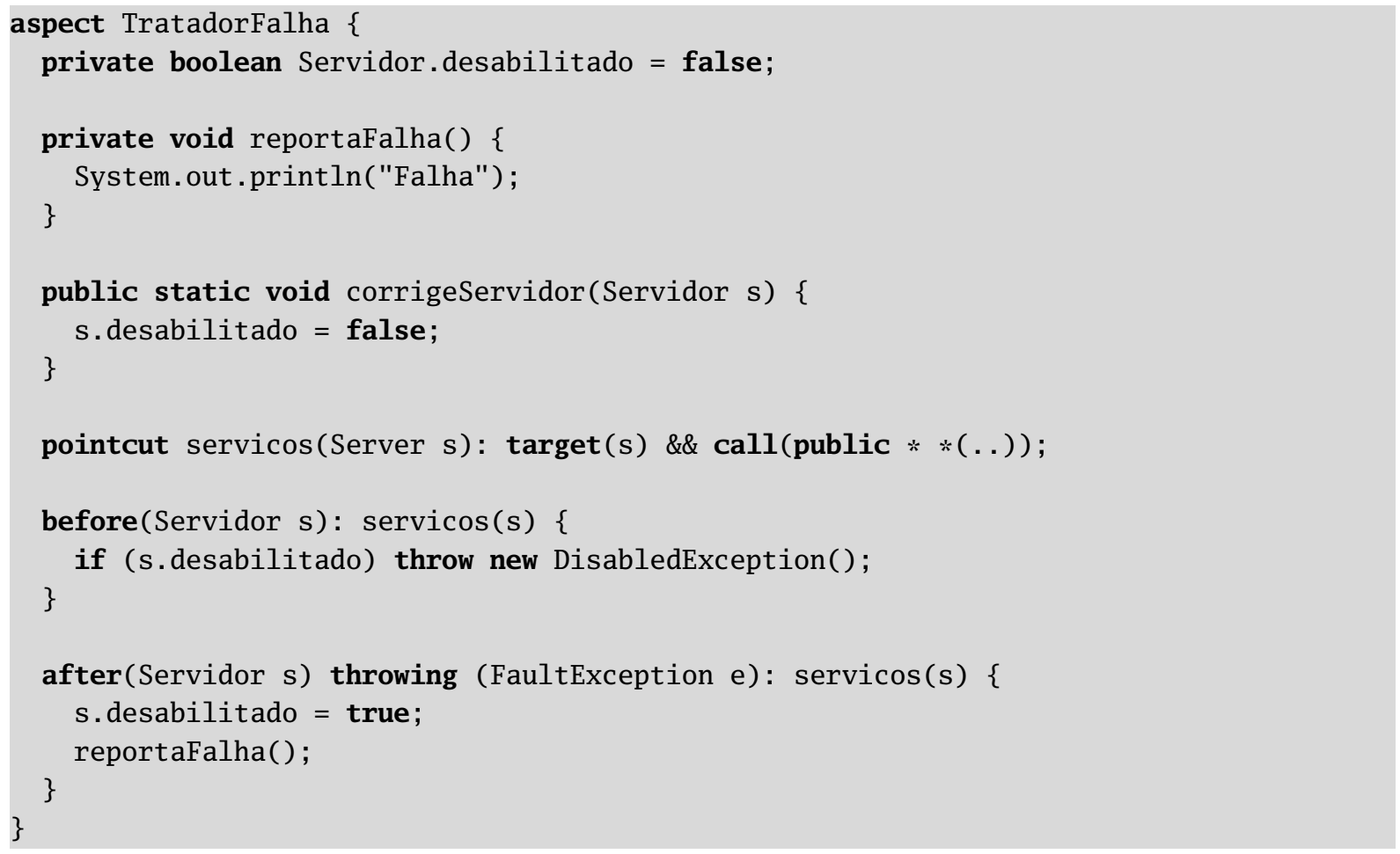

Figura 3.7: Exemplo de um aspecto (adaptado de AspectJ Team (2003))

\subsection{Teste auxiliado por POA}

Apesar da Programação Orientada a Aspectos ser uma abordagem recente, já existem iniciativas do seu uso para o apoio ao teste de software. A separação entre código funcional e código de teste auxilia o manuseio de ambos, e a facilidade de inserir/remover aspectos na aplicação pode levar à criação de cenários de teste de forma mais rápida. Além disso, os aspectos podem ser facilmente removidos quando a atividade de teste for finalizada, conservando intacto o programa original.

Os aspectos utilizados para o teste de software são classificados como aspectos de desenvolvimento (AspectJ Team, 2003), uma vez que são utilizados apenas nessa fase e removidos da versão final da aplicação. Nesta Seção são apresentadas algumas propostas desta utilização, enfatizando o AspectJ.

\subsubsection{Imitações virtuais de objetos}

O uso de imitações virtuais de objetos foi proposto por Monk e Hall (2002), como uma alternativa aos objetos imitadores (mock) tradicionais no teste de unidade. Objetos imitadores desempenham papel semelhante ao dos módulos pseudo-controlados na programação OO (ou procedimental), e procuram imitar o comportamento de objetos reais. Nessas implementações a 
ênfase é geralmente dada à simplicidade e os objetos possuem métodos com pouca implementação, retornando apenas valores fixos.

Na Figura 3.8 observa-se um diagrama de classes contendo algumas classes de uma aplicação. A classe VistaAcesso possui os atributos usuario e senha, que são preenchidos antes da chamada ao método validar. Na chamada ao método, a classe ControladorAcesso valida os dados do usuário por meio do método acessar e retorna um código de status de acordo com o resultado dessa operação. A classe VistaAcesso interpreta esse código e guarda no atributo situacao a mensagem correspondente (usuário válido, usuário inválido, senha inválida, etc.).

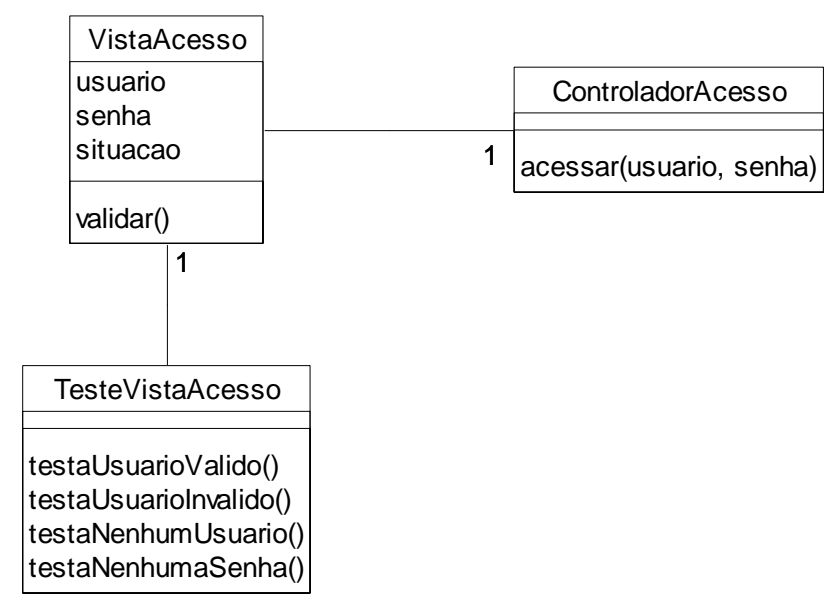

Figura 3.8: Diagrama de classes - adaptado de Monk e Hall (2002)

A classe TesteVistaAcesso é responsável por executar os testes das diversas condições, o que é feito por meio dos seus quatro métodos. A funcionalidade que se deseja testar - a unidade - corresponde apenas ao método validar da classe VistaAcesso. Assim, quando são passados os dados desejados ao método, o valor de status retornado deve ser o esperado. Como a classe VistaAcesso utiliza o serviço acessar fornecido pela classe ControladorAcesso, o teste do método validar acaba por testar a classe ControladorAcesso, o que não é desejável.

Uma aparente solução é a utilização de objetos imitadores, como mostrado na Figura 3.9. Nesse diagrama foi adicionada uma nova classe (ImitadorControladorAcesso) que, por compatibilidade, herda da classe ControladorAcesso. Na nova classe o método acessar é sobrescrito por uma implementação bem simples, que retorna o valor diretamente (por exemplo USUARI0_VALIDO). No novo esquema, a classe VistaAcesso utiliza o método acessar da classe ImitadorControladorAcesso e assim é possível separar a unidade que está sendo testada.

A adoção de objetos imitadores no entanto, ainda apresenta problemas. Na nova configuração a classe VistaAcesso precisa ser construída para ser compatível com a classe ImitadorControladorAcesso (criada apenas para o teste) e assim, considerações de teste acabam por afetar o projeto. Além disso, para cada um dos quatro métodos da classe TesteVistaAcesso é 


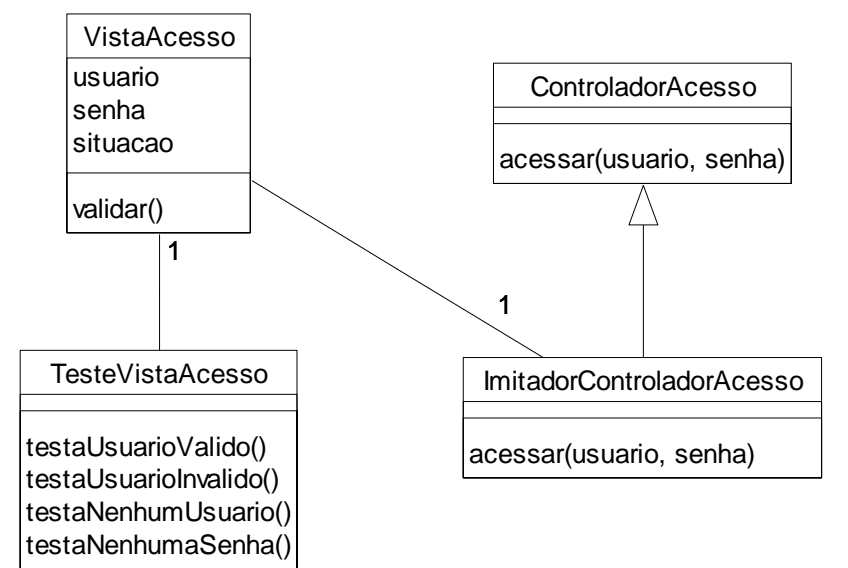

Figura 3.9: Objetos imitadores - adaptado de Monk e Hall (2002)

necessário que a classe imitadora retorne um valor distinto de acordo com os valores recebidos, o que torna o método acessar mais complexo.

Os autores propõem o uso de POA para solucionar esses problemas, por meio da utilização de objetos imitadores virtuais. Nessa abordagem nenhum objeto imitador é criado e, ao invés disso, o AspectJ é utilizado para interceptar chamadas aos métodos que estão sendo testados e retornar o valor desejado. Na Figura 3.10 é exibido o novo diagrama.

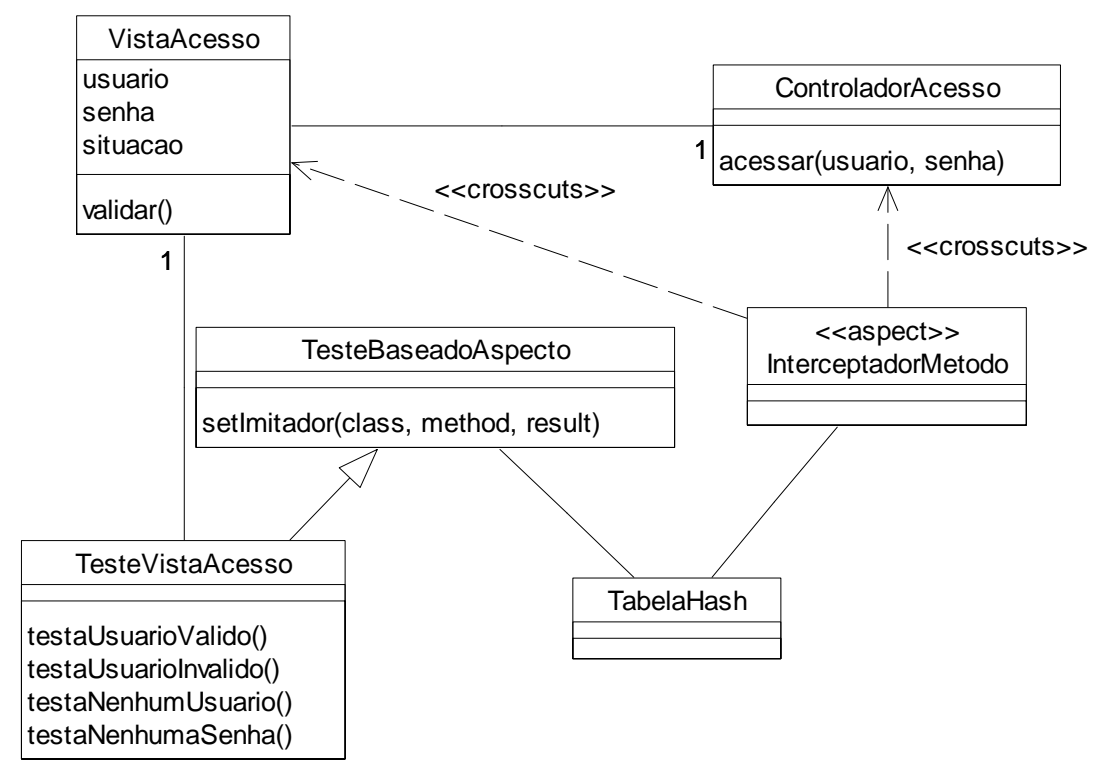

Figura 3.10: Objetos imitadores virtuais - adaptado de Monk e Hall (2002)

A classe TesteVistaAcesso, responsável pelo teste do método validar, herda da classe TesteBaseadoAspecto, que implementa o método setImitador. Este método é utilizado para criar uma associação entre o método que está sendo testado e o resultado desejado, associação esta, que fica guardada em uma tabela hash (TabelaHash). O aspecto InterceptadorMetodo intercepta todas as chamadas a métodos e, para cada método interceptado, verifica se uma refe- 
rência existe em TabelaHash. Em caso positivo, o valor imitador existente na tabela é retornado; caso contrário o método prossegue normalmente.

O uso de objetos imitadores virtuais permite que os dados de teste sejam definidos no próprio teste, e que testes diferentes atribuam valores imitadores distintos para o mesmo método. Além disso, com o uso dessa técnica apenas os componentes de interesse são testados, e não é necessário instanciar objetos imitadores.

\subsubsection{Teste embutido em componentes de software}

Segundo Bruel et al. (2003), testabilidade ${ }^{2}$ pode ser vista como um interesse não funcional, e ser implementada sob a forma de aspectos. Os autores propõem o uso da POA no teste de componentes de software, no qual cada caso de teste é descrito por um aspecto. O processo de combinação insere código de teste no componente, tornado-o "testável". Como exemplo foi desenvolvido um ambiente bastante simples que implementa uma pilha. No diagrama da Figura 3.11 visualizam-se a classe Pilha e o aspecto utilizado para o teste.

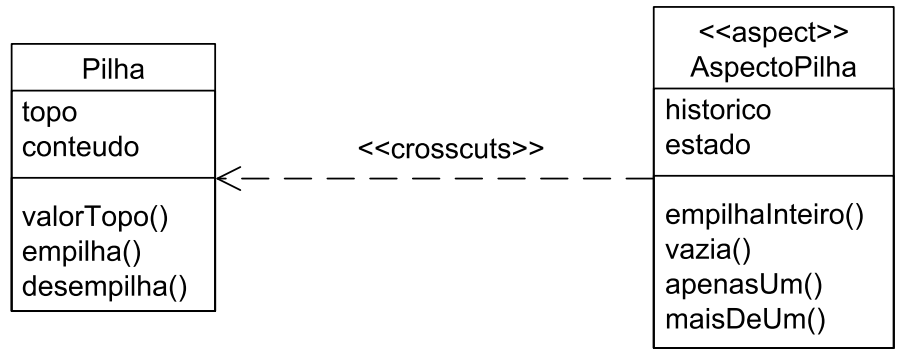

Figura 3.11: Classe e aspecto de teste - adaptado de Bruel et al. (2003)

Para este exemplo apenas um aspecto é criado (AspectoPilha). Para dar suporte ao teste, o aspecto adiciona novos atributos e métodos à classe entrecortada (Pilha), além de declarar conjuntos de junção. São introduzidos dois novos atributos na classe: historico, que tem por função monitorar o que ocorre com o componente Pilha, e estado que guarda o estado da pilha (Figura 3.12).

private LinkedList Pilha.historico = new LinkedList();

private String Pilha.estado = "Vazia";

Figura 3.12: Introdução de atributos - adaptado de Bruel et al. (2003)

Métodos também são introduzidos na classe base, e são responsáveis por implementar os casos de teste. Esses métodos complementam a interface do objeto e incluem operações genéricas de teste e operações específicas, como teste de valores particulares (Figura 3.13). Além

\footnotetext{
${ }^{2}$ Testabilidade refere-se à medida de dificuldade em satisfazer um objetivo particular de teste (VOAS; MILLER, 1995)
} 
disso, também são adicionadas funções que testam os três possíveis estados da pilha (Figura 3.14).

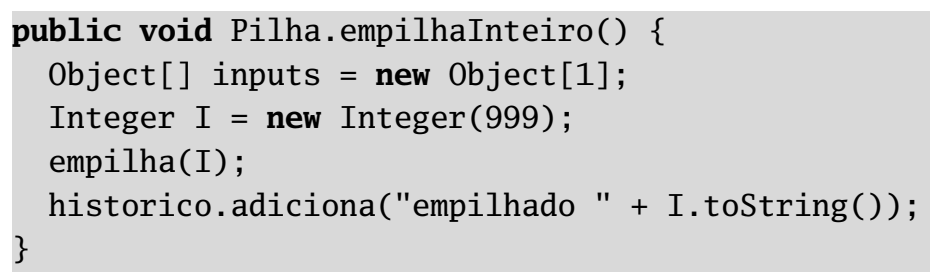

Figura 3.13: Introdução de método específico - adaptado de Bruel et al. (2003)

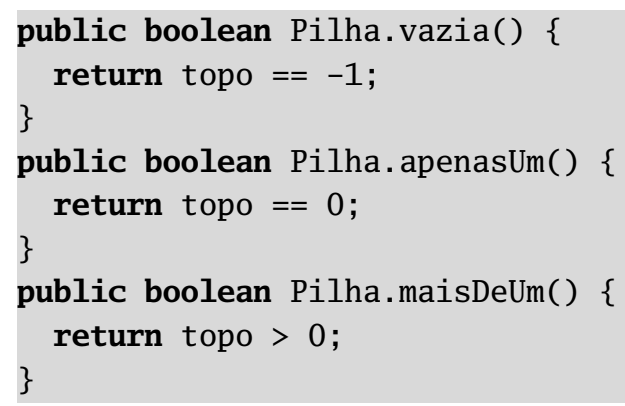

Figura 3.14: Introdução de funções - adaptado de Bruel et al. (2003)

Transições de estado são capturadas por meio de conjuntos de junção e tratadas nas execuções dos adendos. O interesse de teste neste caso é saber se o número de itens da pilha cresce ou decresce, o que é conseguido por meio de dois conjuntos de junção e adendos after que ajustam o estado da pilha (Figura 3.15). A combinação final gera a classe PilhaTestavel (Figura 3.16), que contém os métodos e atributos introduzidos (em negrito) e servirá ao teste do componente Pilha. A classe TestePilha é responsável por executar os testes, utilizando a classe composta. Na Figura 3.16 exibe-se a classe “testável”, após o processo de combinação.

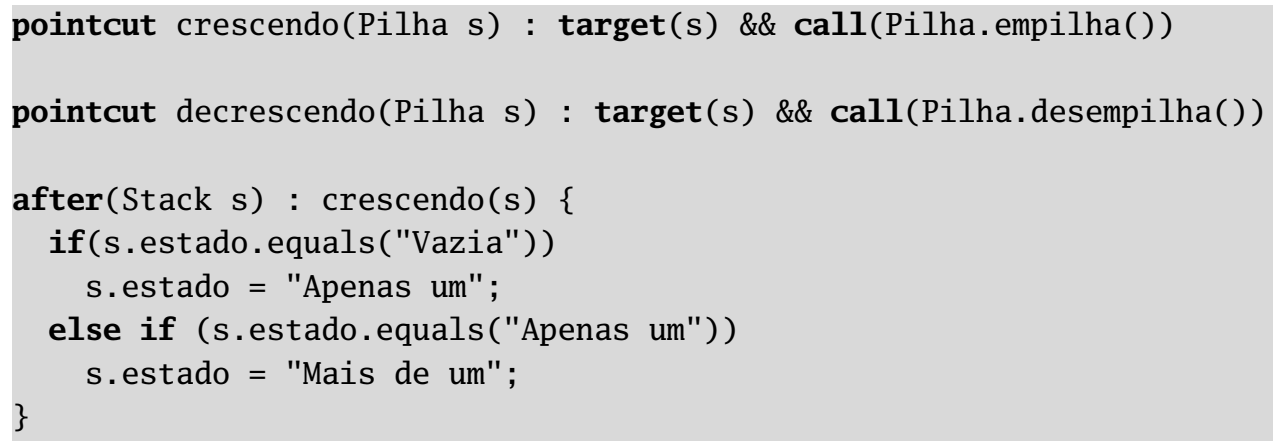

Figura 3.15: Conjuntos de junção e adendos- adaptado de Bruel et al. (2003)

O uso de aspectos permite embutir testabilidade em componentes de software e separar código funcional do código de teste. Utilizando as construções fornecidas pela POA é possível introduzir nas classes em teste métodos e atributos que facilitem a captura e alteração do estado do objeto, tarefa muitas vezes difícil utilizando apenas programação OO. Além disso, a 


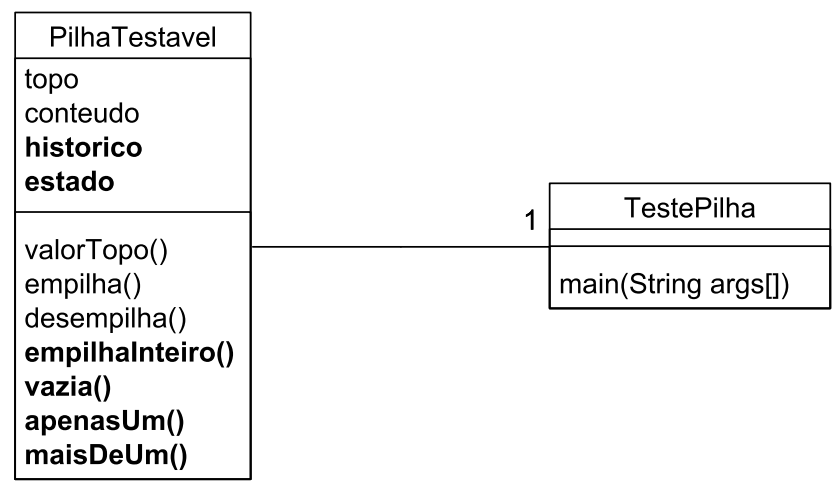

Figura 3.16: Classe testável - adaptado de Bruel et al. (2003)

implementação de casos de teste por meio de aspectos facilita a adição e remoção de teste ao sistema.

\subsubsection{Framework para teste de integração}

Mao e May (2004) propõem uma abordagem que utiliza a POA para o teste de integração para softwares baseados em componentes. O foco da abordagem é nos componentes adaptadores, que coordenam a interação entre os diversos componentes que compõem o sistema. Geralmente a colaboração entrecorta diversos componentes e portanto justifica-se o uso da POA no teste de integração.

No framework proposto os componentes são testados por meio de cenários de teste, onde seus métodos são invocados seqüencialmente. Os cenários são descritos utilizando classes de teste do JUnit. Os autores utilizam o AspectJ para verificar interações entre componentes (que podem ocorrer dentro de um determinado fluxo de controle), a ordem em que essas interações acontecem e determinadas condições de guarda que devem ser obedecidas.

Uma interação entre componentes é revelada identificando-se chamadas a métodos específicos e os componentes envolvidos nessas chamadas. Os componentes cumprem o papel de chamador (cliente) e chamado (provedor do serviço). No código da Figura 3.17 observa-se como é feita a identificação das interações. Todas as chamadas de métodos são capturadas e uma tupla com os dados da interação, <chamador, chamado, método $>$, armazenada para referência futura.

A ordem em que as interações entre os componentes ocorre é outro ponto importante e também abordado nessa proposta. No código dessa Figura 3.18 é exibida a implementação da verificação da ordem de interação em um determinado fluxo de controle. Neste exemplo, uma chamada ao método metodo_2 sempre deve ocorrer dentro do fluxo de controle de uma chamada ao método metodo_1. Ocorrências que violem essa regra serão registradas e um erro será exibido alertando sobre a violação. 


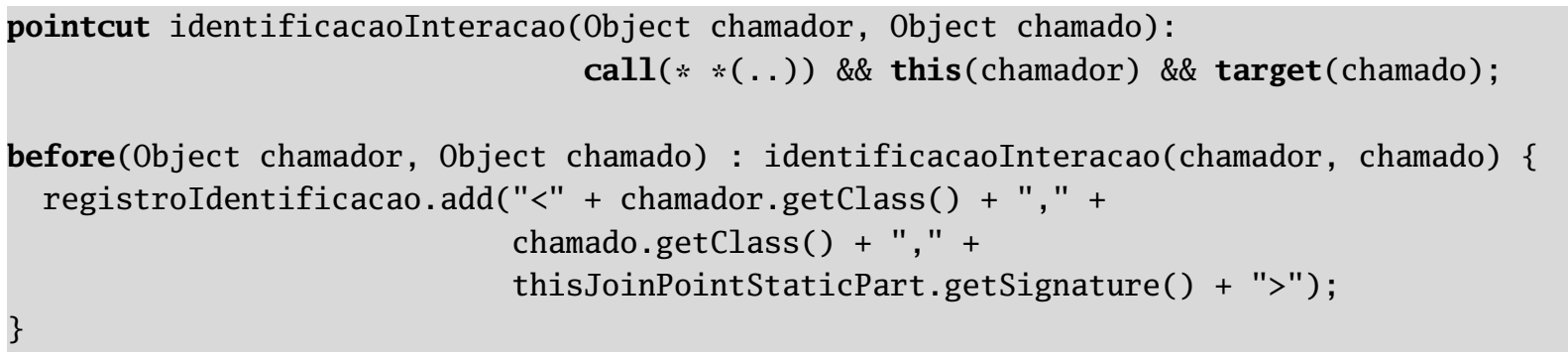

Figura 3.17: Identificação de interação - adaptado de Mao e May (2004)

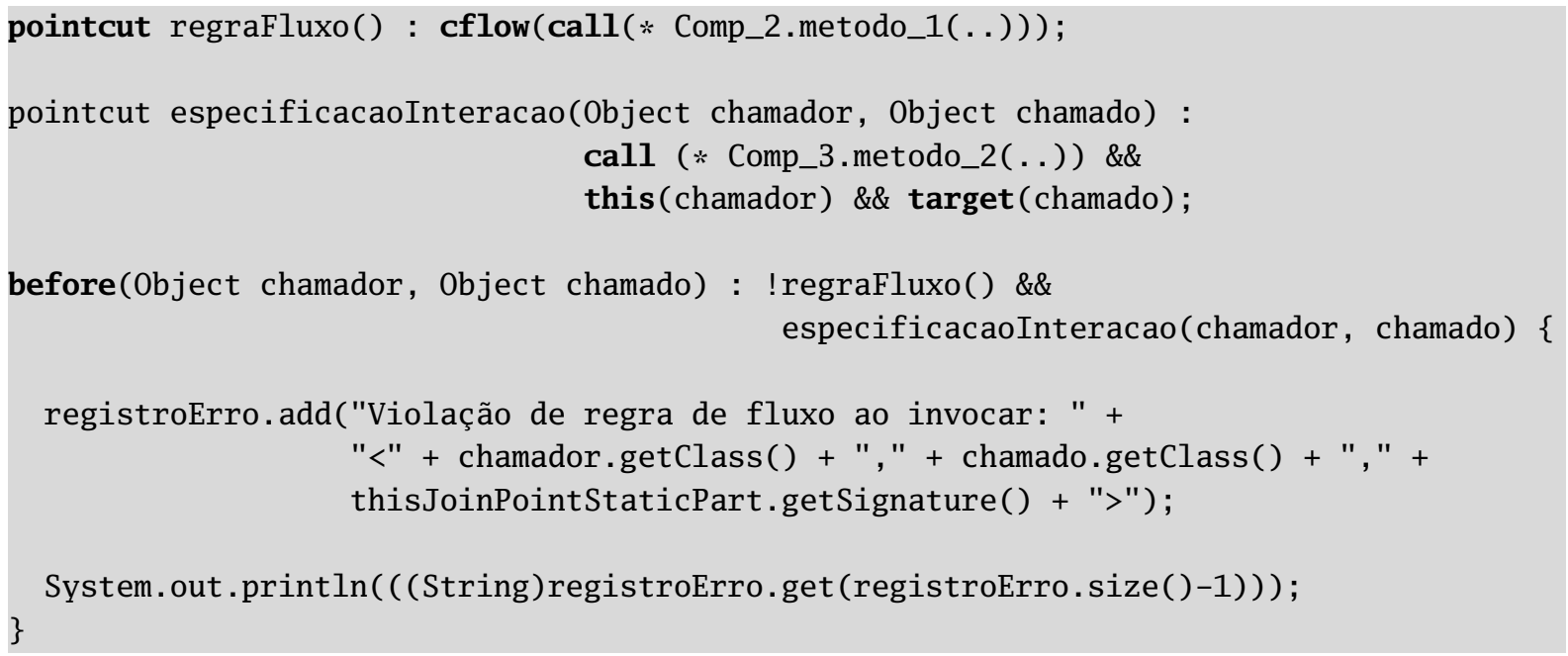

Figura 3.18: Verificação de interação em um fluxo de controle - adaptado de Mao e May (2004)

Além das verificações descritas, o registro de execução dos testes também é feito por meio do AspectJ, pois igualmente constitui um interesse ortogonal. Todos os resultados de verificações, assim como dados dos componentes participantes, são armazenados em um arquivo XML e podem ser analisados posteriormente.

Ao contrário da abordagem apresentada anteriormente, que tem o objetivo de testar unidades e verificar os contratos dos componentes, esta busca revelar uma outra categoria de erros: aqueles relacionados à comunicação entre componentes.

\subsubsection{Aspecto abstrato de teste}

O AspectJ é usado por Wenner (2004) para implementar o padrão de projeto Teste Abstrato (GEORGE, 2002). Esse padrão fornece uma maneira de construir um conjunto de testes que possa ser utilizado em diversas implementações (da mesma hierarquia) e reusado em implementações ainda não identificadas.

No exemplo adotado pelo autor, o método equals é abordado. Esse método é definido na classe object da linguagem Java e pode ser redefinido em suas subclasses, uma vez que 
nessa linguagem qualquer objeto herda automaticamente da classe object. As classes que implementam esse método devem "honrar" seu contrato: o método equals deve ser reflexivo, simétrico, transitivo, consistente e deve retornar falso se o objeto a ser comparado for nulo.

Utilizando o padrão proposto por George (2002), o testador deriva classes de uma classe abstrata (ex. TesteAbstratoEquals), que por sua vez, define métodos para os testes do contrato (ex. testReflexividade, para o teste da reflexividade) e um método abstrato que retorna o objeto que será testado (esse método deve ser implementado na classe descendente). O problema levantado pelo autor é que o teste das propriedades do método equals exige diversos objetos distintos (a transitividade, por exemplo, exige ao menos três instâncias) e sua implementação, segundo o padrão tradicional, pode ser trabalhosa.

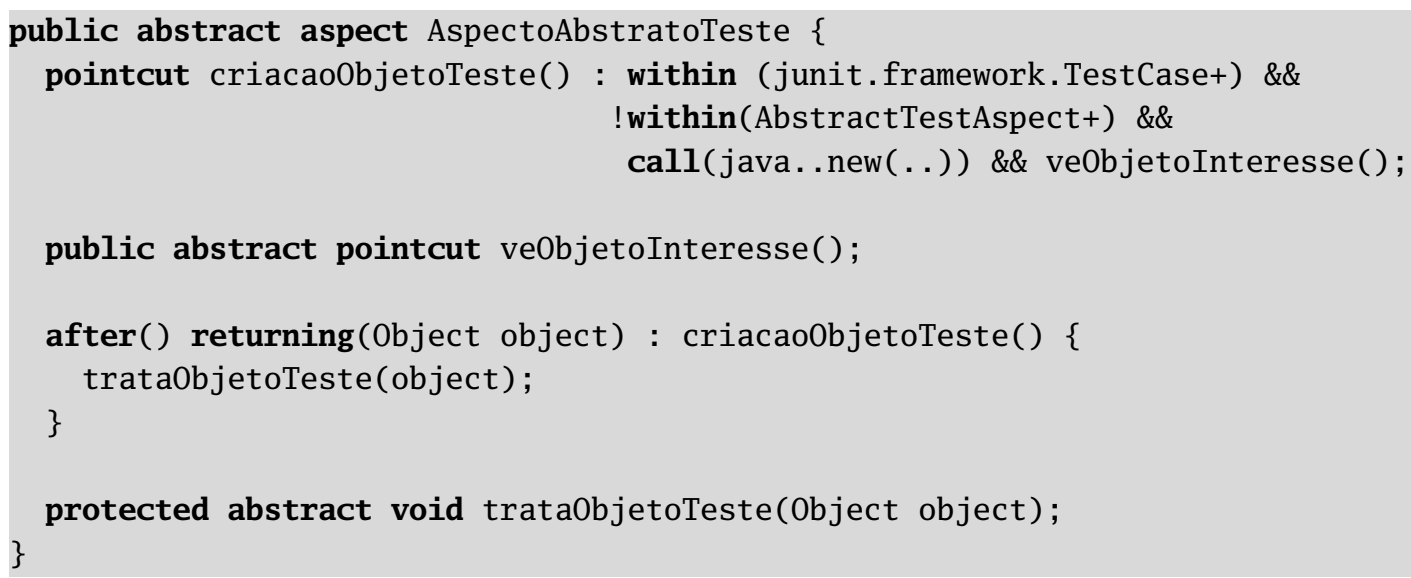

Figura 3.19: Aspecto AspectoAbstratoTeste - adaptado de Wenner (2004)

$\mathrm{Na}$ abordagem proposta, o aspecto AspectoAbstratoTeste cumpre o papel da classe abstrata do padrão em questão (Figura 3.19). O conjunto de junção composto criacao0bjetoTeste intercepta a criação de objetos a partir das classes de teste (junit.framework. TestCase+) e utiliza o conjunto de junção abstrato ve0bjetoInteresse (que deve ser definido nos aspectos descendentes) para permitir personalização. Um adendo do tipo after returning está associado ao conjunto de junção criacao0bjetoTeste e é responsável por executar o método trata0bjetoTeste, passando o objeto criado como parâmetro, sempre que esse conjunto de junção for alcançado.

O método trata0bjetoTeste é um método abstrato (deve ser implementado nos aspectos herdados) e representa papel importante no padrão, pois nele são tratados os objetos em teste. Essa abordagem permite diversas implementações. Pode-se, por exemplo, armazenar os objetos interceptados e executar os testes posteriormente, a partir desses valores. Ou ainda, executar o próprio teste do contrato no corpo do método.

O Aspecto Abstrato de Teste é uma alternativa ao padrão tradicional de teste. Sua principal vantagem está no fato de não requerer a implementação de métodos para obtenção do objeto em teste, uma vez que isso é feito automaticamente pelos conjuntos de junção. Além disso, o 
padrão é flexível, pois conjuntos de junção podem ser genéricos o suficiente para interceptar objetos e interfaces acrescentados ao sistema sem necessidade de modificação no código de teste.

\subsubsection{Verificação de padrões de código}

A POA também tem sido utilizada com o intuito de garantir padrões de codificação e regras de construção (AspectJ Team, 2003; MASSOL et al., 2002; ISBERG, 2002; DIOTALEVI, 2004; EICHBERG et al., 2004). Em tempo de compilação diversas informações podem ser obtidas do programa estaticamente, e dessa forma algumas checagens já podem ser feitas. Construções de erros e avisos do AspectJ são utilizados nesse contexto. Esse tipo de aplicação da POA pode detectar situações que indicam enganos de programação ou o não cumprimento de padrões de codificação.

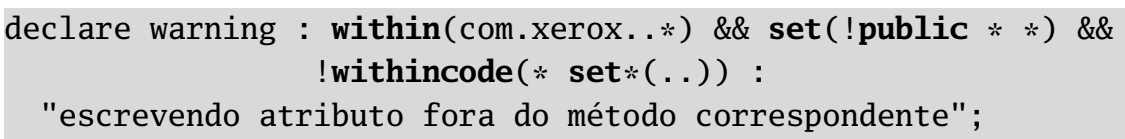

Figura 3.20: Verificação de escrita de atributos - adaptado de Isberg (2002)

Na Figura 3.20 observa-se um exemplo sugerido por Isberg (2002), para tratamento da escrita de atributos. Na Orientação a Objetos os atributos de uma classe não devem ser visíveis externamente, e é elegante que o acesso a eles seja feito por meio de métodos próprios de leitura e escrita, de forma que o encapsulamento - propriedade essencial nesse paradigma - não seja quebrado. $\mathrm{O}$ exemplo exibe um aviso sempre que o valor de um atributo não-público no pacote xerox ou nos seus subpacotes é modificado sem utilizar o método de escrita correspondente (um método cujo nome seja iniciado com "set"). Os atributos podem ser de qualquer tipo e possuírem qualquer nome, e os métodos de escrita podem retornar qualquer valor e possuírem qualquer número de argumentos.

Outro exemplo sugerido pelo mesmo autor (Figura 3.21) força a criação de objetos por meio de métodos fábricas de objetos (Factory). Um erro será exibido em tempo de compilação sempre que houver uma tentativa de criação de um objeto de uma subclasse de Ponto fora do método fábrica correspondente (criar).

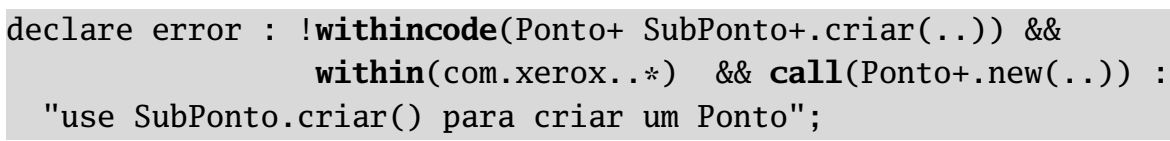

Figura 3.21: Verificação de métodos fábrica - adaptado de Isberg (2002)

Padrões de código são uma forma de assegurar que programadores sigam as melhores práticas de programação, atribuindo legibilidade e consistência ao código. Apesar de sua impor- 
tância, a verificação desse tipo de propriedade pode se tornar bastante trabalhosa, utilizando apenas os recursos de uma linguagem Orientada a Objetos. A POA oferece diversos recursos que podem ser explorados e utilizados com esse intuito.

\subsubsection{Teste de invariantes, pré e pós-condições}

A técnica de Projeto por Contrato (MEYER, 1992) pode ser considerada uma aplicação típica da POA. A implementação de um mecanismo que realize a verificação de invariantes, pré e pós-condições utilizando apenas orientação a objetos leva ao entrelaçamento e espalhamento do código que implementa esse mecanismo com o código funcional.

O teste de pré e pós condições também auxilia na atividade de teste, uma vez que impõe comportamento específico ao programa. O teste desse tipo de propriedade só pode ser feito durante a execução do programa e é executado por meio de conjuntos de junção e adendos. $\mathrm{Na}$ Figura 3.22 observa-se o teste de pré-condições para os métodos que movem um ponto (alteram suas coordenadas). Antes de cada operação uma checagem é efetuada e verifica-se se as novas coordenadas estão dentro dos limites e caso isso não ocorra uma exceção é lançada.

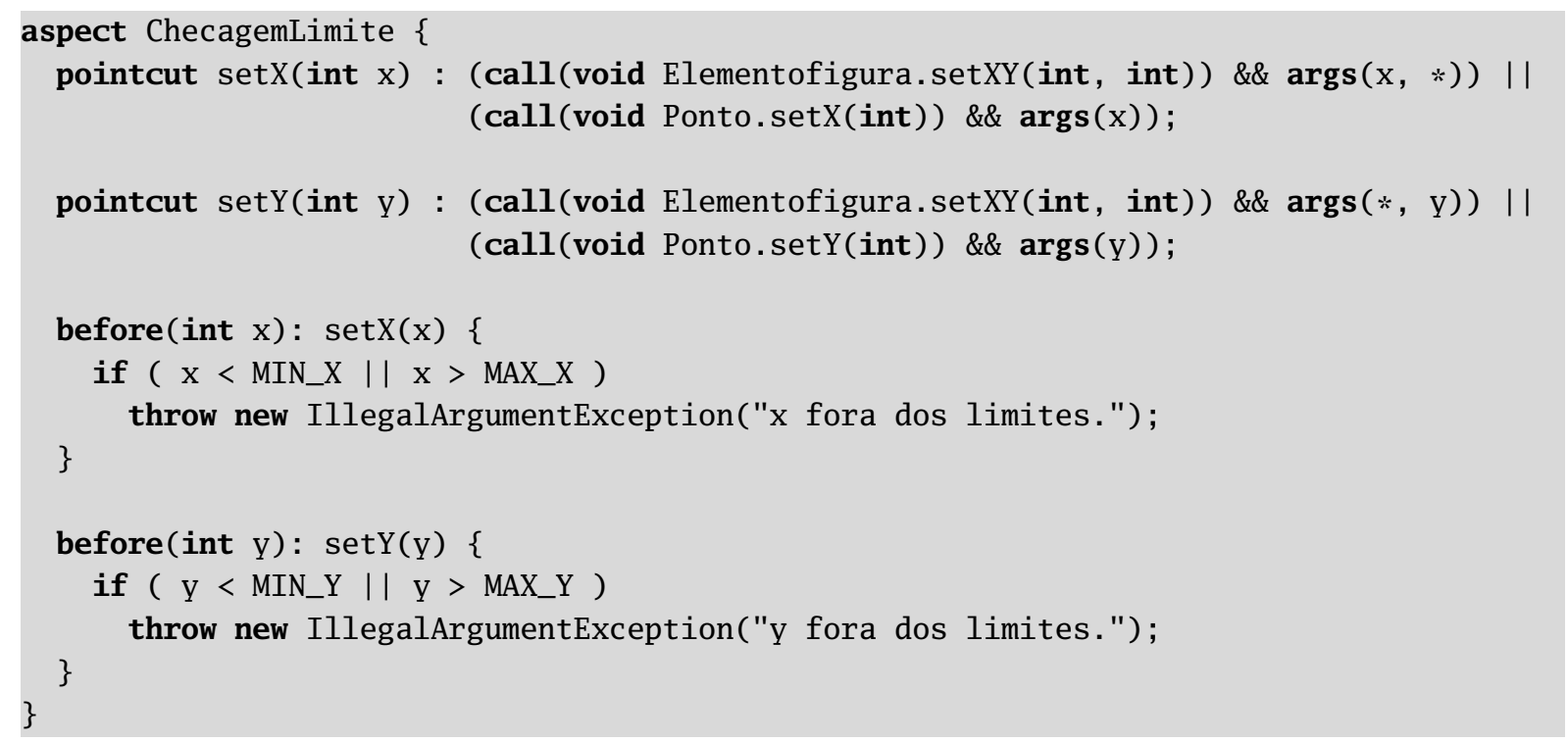

Figura 3.22: Verificação de pré-condições - adaptado de AspectJ Team (2003)

A verificação de invariantes é um recurso que também pode ser utilizado no teste de programas. Invariantes podem ser checadas por meio da execução do programa e auxiliam na detecção de defeitos que podem não ter sido detectados por testes caixa-preta (ISBERG, 2002). Na Figura 3.23 é verificada a criação de objetos nulos por meio de métodos de fabricação de objetos, e sempre que um objeto nulo é criado, um erro é lançado. 


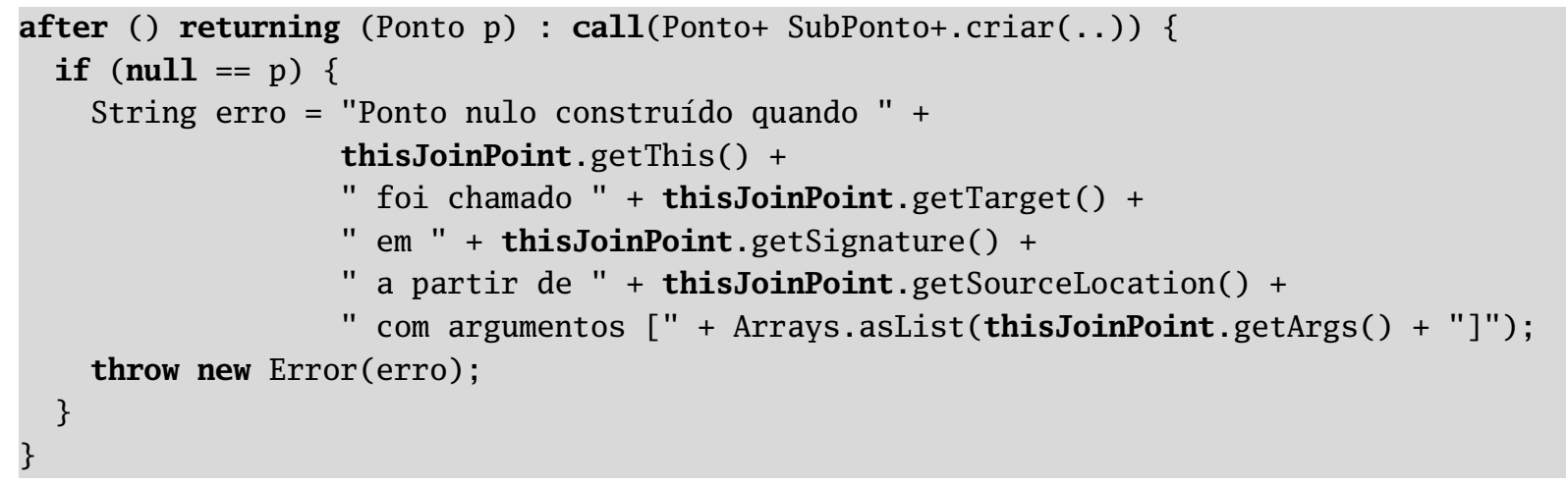

Figura 3.23: Verificação de asserções - adaptado de Isberg (2002)

\subsubsection{Outras abordagens}

Além das abordagens apresentadas, a POA também tem sido aplicada para simular pseudocontroladores e variar o comportamento de objetos no sistema (especialmente em condições de falha), gravar entradas e comportamento de métodos (ISBERG, 2002).

Alguns autores têm aplicado a POA em atividades que estão relacionadas direta ou indiretamente com o teste de software. A instrumentação de programas por meio dessa técnica foi abordada por Mahrenholz, Spinczyk e Schroder-Preikschat (2002), usando AspectC++. O AspectJ também foi utilizado com esse mesmo objetivo (DETERS; CYTRON, 2001; PEARSON, 2003; DEBUSMANN; GEIHS, 2003).

Rajan e Sullivan (2004) propõem uma linguagem de programação orientada a aspectos que permite identificar pontos no código que serão utilizados para cobertura de critérios estruturais. Segundo os autores, um critério de adequação pode ser visto como um interesse ortogonal uma vez que constitui um requisito de teste que é mapeado para monitorar a execução de elementos do programa espalhados pelo código base. Assim, na linguagem proposta é possível identificar pontos de junção de menor granularidade, como arcos do grafo de fluxo de controle.

Kaeli et al. (2001) aplicaram a POA para facilitar o entendimento de programas, utilizando o AspectJ para identificar código não utilizado e criar o grafo de chamadas a partir da execução do programa. Gschwind e Oberleitner (2003) também trabalharam nesse contexto, analisando dentre outros tópicos, métodos reflexivos.

Ferramentas que utilizam a POA para o teste de programas também têm surgido. Cricket Cage (WALEND, 2002) é uma ferramenta que utiliza recursos do AspectJ para criar casos de teste compatíveis com o JUnit. Para isso, disponibiliza um método para geração de casos de teste que deve ser adicionado à classe em teste, e um aspecto abstrato contendo um conjunto de junção, responsável por filtrar as chamadas que serão interceptadas, que deve ser estendido. A combinação do código em teste com os aspectos definidos na ferramenta leva à geração de casos de teste quando a aplicação é executada. 
Utilizando um conceito semelhante ao descrito na Seção 3.5.1, a ferramenta VirtualMock (WOOLLEY, 2003) auxilia o teste de unidade por meio de objetos imitadores virtuais criados com o AspectJ. Usando a ferramenta, executa-se o teste em três etapas. Na primeira as chamadas provenientes da classe em teste e direcionadas para classes externas (chamadas de colaboradoras), incluído argumentos, são gravadas. A seguir, as chamadas são executadas e o resultado capturado. Na última etapa, os resultados são comparados com os esperados.

\subsection{Considerações finais}

Este capítulo abordou a Programação Orientada a Aspectos e algumas de suas construções e linguagens. O AspectJ foi enfatizado por tratar-se da linguagem que será utilizada na proposta de trabalho. Além disso foram ilustradas algumas iniciativas na área de teste de software utilizando a Programação Orientada a Aspectos.

Como é possível observar nas abordagens apresentadas, a POA mostra-se adequada ao teste de programas. Apesar de alguns trabalhos já terem sido publicados nessa área, ainda são desconhecidas propostas para aplicar a POA ao teste utilizando as técnicas e critérios estabelecidos pela comunidade especializada (abordados no Capítulo 2). As iniciativas existentes enfatizam apenas as características práticas dessa atividade e as implementações, ainda que bastante úteis, limitam-se a abordagens ad-hoc nas quais conceitos importantes de teste de software são ignorados. Essa perspectiva, em que desconsideram-se princípios importantes de teste, pode levar a testes incompletos ou muitas vezes dispendiosos.

Com o objetivo de preencher essa lacuna, é apresentada no próximo capítulo a ferramenta J-FuT, desenvolvida nesta pesquisa. A ferramenta oferece apoio ao teste funcional e utiliza a POA para auxiliar a intrumentação e teste de programas. 


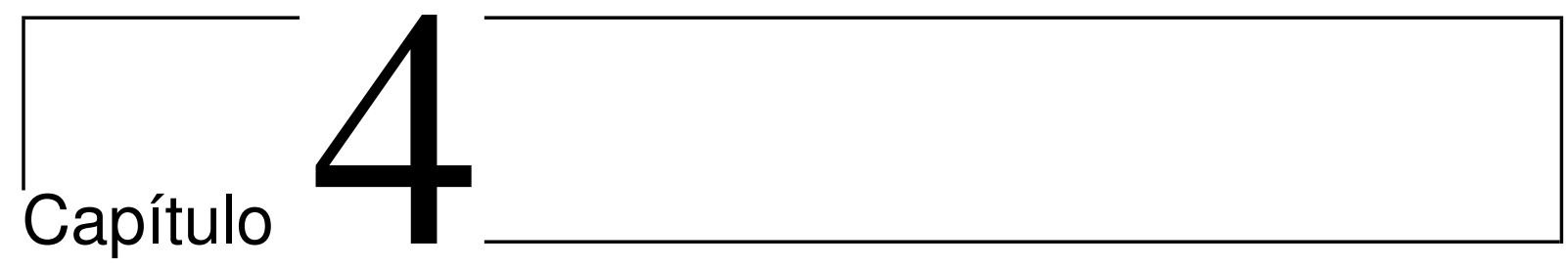

\section{A ferramenta J-FuT}

\subsection{Considerações iniciais}

presenta-se neste capítulo uma ferramenta para o teste funcional de programas Java,
denominada J-FuT (Java Functional Testing). A J-FuT utiliza aspectos para auxiliar
o teste funcional, permitindo que a análise de cobertura de diversos critérios funcionais seja feita a partir de casos de teste elaborados no JUnit. A ferramenta oferece suporte aos critérios Particionamento de Equivalência, Análise de Valor-Limite e Teste Funcional Sistemático. Além disso, permite que pré e pós-condições do sistema sejam verificadas.

Este capítulo está organizado da seguinte maneira: inicialmente, na Seção 4.2, são apresentadas a motivação para a construção da J-FuT e uma breve introdução à ferramenta. A seguir, na Seção 4.3, aborda-se a arquitetura da ferramenta e na Seção 4.4 sua modelagem, em que as principais classes da ferramenta são descritas. Na Seção 4.5 aborda-se o processo de instrumentação utilizado pela J-FuT e descrevem-se os aspectos utilizados durante o teste de uma aplicação. Por fim, na Seção 4.6 descreve-se como é efetuada a análise de dados e os algoritmos utilizados para o cálculo de cobertura.

\subsection{Motivação}

Conforme descrito no Capítulo 3, a POA possui características que podem auxiliar na atividade de teste. Especificamente no que diz respeito ao teste funcional e ao AspectJ, percebe-se uma clara relação entre o modelo de pontos de junção adotado pela linguagem e os pontos de interesse desse tipo de teste. Rajan e Sullivan (2004) referem-se aos pontos de junção do AspectJ 
como "pontos de junção caixa-preta", tendo em vista a sua granularidade (que não contempla, por exemplo, arestas do grafo de fluxo de controle).

Os denominados "pontos de junção caixa-preta" encaixam-se perfeitamente no tipo de teste executado pelos critérios funcionais, nos quais consideram-se principalmente as entradas, saídas e estado do programa e não, necessariamente, sua implementação. Além disso, a captura do contexto dos pontos de junção, fornecida pelo AspectJ, oferece subsídios para analisar o comportamento interno do programa e responder a questões do tipo:

- Dado um conjunto de casos de teste, quais classes de equivalência de uma operação ${ }^{1}$ esse conjunto exercita?

- Dado um conjunto de casos de teste que sensibiliza uma determinada operação e um método chamado por esta, quais classes de equivalência desse método são exercitadas por esse conjunto?

Dessa forma, o uso da POA além de auxiliar o teste de sistema, permite a execução do "teste funcional de unidade", no qual considera-se o método como a unidade de teste que será analisada conforme sua especificação.

A J-FuT tem o objetivo de apoiar o teste funcional de programas desenvolvidos em Java. A ferramenta enfatiza a análise de cobertura segundo critérios funcionais e permite a avaliação da adequação de um determinado conjunto de casos de teste a um critério específico. Utilizando a J-FuT o testador pode efetivar as atividades básicas para a aplicação de critérios funcionais: instrumentação, seleção e execução de casos de teste e, por fim, análise de cobertura. O teste de uma aplicação utilizando a ferramenta é feito seguindo quatro etapas:

1. Abertura de uma sessão de teste. Nesta etapa é possível abrir uma sessão de teste existente ou criar uma nova sessão de teste. Observa-se que a ferramenta possibilita o teste em sessões, permitindo que uma sessão seja interrompida e posteriormente retomada;

2. Instrumentação. Na segunda etapa são selecionadas as operações do programa em teste que serão testadas;

3. Manipulação dos casos de teste. Nesta etapa faz-se a seleção e execução dos casos de teste;

4. Análise de cobertura. A última etapa consiste na avaliação dos resultados e análise de cobertura segundo o critério de teste escolhido.

As próximas seções são dedicadas à descrição da ferramenta e das decisões de projeto tomadas durante o seu desenvolvimento.

\footnotetext{
${ }^{1}$ Operações referem-se a métodos que cruzam a fronteira do sistema e normalmente fazem uso de métodos de diversas classes, isto é, são disparados a partir de eventos externos ao sistema.
} 


\subsection{Arquitetura}

A arquitetura da ferramenta é mostrada na Figura 4.1, na qual observa-se a comunicação entre os vários módulos que compõem a ferramenta, os casos de teste (especificados no JUnit) e o programa em teste. No projeto da ferramenta buscou-se a segmentação em camadas que refletissem as principais funcionalidades da J-FuT.

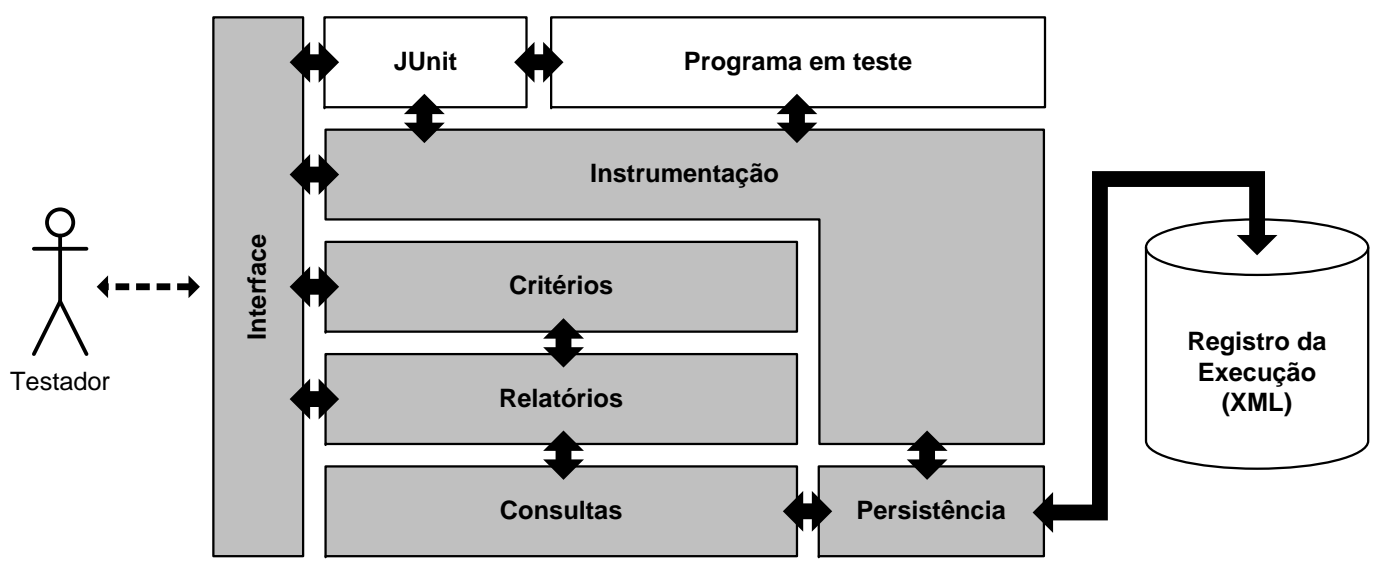

Figura 4.1: Arquitetura da J-FuT

A J-FuT disponibiliza uma interface gráfica baseada no Swing (Sun Microsystems, 2002) por meio da qual o testador tem acesso às funcionalidades do software. A manipulação dos casos de teste é feita por meio dessa interface, que fornece funções para execução, edição, habilitação e desabilitação de casos de teste. É importante notar que não há acesso direto ao programa em teste e sua execução sempre é feita a partir dos casos de teste implementados.

Abaixo da camada que contém o programa em teste e os casos de teste encontra-se o módulo que implementa a instrumentação. Na instrumentação são utilizados aspectos, que são responsáveis por capturar operações específicas do programa em teste, além de executar os critérios funcionais. As informações necessárias para instrumentação também são fornecidas pelo testador, utilizando a interface gráfica. O relacionamento entre esse módulo e o módulo de persistência permite que os dados observados durante a execução do programa possam ser registrados. Esses dados são armazenados em um repositório XML utilizando o módulo de persistência, que implementa a interface de acesso ao registro da execução.

O módulo de consulta, por sua vez, utiliza o módulo de persistência para efetuar consultas específicas sobre o repositório, usadas para a geração dos relatórios. Os relatórios são gerados de acordo com o critério de teste utilizado, que mais uma vez é especificado pelo testador por meio da interface gráfica. 


\subsection{Modelagem}

A J-FuT possui dezenas de classes, divididas em dezesseis pacotes. Optou-se por utilizar o AspectJ apenas na instrumentação e rastreamento do programa em teste e registro de operações executadas internamente pela ferramenta.

\subsubsection{Conceitos básicos}

O teste de uma aplicação usando a J-FuT é feito a partir de um projeto de teste. Um projeto de teste armazena todos os dados relativos ao teste, incluindo seu nome, classes e métodos em teste, bibliotecas necessárias, requisitos de teste, condições de entrada e registro de execução. A classe Project representa um projeto na ferramenta. A manipulação dos projetos de teste é feita por meio da classe ProjectManager. Essa classe é responsável por criar, abrir, excluir e persistir projetos de teste em arquivos XML. No diagrama da Figura 4.2 são exibidas as classes básicas da ferramenta e seus relacionamentos.

\begin{tabular}{|c|c|c|c|c|}
\hline \multirow[b]{2}{*}{ Criterion } & \multirow{6}{*}{$0 .{ }^{*}$} & \multirow{5}{*}{\begin{tabular}{l}
\multicolumn{1}{c}{ Project } \\
instrumented \\
testsExecuted \\
projectName \\
projectLibs \\
operations \\
testCaseFiles \\
operations
\end{tabular}} & \multirow{6}{*}{$0 .{ }^{*}$} & \multirow{2}{*}{\begin{tabular}{|l} 
ProjectManage \\
path
\end{tabular}} \\
\hline & & & & \\
\hline name & & & & \multirow{4}{*}{\begin{tabular}{|l} 
ProjectManager() \\
createProject() \\
addProject() \\
deleteProject() \\
closeProject() \\
saveProject()
\end{tabular}} \\
\hline \multirow{3}{*}{$\begin{array}{l}\text { Criterion() } \\
\text { minTestsToCover() } \\
\text { maxEquivPerTest() }\end{array}$} & & & & \\
\hline & & & & \\
\hline & & Project() & & \\
\hline
\end{tabular}

Figura 4.2: Classes básicas

Na solução adotada, os critérios de teste são representados pela classe Criterion e descritos externamente por um arquivo XML. Esse arquivo, que obedece a uma DTD (Document Type Definition) específica, contém os valores dos atributos de cada critério, assim como o critério padrão utilizado pela ferramenta. A configuração externa permite que novos critérios possam ser criados e os critérios existentes alterados de forma simplificada. Os critérios são carregados automaticamente durante a iniciação da ferramenta e estarão disponíveis para uso.

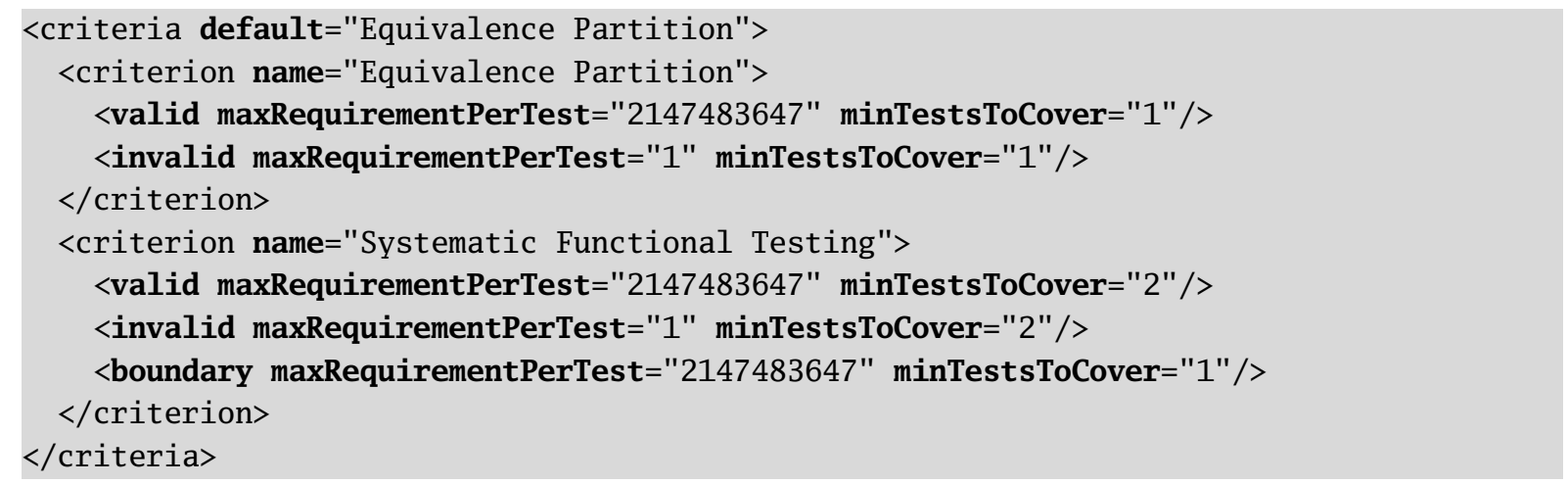

Figura 4.3: Exemplo de configuração dos critérios de teste 
Um exemplo de configuração é mostrado no código da Figura 4.3. As propriedades de cada critério são especificadas por meio de um elemento criterion, que por sua vez possui marcadores (tags) específicos para descrição de suas propriedades. Os marcadores representam requisitos de teste e podem ser de cinco tipos, como descrito no Quadro 4.1. O testador pode criar critérios personalizados por meio de novos elementos criterion contendo um ou mais marcadores.

Quadro 4.1: Nomes de marcadores para os critérios de teste

\begin{tabular}{|c|c|c|}
\hline Marcador & Descrição & Exemplo de uso \\
\hline valid & Classe de equivalência válida & \multirow{3}{*}{$\begin{array}{l}\text { Particionamento de Equivalência, } \\
\text { Análise de Valor-Limite e } \\
\text { Teste Funcional Sistemático }\end{array}$} \\
\hline invalid & Classe de equivalência inválida & \\
\hline boundary & Valor-limite & \\
\hline pre & Pré-condição & \multirow[t]{2}{*}{ Pré e pós-condições } \\
\hline pos & Pós-condição & \\
\hline
\end{tabular}

Cada marcador deve possuir obrigatoriamente dois atributos de valor numérico ${ }^{2}$, como mostrado no Quadro 4.2. Esses atributos especificam o comportamento do requisito de acordo com o critério. Utilizando como exemplo o critério de nome "Equivalence Partition" da Figura 4.3 , percebe-se que um caso de teste só pode exercitar, no máximo, uma classe de equivalência inválida (marcador invalid, atributo maxRequirementPerTest) e basta um único caso de teste para que a classe de equivalência seja considerada exercitada (marcador invalid, atributo minTestsToCover).

Quadro 4.2: Atributos dos marcadores

\begin{tabular}{|l|l|}
\hline Atributo & Descrição \\
\hline maxRequirementPerTest & $\begin{array}{l}\text { Máximo de requisitos de teste de um determinado tipo } \\
\text { que um caso de teste pode exercitar }\end{array}$ \\
\hline minTestsToCover & $\begin{array}{l}\text { Mínimo necessário de casos de teste para exercitar um } \\
\text { determinado tipo de requisito de teste }\end{array}$ \\
\hline
\end{tabular}

\subsection{Instrumentação e teste}

A POA permite identificação de pontos específicos na execução de um programa e por isso trata-se de uma solução elegante para a sua instrumentação. Seguindo essa premissa, a J-FuT utiliza aspectos no processo de instrumentação e teste. Além de fundamental ao cálculo de cobertura, a instrumentação é essencial para o registro do comportamento do programa em teste. Esse registro é utilizado pela ferramenta como auxílio ao processo de depuração, de forma semelhante à proposta por Molnár, Berényi e Siklósi (2002).

A instrumentação constitui uma etapa obrigatória para o teste de um programa utilizando a ferramenta. No diagrama da Figura 4.4 encontram-se as classes (em branco) e aspectos (em

\footnotetext{
${ }^{2}$ Os valores dos atributos devem ser inteiros positivos. O valor 2147483647 corresponde ao maior inteiro positivo armazenado pelo Java em plataformas de 32 bits.
} 
cinza) utilizados nesta etapa. Os elementos na parte superior do diagrama pertencem à ferramenta, enquanto que aqueles na parte inferior são implementados pelo testador.

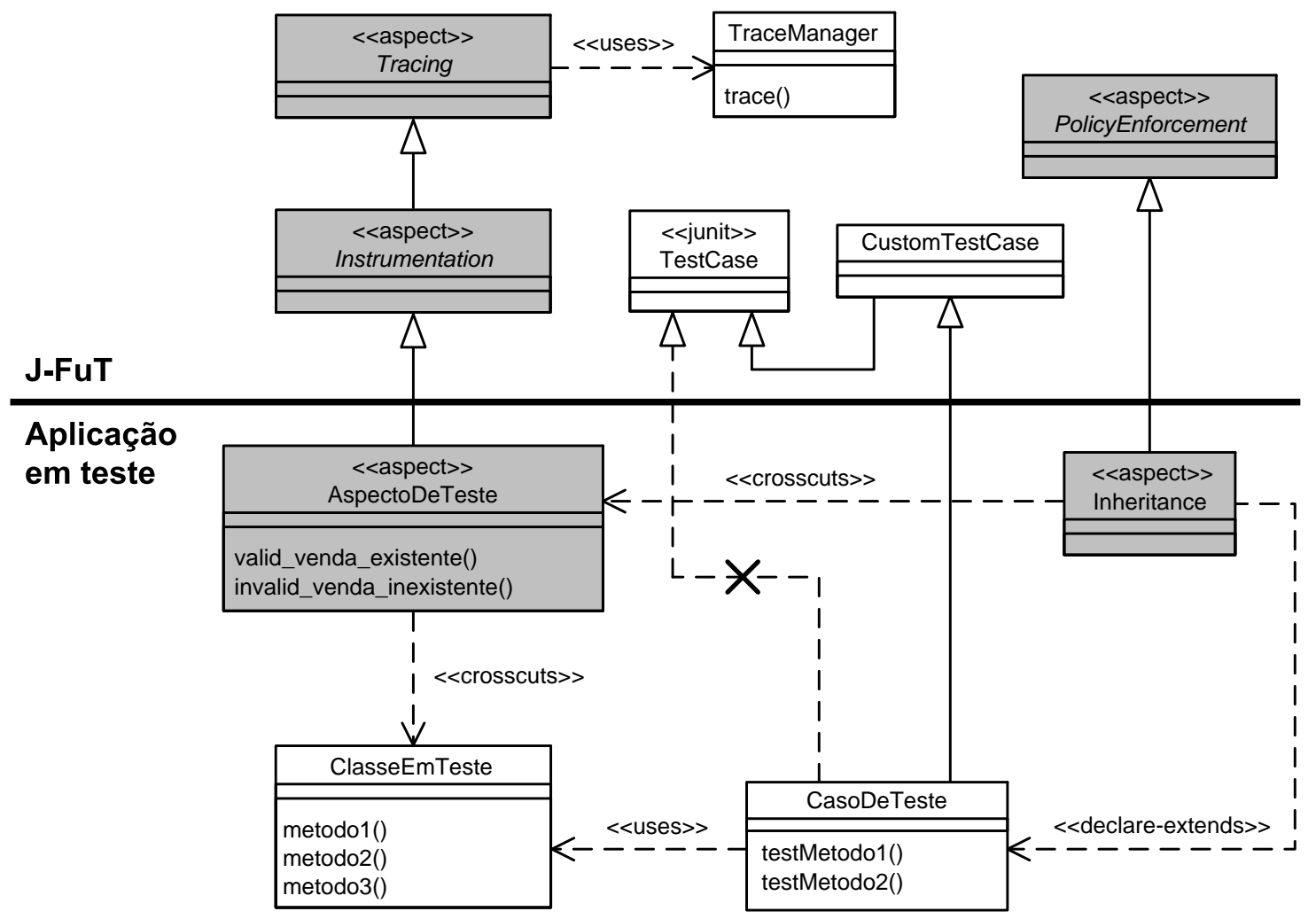

Figura 4.4: Classes e aspectos utilizados na instrumentação e teste

A J-FuT utiliza casos de teste construídos no JUnit. Para a instanciação desse framework, as classes que representam casos de teste devem ser especializações da classe TestCase. Métodos de teste implementados nessas classes devem possuir nomes iniciados com o prefixo test. Uma classe desse tipo encontra-se no diagrama com nome CasoDeTeste.

É necessário à ferramenta armazenar dados importantes dos casos de teste executados durante o teste de uma aplicação, a exemplo de seus nomes e resultados. Esses dados serão utilizados posteriormente na confecção dos relatórios de cobertura. Para que esses dados sejam colhidos é necessário de alguma forma instrumentar a classe TestCase (ou especializá-la), inserindo código que permita realizar esse tipo de tarefa. Essa nova classe deve então ser utilizada pelo testador quando da construção dos casos de teste.

O inconveniente dessa abordagem é que uma nova biblioteca deve ser disponibilizada e o testador deve obrigatoriamente utilizá-la durante o teste. Além disso, um engano pode ser facilmente cometido, uma vez que a classe TestCase poderia ser utilizada inadvertidamente. Como alternativa a esse problema e visando o aproveitamento de casos de teste já implementados no JUnit, optou-se pela criação de um aspecto que realizasse a instrumentação requerida sem exigir que isso seja feito explicitamente pelo testador. 
Por meio de uma declaração inter-tipo, o aspecto Inheritance insere um novo elemento (a classe CustomTestCase) na hierarquia dos casos de teste. O testador implementa normalmente as classes de teste como descendentes de TestCase e, após a combinação, a herança normal é desviada e as classes passam a herdar de CustomTestCase. Como CustomTestCase é uma descendente direta de TestCase, que contém informações adicionais de instrumentação, o teste pode ser executado normalmente.

O aspecto Inheritance também efetua verificações sobre os aspectos implementados pelo testador (descendentes de Instrumentation) e observa se as regras de construção foram seguidas. Essas regras são descritas no aspecto PolicyEnforcement e são tratadas em detalhes na Seção 4.5.3.

A instrumentação das classes da aplicação é feita por meio de uma hierarquia composta de dois aspectos abstratos: Tracing e Instrumentation. O aspecto Tracing (Figura 4.5) é responsável por capturar chamadas a métodos que ocorram durante a execução do programa em teste. Este aspecto possui três conjuntos de junção: validCalls, que seleciona chamadas a métodos pertencentes a pacotes implementados pelo usuário, testExecution, que intercepta execuções de métodos de teste da classe CustomTestCase e callsForTrace, que reduz a abrangência do conjunto de junção validCalls, interceptando apenas chamadas a métodos que ocorram no fluxo de execução de um método de teste. Essas informações são armazenadas por meio de um adendo around e além de auxiliarem o teste da aplicação (vide Seção 4.5.1), poderão ser utilizadas posteriormente para depuração se o registro estiver habilitado.

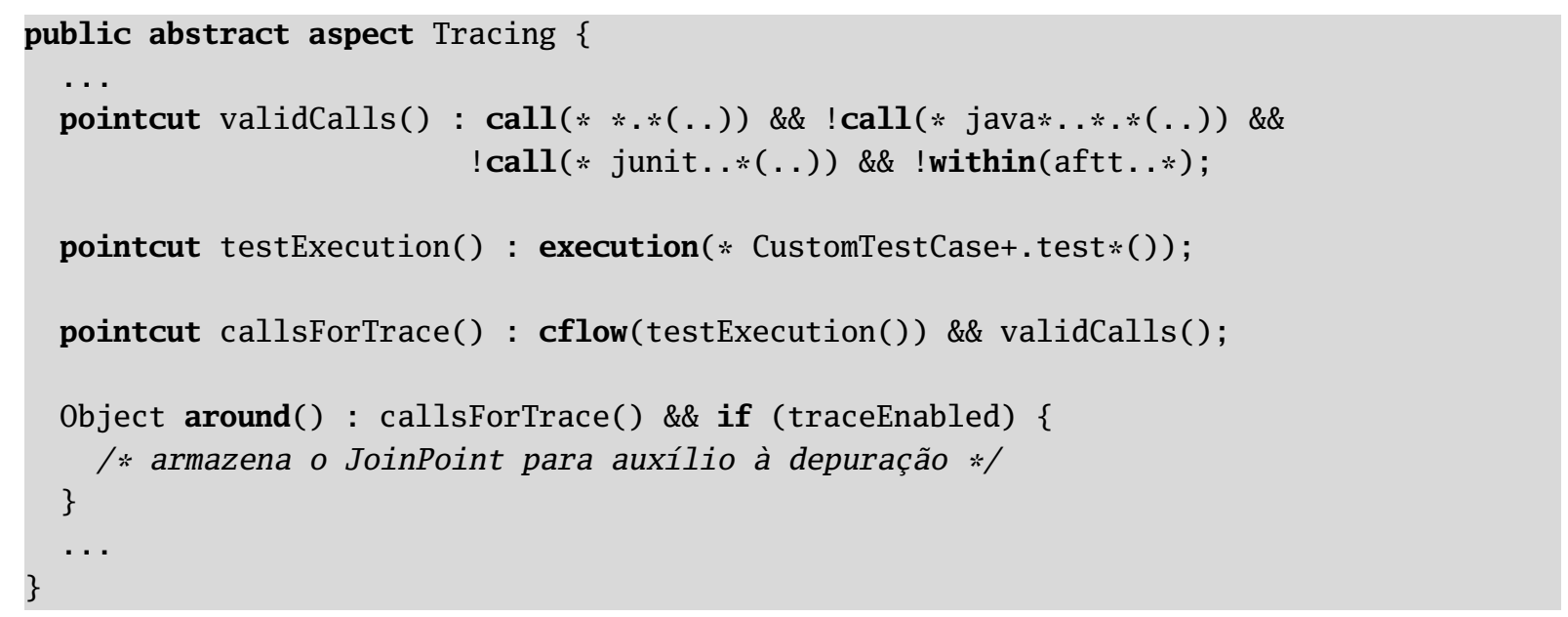

Figura 4.5: Aspecto Tracing

$\mathrm{O}$ aspecto Instrumentation constitui o elemento mais importante da J-FuT. Esse aspecto implementa as características e comportamento básicos para a instrumentação de operações da aplicação em teste e execução de critérios funcionais e é descrito em detalhes na Seção 4.5.1. 


\subsubsection{Aspectos elaborados para o teste de uma aplicação}

Para o teste de uma aplicação a ferramenta J-FuT deve ser instanciada corretamente, e o testador deve criar aspectos concretos que especializem o aspecto Instrumentation (denominados aspectos de teste). $\mathrm{O}$ aspecto Instrumentation, exibido na Figura 4.6, especializa o aspecto Tracing descrito anteriormente e contém um novo conjunto de junção abstrato (operationCall), responsável por interceptar uma operação em teste. Esse conjunto de junção deve ser concretizado pelo testador em cada aspecto descendente.

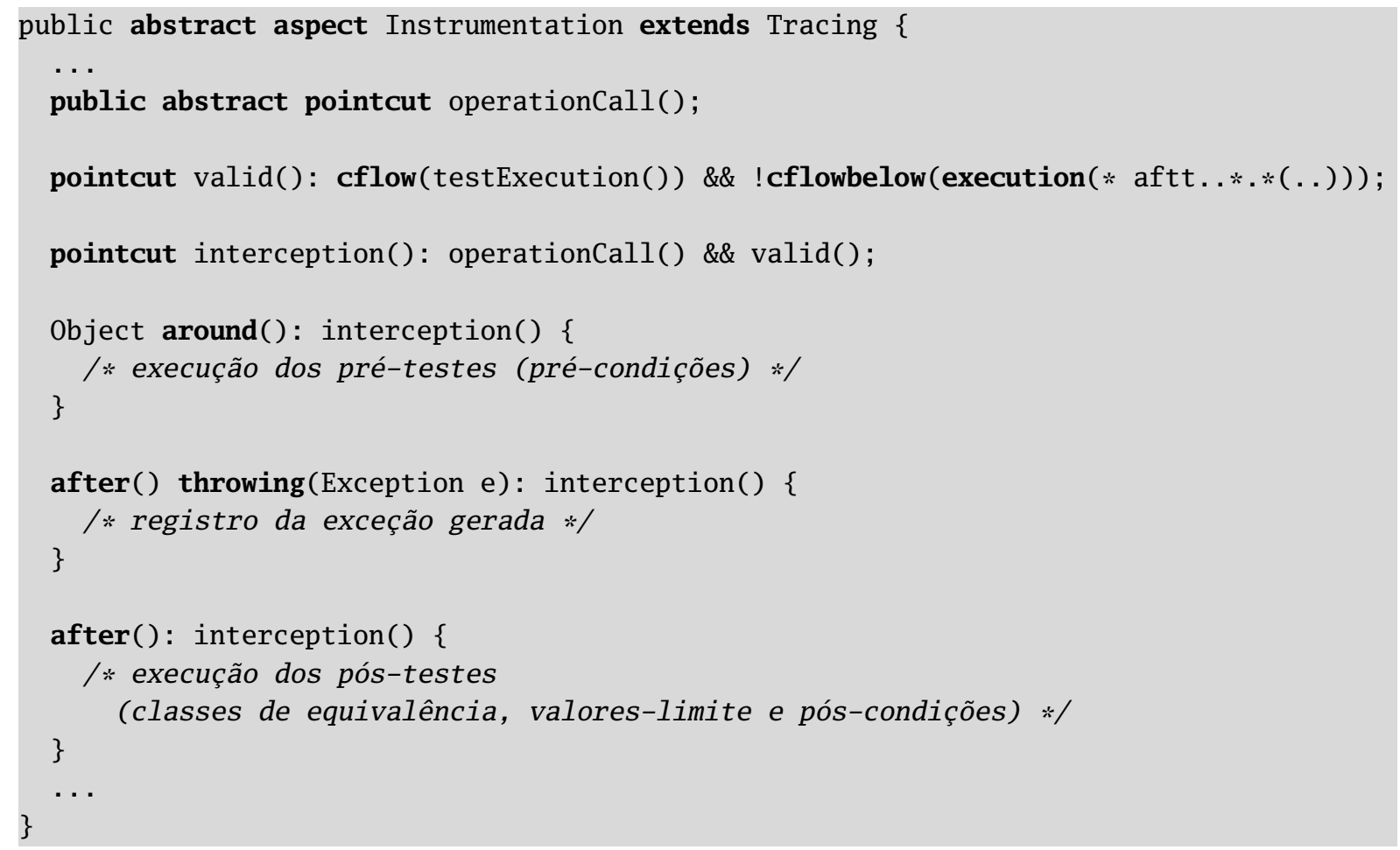

Figura 4.6: Aspecto Instrumentation

A utilização de um conjunto de junção abstrato justifica-se porque a operação em teste ainda não é conhecida pela ferramenta e variará de acordo com a aplicação que está sendo testada. No projeto da J-FuT foi utilizado o idioma Abstract Pointcut proposto por Hanenberg e Schmidmeier (2003), para permitir a definição tardia dos locais de instrumentação.

O segundo conjunto de junção, denominado valid, define um escopo de atuação: execuções de métodos no fluxo de execução dos casos de teste e não abaixo do fluxo de execução de métodos da ferramenta. É importante notar que o componente testExecution, que forma o conjunto de junção composto valid, foi descrito no aspecto Tracing e é reutilizado aqui.

Por fim, o conjunto de junção composto interception utiliza os dois conjuntos de junção descritos para definir os locais de instrumentação. Essa abordagem permite que a concretização do conjunto de junção operationCall feita pelo testador possa ser restringida por meio do conjunto de junção valid. 
Sobre o ponto de junção interception atuam três adendos, que executam os critérios funcionais por meio da execução de requisitos de teste. No adendo around são testadas as précondições da operação, enquanto no adendo after returning testam-se as pós-condições, classes de equivalência e valores-limite. As exceções geradas durante o teste são capturadas no adendo after throwing.

Os requisitos de teste são implementados por meio de métodos, que devem ser declarados como públicos e implementados com retorno booleano, permitindo sua descrição sob a forma de predicado. Os métodos devem ser nomeados com prefixos especiais, de acordo com sua função. Os prefixos utilizados na nomenclatura dos métodos seguem o mesmo padrão adotado para os marcadores de um critério de teste, exibidos no Quadro 4.1.

Um aspecto de teste é portanto constituído basicamente pela concretização do conjunto de junção operationCall e implementação de métodos que definem pré e pós-condições, classes de equivalência e valores-limite (requisitos de teste). Os métodos são executados por reflexão, na ordem em que foram implementados, toda vez que o conjunto de junção operationcall é atingido. O resultado da execução de cada método avalia se o requisito descrito por ele foi exercitado. Uma recomendação é que cada aspecto de teste elaborado represente uma condição de entrada (ou restrição de entrada), de forma a facilitar o entendimento da cobertura. Na Seção 4.5.2 são detalhados a construção e o funcionamento dos aspectos de teste.

\subsubsection{Regras para construção dos aspectos de teste}

Na Figura 4.7 é exibido o exemplo de um aspecto de teste. Nesse código é possível observar a concretização do conjunto de junção operationcall, definido para selecionar chamadas ao método verifica da classe Identificador. Também é exibido um método especial: setUp. Esse método é executado sempre que o conjunto de junção operationCall é alcançado e antes dos requisitos de teste serem chamados. O método setUp possui parâmetros idênticos ao da operação interceptada (nesse exemplo, um único parâmetro do tipo string) e é responsável por capturar os parâmetros dessa operação, auxiliando na elaboração dos predicados.

Apesar de opcional, quando implementado, o método setUp permite que em um único local os valores dos parâmetros sejam capturados e armazenados em atributos do aspecto (nesse exemplo, nos atributos parametro e objetoTeste). A J-FuT fornece métodos auxiliares, definidos no aspecto Instrumentation, que podem ser utilizados nos aspectos de teste para facilitar a implementação do método setUp. Esses métodos permitem obter informações a respeito do ponto de junção interceptado e são explicados no Quadro 4.3.

Ainda na Figura 4.7, dois requisitos de teste pertencentes ao aspecto PrimeiroCaractere são mostrados: valid_primeiro_letra (que descreve uma classe de equivalência válida) e invalid_primeiro_nao_letra (que descreve uma classe de equivalência inválida). No código 
Quadro 4.3: Métodos auxiliares definidos no aspecto Instrumentation

\begin{tabular}{|l|l|}
\hline Método & Descrição \\
\hline getTarget0bject() & Retorna o objeto que contém a operação interceptada \\
\hline getResult0bject() & $\begin{array}{l}\text { Retorna o resultado da operação interceptada. O valor } \\
\text { null é retornado caso a operação seja do tipo void }\end{array}$ \\
\hline getException0bject() & $\begin{array}{l}\text { Retorna a exceção gerada na execução da operação inter- } \\
\text { ceptada. O valor null é retornado caso não haja exceção }\end{array}$ \\
\hline
\end{tabular}

implementado, o método valid_primeiro_letra retorna verdadeiro (true) se o primeiro caractere de parametro for uma letra e falso (false) se essa condição não for satisfeita. O método invalid_primeiro_nao_letra é a negação do método anterior.

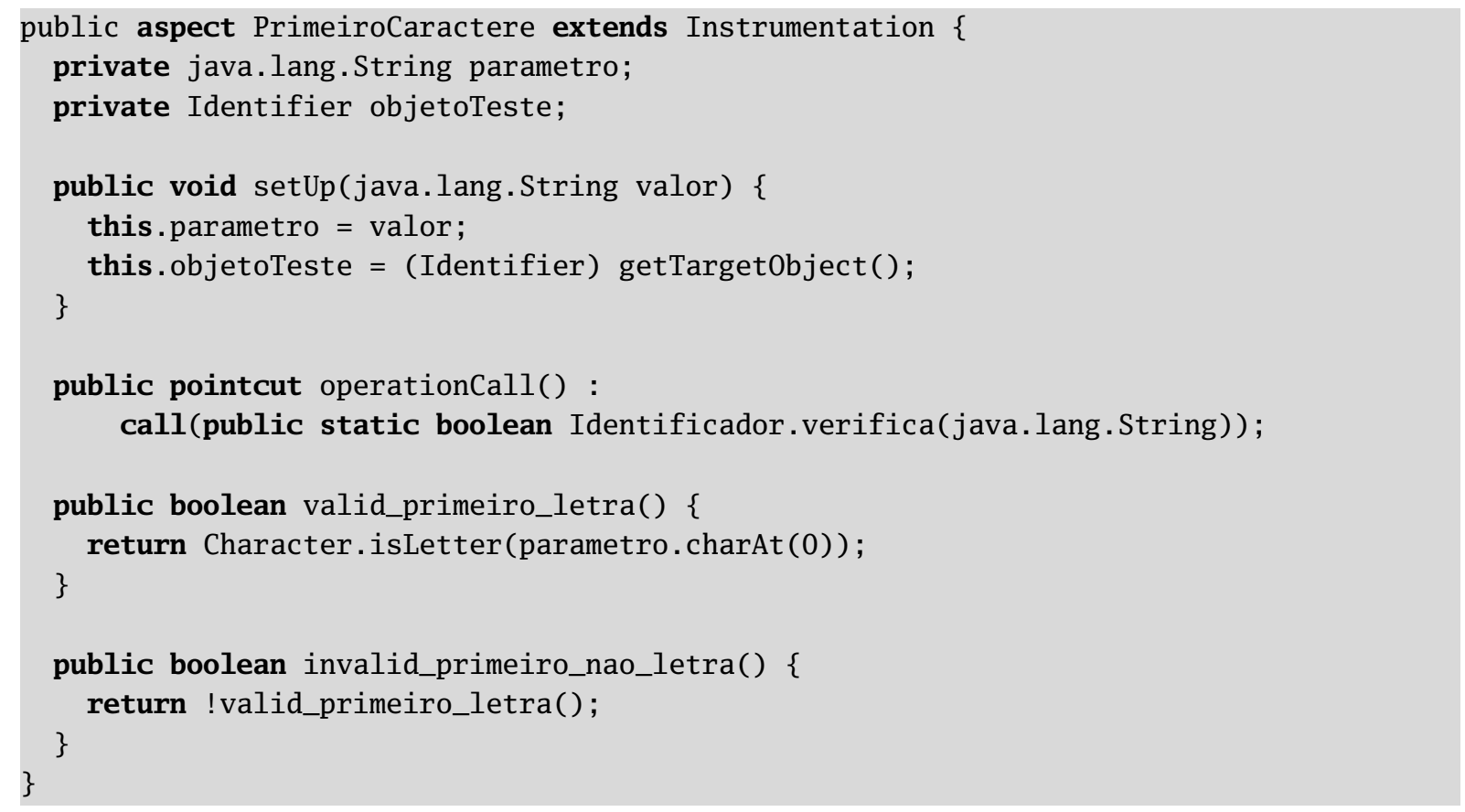

Figura 4.7: Aspecto de teste PrimeiroCaractere

As chamadas a métodos que foram armazenadas pelo adendo around do aspecto Tracing podem ser utilizadas para facilitar a criação dos requisitos de teste. $\mathrm{O}$ acesso a essa pilha de execução é feito por meio de três métodos auxiliares, descritos no Quadro 4.4. Utilizando essa API a descrição de requisitos é facilitada, sendo possível, por exemplo, elaborar um predicado que especifique que uma determinada classe de equivalência será coberta se um método específico for chamado.

O funcionamento do teste é ilustrado no diagrama de sequiência da Figura 4.8. É possível observar que quando uma operação de interesse é chamada, o aspecto de teste faz a interceptação e executa os métodos de teste implementados nesse aspecto. Os dados inerentes à execução desses métodos (classe em teste, método em teste, aspecto, método de teste, resultado) são armazenados em um repositório XML utilizando a classe TraceManager. 
Quadro 4.4: Métodos auxiliares definidos no aspecto Tracing

\begin{tabular}{|l|l|}
\hline Método & Descrição \\
\hline methodCalled(String) & $\begin{array}{l}\text { Retorna verdadeiro se um método com nome específico } \\
\text { foi chamado }\end{array}$ \\
\hline methodCalled(String, 0bject[]) & $\begin{array}{l}\text { Retorna verdadeiro se um método com nome específico } \\
\text { foi chamado com parâmetros específicos. Os valores } \\
\text { dos parâmetros são convertidos em strings para efeito de } \\
\text { comparação }\end{array}$ \\
\hline methodCalled(String, 0bject[], 0bject) & $\begin{array}{l}\text { Retorna verdadeiro se um método com nome específico } \\
\text { foi chamado com parâmetros específicos e retornou um } \\
\text { valor específico. Os valores dos parâmetros e o resultado } \\
\text { são convertidos em strings para efeito de comparação }\end{array}$ \\
\hline
\end{tabular}

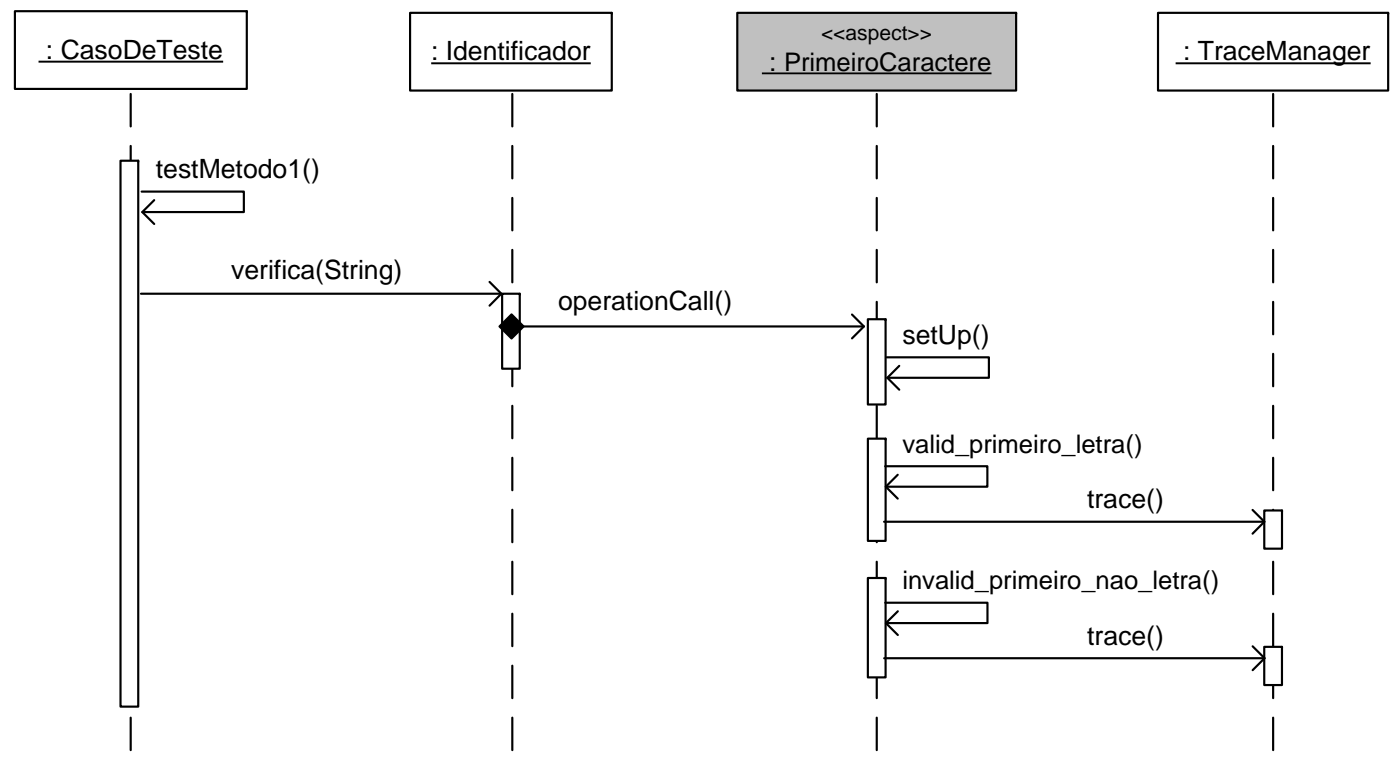

Figura 4.8: Seqüência de execução dos teste

Vale ressaltar que a J-FuT cria automaticamente o esqueleto de todos os aspectos de teste, contendo os métodos de configuração e os requisitos de teste. É necessário portanto alterar apenas o código relativo a esses últimos, implementando a lógica que descreve os predicados associados.

\subsubsection{O aspecto Inheritance}

Conforme descrito anteriormente, o aspecto Inheritance define uma nova herança para as classes que representam casos de teste. Além disso, esse aspecto efetua verificações sobre a implementação dos aspectos de teste, de forma semelhante à proposta por Rocha, Camargo e Masiero (2004), pois algumas regras devem ser obedecidas durante a implementação dos requisitos de teste.

Um exemplo do aspecto Inheritance é mostrado na Figura 4.9. Por meio da construção declare parents a nova herança é adicionada aos casos de teste. A construção declare precedence define a ordem em que os diversos aspectos de teste atuarão. É importante notar que a 
implementação desse aspecto variará de acordo com a aplicação em teste e, portanto, também é gerada automaticamente pela ferramenta.

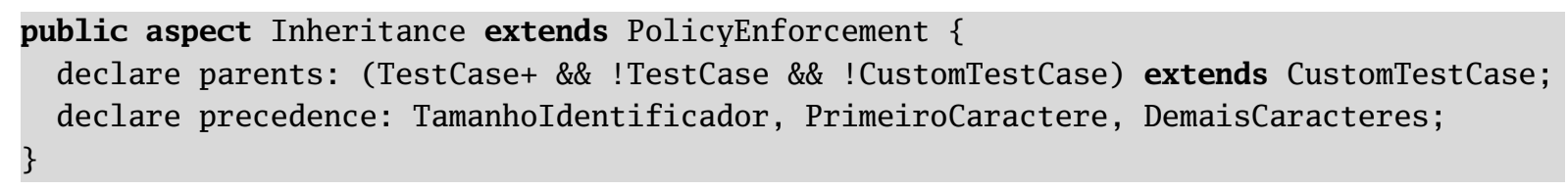

Figura 4.9: Aspecto Inheritance

Também é possível observar no código da Figura 4.9 que o aspecto Inheritance estende o aspecto PolicyEnforcement. Essa herança é necessária, pois o aspecto PolicyEnforcement é abstrato e necessita de uma instância para funcionar. Além disso, a sua implementação não está disponível e a combinação é efetuada a partir do código fonte do aspecto Inheritance.

O aspecto PolicyEnforcement implementa três verificações estáticas sobre os aspectos de teste, que estão disponíveis no aspecto Inheritance:

- Métodos de teste não devem possuir parâmetros e essa verificação inibe que enganos sejam cometidos pelo testador;

- O estado do objeto em teste não pode ser alterado dentro dos métodos de teste, pois os requisitos de teste são executados em seqüência e uma alteração de estado poderia levar a um falso-positivo no resultado dos requisitos executados posteriormente;

- Chamadas aos métodos getResult0bject e getException0bject no interior de métodos que definem pré-condições sempre retornarão nulo, pois métodos com prefixo pre são executados antes da operação ser concluída.

Na Figura 4.10 é exibido um trecho do aspecto PolicyEnforcement, que implementa a terceira verificação descrita anteriormente. O conjunto de junção invalidCall seleciona chamadas aos métodos getResult0bject e getException0bject executadas dentro de métodos de classes descendentes de Instrumentation e cujo nome seja iniciado com pre. Durante a compilação uma mensagem será exibida sempre que esse conjunto de junção for alcançado. 


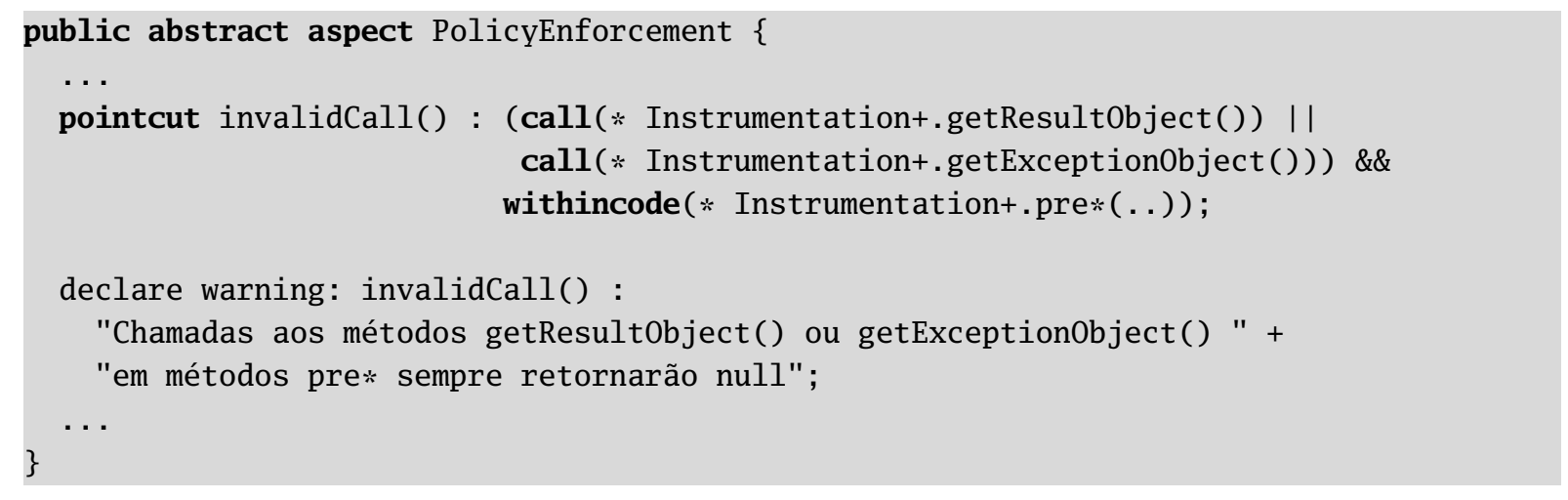

Figura 4.10: Aspecto PolicyEnforcement

\subsubsection{Registro de teste}

Conforme descrito na seção anterior, o registro de execução do programa instrumentado é feito em um arquivo XML por meio da classe TraceManager. Esse arquivo obedece a uma DTD específica, e contém os dados relativos às classes e métodos em teste, assim como requisitos de teste e os resultados de suas execuções. Esse repositório de dados é utilizado pela J-FuT como base para a análise de cobertura. Um exemplo desse arquivo é exibido na Figura 4.11.

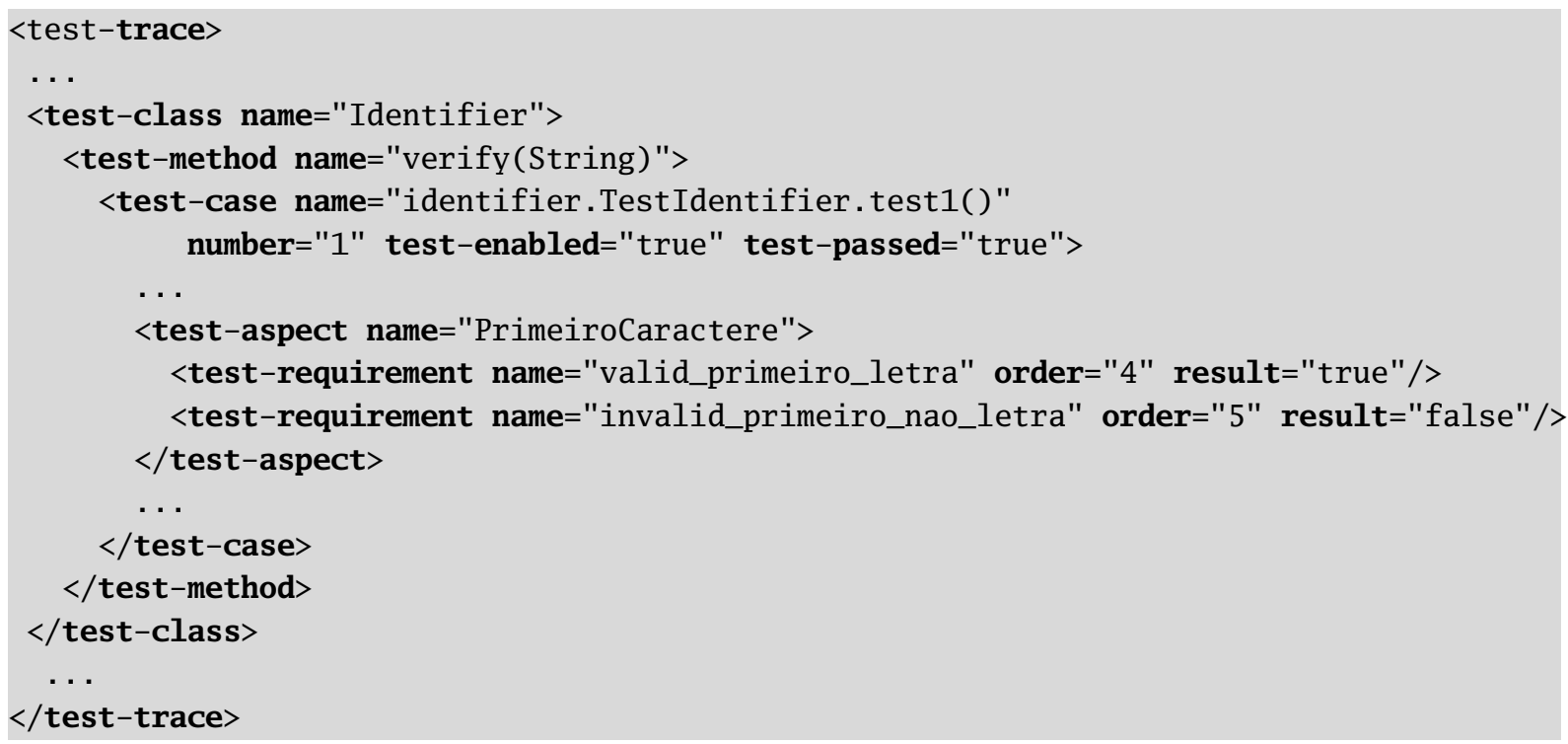

Figura 4.11: Exemplo de registro de teste

Os dados são armazenados em uma estrutura hierárquica de marcadores, na qual cada marcador específico contém suas características mapeadas em atributos. O marcador test-class descreve cada classe em teste e possui um único atributo, que armazena seu nome. As classes em teste possuem métodos em teste, ou seja, métodos que são interceptados pelos aspectos de teste. Esses métodos são representados utilizando marcadores test-method. Cada método em 
teste possui associado a ele os diversos casos de teste que o executaram, representados por marcadores test-case. Estes possuem atributos que descrevem os seus dados (nome e número) e estado (habilitado e executado com sucesso).

Cada caso de teste associado a uma classe agrupa os aspectos de teste elaborados pelo testador para testar essa classe, que são descritos por meio de marcadores test-aspect. Marcadores test-aspect contém apenas um atributo, representado o seu nome. Os requisitos de teste pertencentes a cada aspecto de teste são armazenados abaixo do marcador test-aspect correspondente, por meio de um marcador test-requirement. Os marcadores test-requirement possuem dois atributos, que representam sua ordem de execução e o resultado da avaliação do seu predicado (vide Seção 4.5.2).

Um ponto que merece destaque é que a estrutura e os dados contidos no registro independem do critério de teste funcional adotado. A análise dos dados, no entanto, leva em consideração essa informação e é explicada na Seção 4.6.

\subsection{Análise dos dados}

A análise dos dados registrados durante a execução do programa em teste permite extrair informações a respeito da cobertura dos requisitos de teste. O cálculo de cobertura é feito a partir da interpretação do arquivo de registro descrito na Seção 4.5.4, que é carregado em uma árvore DOM (Document Object Model) na memória e serve como fonte de dados para os algoritmos de cobertura. Durante o processo de análise dos dados, os resultados da execução dos requisitos de teste (atributos result dos marcadores test-requirement) são analisados, sendo possível avaliar a cobertura alcançada de acordo com o critério de teste escolhido e o total de resultados do tipo verdadeiro (true).

O critério de teste escolhido define os valores que serão utilizados para efetuar a análise de cada requisito de teste, por meio dos atributos descritos no Quadro 4.2. Assim, um determinado requisito de teste é exercitado se possui o número mínimo de casos de teste que o executam com retorno verdadeiro (true) (vide Seção 4.4.1). Um caso de teste, por sua vez, possui um número máximo de requisitos de teste que pode exercitar. Utilizando esse conceito, a J-FuT permite a quantificação da atividade de teste segundo dois tipos de cobertura, descritos no Quadro 4.5.

Quadro 4.5: Tipos de cobertura disponíveis na J-FuT

\begin{tabular}{|l|l|}
\hline Tipo de cobertura & Descrição \\
\hline Condição de entrada (aspecto) & $\begin{array}{l}\text { Uma condição de entrada de um método é coberta quando } \\
\text { todos os seus requisitos de teste (classes de equivalência, } \\
\text { pré e pós-condições e valores-limite) são exercitados. É } \\
\text { recomendável que cada aspecto de teste represente uma } \\
\text { condição de entrada }\end{array}$ \\
\hline Método & $\begin{array}{l}\text { Um método é coberto quando todas as suas condições de } \\
\text { entrada são cobertas }\end{array}$ \\
\hline
\end{tabular}


Nota-se que a cobertura sempre é avaliada a partir dos requisitos de teste, que são descritos como predicados (vide Seção 4.5.1). Esses predicados compõem os aspectos de teste que, por sua vez, representam as condições de entrada da operação em teste. Assim, a cobertura de um aspecto (condição de entrada) fornece uma medida para avaliar o quanto uma determinada restrição referente àquela operação foi satisfeita. A cobertura de um método (ou operação), por outro lado, mede a quantidade de restrições daquele método que foi cumprida.

No Quadro 4.6 é apresentado um exemplo de cobertura para um método fictício de uma classe qualquer. Para o teste desse método foram implementados três aspectos de teste, cada um com uma quantidade distinta de predicados (requisitos de teste). O cálculo de cobertura para os aspectos de teste é feito de forma direta, dividindo-se o número de requisitos cobertos pelo total de requisitos do aspecto. Para o aspecto $A_{1}$, por exemplo, tem-se a cobertura de $60 \%$, resultante do cálculo $3 \div 5$. A cobertura do método, por sua vez, é obtida a partir da divisão do somatório dos requisitos de cada aspecto $(5+4+10)$ pelo somatório dos requisitos cobertos em cada aspecto $(3+2+7)$. Assim, a cobertura de $63 \%$ é resultante da divisão $12 \div 19$.

Quadro 4.6: Exemplo de análise de cobertura

\begin{tabular}{|c|c|c|c|c|}
\hline Aspecto & Requisitos & Requisitos cobertos & Cobertura aspecto & Cobertura método \\
\hline$A_{1}$ & 5 & 3 & $60 \%$ & \multirow{2}{*}{$63 \%$} \\
\hline$A_{2}$ & 4 & 2 & $50 \%$ & \\
\hline$A_{3}$ & 10 & 7 & $70 \%$ & \\
\hline
\end{tabular}

Os requisitos de teste representam um papel importante na J-FuT e sua modelagem é exibida na Figura 4.12. Nota-se que cada requisito possui uma classe específica, derivada da classe Requirement. A instanciação dos requisitos é feita durante a análise do arquivo de registro, utilizando o padrão Factory (GAMMA et al., 2000). A classe RequirementFactory analisa o nome do requisito de teste descrito em cada marcador test-requirement e cria o objeto correspondente, contendo as características descritas em seus atributos. As referências aos casos de teste que exercitaram cada requisito são armazenadas no próprio requisito de teste e o relacionamento com a classe Criterion permite saber se o requisito foi exercitado ou não.

\subsubsection{Estratégias de análise}

Utilizando a J-FuT o testador pode configurar, por meio do atributo maxRequirementPerTest, o número máximo de requisitos de um determinado tipo que um caso de teste pode exercitar. Os requisitos do tipo classe de equivalência inválida, no entanto, possuem tratamento diferenciado. Uma regra importante adotada no projeto da ferramenta em relação a esses requisitos, e que independe do valor do atributo maxRequirementPerTest, é descrita a seguir:

Regra de análise. Independente do critério de teste adotado, casos de teste que exercitam classes de equivalência inválidas não podem exercitar classes de equivalência válidas. 


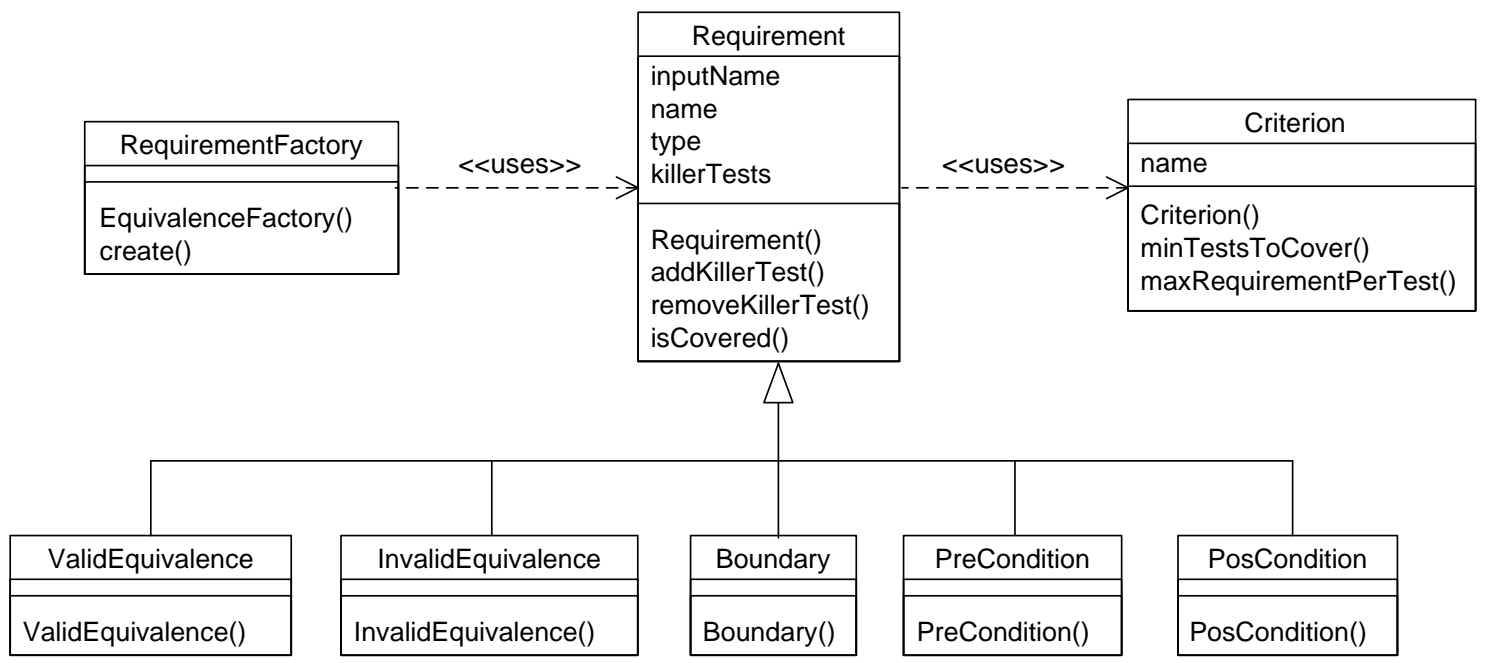

Figura 4.12: Representação dos requisitos de teste na J-FuT

Essa regra tem o objetivo de evitar o "mascaramento" de erros no programa em teste. O exercício de uma classe de equivalência inválida por um caso de teste já aponta um erro no programa e portanto esse mesmo caso de teste não pode ser utilizado para exercitar classes de equivalência válidas. É importante notar que esse conceito só se aplica às classes de equivalência. Os demais requisitos de teste (pré-condições, pós-condições e valores-limite) não estão sujeitos a essa análise especial.

No Quadro 4.7 é exibido o resumo de um registro de execução de cinco casos de teste sobre uma aplicação fictícia. As linhas contém os casos de teste e as colunas os requisitos de teste (classes de equivalência) de uma determinada operação. Nas células do mesmo quadro é possível observar as classes de equivalência que cada caso de teste exercitou. O símbolo indica que a classe de equivalência foi exercitada pelo caso de teste, enquanto o símbolo indica que a classe não foi exercitada.

Quadro 4.7: Exemplo de registro de execução

\begin{tabular}{|c|c|c|c|c|}
\hline Casos de teste & $\begin{array}{c}\text { Classe equiv. A } \\
\text { (válida) }\end{array}$ & $\begin{array}{c}\text { Classe equiv. B } \\
\text { (inválida) }\end{array}$ & $\begin{array}{c}\text { Classe equiv. C } \\
\text { (válida) }\end{array}$ & $\begin{array}{c}\text { Classe equiv. D } \\
\text { (inválida) }\end{array}$ \\
\hline Caso de teste 1 & $\mathbf{\square}$ & $\square$ & 口 & $\square$ \\
\hline Caso de teste 2 & $\square$ & 口 & $\square$ & $\mathbf{\square}$ \\
\hline Caso de teste 3 & $\mathbf{\square}$ & $\square$ & $\square$ & $\square$ \\
\hline Caso de teste 4 & $\square$ & च & च & $\square$ \\
\hline Caso de teste 5 & $\square$ & $\square$ & $\square$ & $\square$ \\
\hline
\end{tabular}

A análise de cobertura implementada na J-FuT é sensível à ordem em que os casos de teste são executados e à ordem de interceptação dos aspectos (e conseqüente execução dos requisitos de teste). A cobertura depende da quantidade de vezes que cada requisito foi exercitado e do critério adotado, pois consideram-se os atributos maxRequirementPerTest e minTestsToCover de cada requisito de teste (vide Quadro 4.2). Observando o Quadro 4.7, nota-se, por exemplo, que a classe de equivalência $\mathbf{A}$ foi exercitada pelos casos de teste $\mathbf{1}, \mathbf{3}$ e $\mathbf{5}$ e o caso de teste $\mathbf{1}$ exercitou as classes de equivalência $\mathbf{A}$ e $\mathbf{C}$. 
A partir da análise do Quadro 4.7, e considerando a definição do critério Particionamento de Equivalência, evidenciam-se dois fatos importantes:

(i) O caso de teste 2 exercita duas classes de equivalência inválidas (B e D), o que não é permitido pelo critério, em que o atributo maxRequirementPerTest possui valor 1 (vide Figura 4.3);

(ii) O caso de teste 4 exercita uma classe de equivalência inválida (B) e outra válida (C), o que também não deve ser permitido, conforme descrito na regra de análise.

A ferramenta trata o problema descrito em (ii) considerando as classes de equivalência válidas como não-exercitadas (regra de análise), e oferece estratégias de análise que buscam contornar a situação descrita em (i). Uma estratégia de análise define a forma como os dados resultantes da execução do teste são analisados durante o cálculo da cobertura. A J-FuT fornece quatro tipos de análise, implementados conforme o padrão Strategy (GAMMA et al., 2000) e apresentados na Figura 4.13.

A classe TestTable armazena a representação do registro de teste (semelhante ao Quadro 4.7) e é utilizada pela estratégia de teste para a análise dos dados. As estratégias correspondem às classes descendentes de TestTableStrategy e implementam o método applyStrategy para definir o algoritmo de análise. Assim, de acordo com a estratégia escolhida pelo testador, a classe que a implementa é instanciada e utilizada.

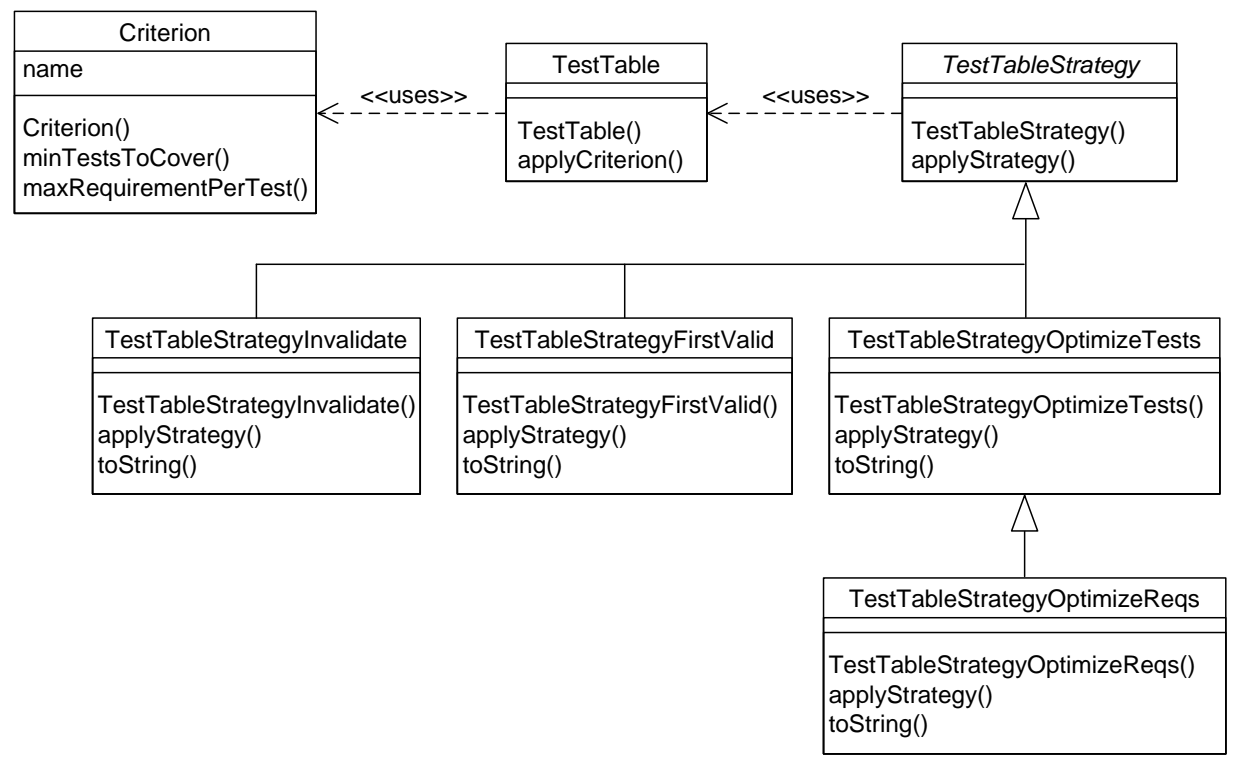

Figura 4.13: Estratégias de análise de dados

As quatro estratégias implementadas na ferramenta são descritas a seguir. Para facilitar o entendimento, nos exemplos a seguir é utilizado o critério Equivalence Partition descrito na Figura 4.3 e o registro de teste do Quadro 4.7. Os conceitos exemplificados aplicam-se a quaisquer critérios ou requisitos de teste. 


\subsubsection{Estratégia "invalidar casos de teste"}

A primeira estratégia, representada pela classe TestTableStrategyInvalidate, estabelece que casos de teste que excedem o máximo de requisitos de um tipo que podem exercitar (descritos pelos atributos maxRequirementPerTest) são invalidados e desconsiderados na análise de cobertura. Dentre as estratégias implementadas na J-FuT esta é a mais simples, e pode ser adotada para avaliar o conjunto de casos de teste disponível de forma mais conservadora, independente da ordem de execução dos casos de teste ou aspectos de teste.

Utilizando essa estratégia sobre os dados do Quadro 4.7, obtém-se o Quadro 4.8, no qual os itens que sofreram alteração encontram-se circulados. É possível notar que o caso de teste 2 foi invalidado, pois exercita mais classes de equivalência inválidas (duas) que o permitido (uma). Além disso, é importante frisar que o exercício da classe de equivalência válida $\mathrm{C}$ pelo caso de teste 4 foi desconsiderado, uma vez que este exercita uma classe de equivalência inválida (B). Assim, apenas as classes de equivalência A, B e C são cobertas, evidenciando-se a necessidade de construção de novos casos de teste para cobrir a classe de equivalência $\mathbf{D}$.

Quadro 4.8: Aplicação da estratégia "invalidar casos de teste"

\begin{tabular}{|c|c|c|c|c|}
\hline Casos de teste & $\begin{array}{c}\text { Classe equiv. A } \\
\text { (válida) }\end{array}$ & $\begin{array}{l}\text { Classe equiv. B } \\
\text { (inválida) }\end{array}$ & $\begin{array}{l}\text { Classe equiv. C } \\
\text { (válida) }\end{array}$ & $\begin{array}{c}\text { Classe equiv. D } \\
\text { (inválida) }\end{array}$ \\
\hline Caso de teste 1 & $\mathbf{a}$ & $\square$ & $\mathbf{\square}$ & $\square$ \\
\hline Caso de teste 2 & $\square$ & (D) & $\square$ & (D) \\
\hline Caso de teste 3 & $\square$ & $\square$ & $\square$ & $\square$ \\
\hline Caso de teste 4 & $\square$ & $\mathbf{\square}$ & (1)) & $\square$ \\
\hline Caso de teste 5 & $\mathbf{\square}$ & $\square$ & $\square$ & $\square$ \\
\hline Total de exercícios & 3 & 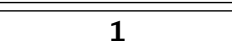 & $\overline{1}$ & $\overline{0}$ \\
\hline Requisito coberto? & $\operatorname{sim}$ & $\operatorname{sim}$ & $\operatorname{sim}$ & não \\
\hline
\end{tabular}

\subsubsection{Estratégia "primeiros válidos"}

Nesta estratégia são considerados os requisitos de teste exercitados por um caso de teste até que este atinja o máximo de requisitos que pode exercitar (atributo maxRequirementPerTest), quando é então invalidado. Os requisitos de teste são lidos da esquerda para direita e portanto a sua ordem de implementação (a precedência dos aspectos e a ordem em que cada requisito foi codificado no aspecto) tem influência direta sobre o cálculo da cobertura. Assim, o uso dessa estratégia é recomendado quando deseja-se preservar a ordem em que os casos de teste e aspectos de teste são executados. Essa estratégia é representada pela classe TestTableStrategyFirstValid.

No Quadro 4.9 são exibidos os novos dados (derivados do Quadro 4.7) após a aplicação dessa estratégia. Como é possível notar, o exercício da classe de equivalência $\mathbf{D}$ pelo caso de teste 2 foi desconsiderado durante a análise, uma vez que esse caso de teste atingiu o limite de classes inválidas que pode exercitar ao exercitar a classe de equivalência B. 
Quadro 4.9: Aplicação da estratégia "primeiros válidos"

\begin{tabular}{|c|c|c|c|c|}
\hline Casos de teste & $\begin{array}{c}\text { Classe equiv. A } \\
\text { (válida) }\end{array}$ & $\begin{array}{l}\text { Classe equiv. B } \\
\text { (inválida) }\end{array}$ & $\begin{array}{c}\text { Classe equiv. C } \\
\text { (válida) }\end{array}$ & $\begin{array}{l}\text { Classe equiv. D } \\
\text { (inválida) }\end{array}$ \\
\hline Caso de teste 1 & $\mathbf{\square}$ & $\square$ & $\mathbf{\square}$ & $\square$ \\
\hline Caso de teste 2 & $\square$ & $\mathbf{\square}$ & $\square$ & (1) \\
\hline Caso de teste 3 & $\square$ & $\square$ & $\square$ & $\square$ \\
\hline Caso de teste 4 & $\square$ & $\square$ & (1) & $\square$ \\
\hline Caso de teste 5 & $\mathbf{\square}$ & $\square$ & $\square$ & $\square$ \\
\hline Total de exercícios & 3 & 2 & 1 & $\overline{0}$ \\
\hline Requisito coberto? & $\operatorname{sim}$ & sim & sim & não \\
\hline
\end{tabular}

Além disso, de forma idêntica à descrita anteriormente (aplicação da regra de análise), o exercício da classe de equivalência $\mathbf{C}$ pelo caso de teste $\mathbf{4}$ foi desconsiderado. Utilizando essa estratégia, novamente as classes de equivalência A, B e C são cobertas e ainda são necessários casos de teste para cobrir a classe de equivalência $\mathbf{D}$.

\subsubsection{Estratégia "otimizar casos de teste"}

Essa estratégia, descrita na classe TestTableStrategy0ptimizeTests, busca rearrumar os dados contidos no registro de teste visando a aumentar a sua cobertura. A otimização leva em consideração o fato de que uma reorganização dos requisitos exercitados pelos diversos casos de teste, preservando alguns exercícios e descartando outros, pode levar a uma nova (maior) cobertura. Nessa reorganização a prioridade é dada aos casos de teste, ou seja, tenta-se fazer com que cada caso de teste exercite o máximo de requisitos possível até atingir seu limite (atributo maxRequirementPerTest), quando é invalidado.

Considerando-se que nessa estratégia cada caso de teste exercita o maior número de requisitos possível, seu uso é recomendado em conjunto com critérios nos quais os requisitos não necessitem de múltiplos exercícios (a partir de diversos casos de teste) para serem considerados cobertos. Além disso, é importante notar que essa estratégia independe da ordem de execução dos casos de teste ou aspectos de teste.

O algoritmo implementado é apresentado na Figura 4.14. O primeiro passo consiste na aplicação da regra de análise, como descrito anteriormente, por meio do procedimento RemoveReferenciasValidas. A seguir os casos de teste são colocados em uma lista de prioridade $(T)$, na qual casos de teste que exercitam menos classes de equivalência inválidas têm prioridade. Os requisitos de teste também são organizados em uma outra lista de prioridade $(R)$, na qual requisitos que contêm menos casos de teste que os exercitam têm prioridade. É importante perceber que os demais tipos de requisitos de teste (classes de equivalência válidas, pré-condições, pós-condições e valores-limite) não têm influência sobre o algoritmo e portanto não definem a prioridade dos elementos nas filas. Requisitos desses tipos são colocados no fim da fila. 


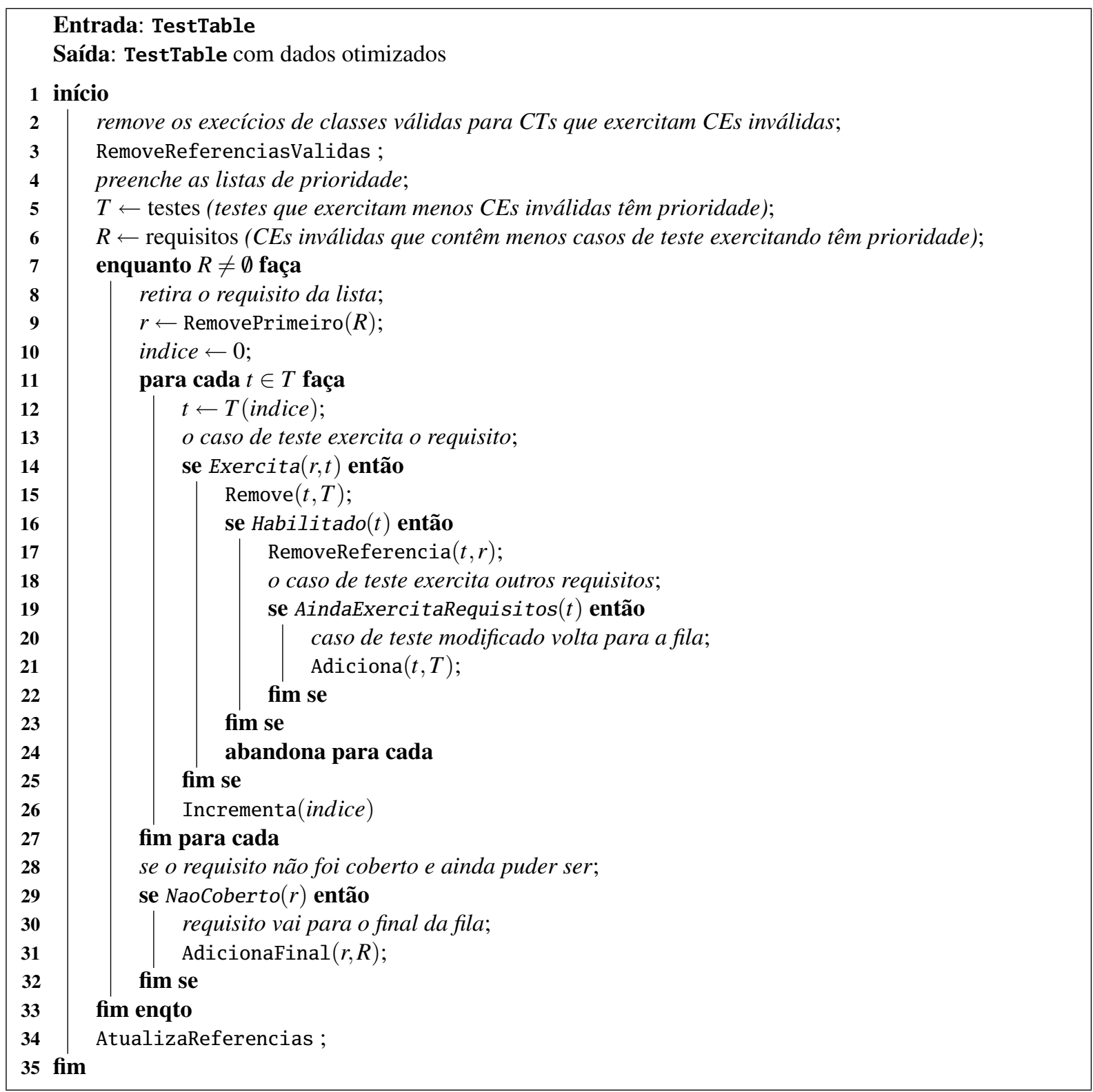

Figura 4.14: Algoritmo para otimização dos casos de teste

Após o preenchimento das listas, os requisitos de teste são retirados um a um, de acordo com sua prioridade, da lista correspondente. Para cada requisito $r$ retirado da lista $R$, procura-se seqüencialmente na lista de testes $T$ um caso de teste $t$ que o exercite, e esse é retirado da lista. Se o caso de teste $t$ está habilitado, sua referência ao requisito $r$ é desfeita e armazenada para uso posterior, indicando que $t$ exercita $r$ (procedimento RemoveReferencia). Se $t$ ainda pode exercitar outros requisitos, volta para a fila. É importante notar que a prioridade de $t$ foi alterada e portanto sua posição na fila muda.

Levando em consideração que um caso de teste que exercita esse requisito foi encontrado, a procura por casos de teste é cancelada. Se o requisito $r$ ainda não foi coberto e existem casos de teste que o exercitam, $r$ vai para o final da lista $R$ (pois a prioridade é dada aos casos de teste). $\mathrm{O}$ processo se repete até que a lista $R$ esteja vazia. 
Quadro 4.10: Aplicação da estratégia "otimizar casos de teste"

\begin{tabular}{|c|c|c|c|c|}
\hline Casos de teste & $\begin{array}{c}\text { Classe equiv. A } \\
\text { (válida) }\end{array}$ & $\begin{array}{l}\text { Classe equiv. B } \\
\text { (inválida) }\end{array}$ & $\begin{array}{c}\text { Classe equiv. C } \\
\text { (válida) }\end{array}$ & $\begin{array}{l}\text { Classe equiv. D } \\
\text { (inválida) }\end{array}$ \\
\hline Caso de teste 1 & $\mathbf{\square}$ & $\square$ & [ & $\square$ \\
\hline Caso de teste 2 & $\square$ & (1) & $\square$ & $\mathbf{\square}$ \\
\hline Caso de teste 3 & $\mathbf{\square}$ & $\square$ & $\square$ & $\square$ \\
\hline Caso de teste 4 & $\square$ & 口 & (1) & $\square$ \\
\hline Caso de teste 5 & $\mathbf{\square}$ & $\square$ & $\square$ & $\square$ \\
\hline Total de exercícios & 3 & 1 & 1 & 1 \\
\hline Requisito coberto? & sim & sim & sim & sim \\
\hline
\end{tabular}

O resultado da aplicação dessa estratégia é exibido no Quadro 4.10. Como é possível observar, o exercício da classe de equivalência $\mathbf{C}$ pelo caso de teste $\mathbf{4}$ foi desconsiderado mais uma vez em função da regra de análise. Considerando que o exemplo abordado utiliza o critério Particionamento de Equivalência e que ele estabelece que apenas uma classe de equivalência inválida seja exercitada por caso de teste, um remanejamento dos exercícios foi executado pelo algoritmo. O exercício da classe de equivalência B pelo caso de teste 2 foi desconsiderado pois essa mesma classe de equivalência já é exercitada pelo caso de teste 4. Assim, o caso de teste 2 passa a exercitar apenas a classe de equivalência $\mathbf{D}$, o que resulta em uma cobertura de todos os requisitos (classes de equivalência A, B, C e D).

\subsubsection{Estratégia "otimizar requisitos de teste"}

Essa estratégia, descrita na classe TestTableStrategy0ptimizeReqs, é bastante semelhante à descrita na Seção 4.6.1.3. A implementação, no entanto, foca na otimização dos requisitos de teste e não mais dos casos de teste. Nessa abordagem cada requisito de teste será exercitado pelo máximo de casos de teste possível. O algoritmo implementado por essa estratégia é praticamente idêntico ao descrito anteriormente, diferindo em apenas três linhas. O novo algoritmo é apresentado na Figura 4.15, na qual o símbolo marca as linhas do algoritmo original que foram alteradas.

A primeira alteração, na linha 21, adiciona o caso de teste $t$ ao final da lista de casos de teste (e não mais de acordo com sua prioridade) depois que esse é processado. Isso ocorre porque a prioridade é dada aos requisitos de teste e dessa forma o próximo caso de teste da lista $T$ deve ser avaliado para o mesmo requisito $r$. Segundo a mesma premissa, na linha 24 o comando abandona para cada foi removido. Por fim, na linha 31, o requisito $r$ é adicionado à lista de acordo com sua prioridade (e não mais ao final da fila) pois um novo requisito da fila $R$ só deve ser avaliado depois que $r$ for exercitado por todos os casos de teste possíveis.

Em razão do número de exercícios do exemplo, a aplicação da estratégia sobre esses dados origina um quadro idêntico ao obtido na Seção 4.6.1.3. De forma complementar à estratégia anterior, essa estratégia tem seu uso indicado em critérios nos quais um requisito de teste deve ser exercitado mais de uma vez para ser coberto. 


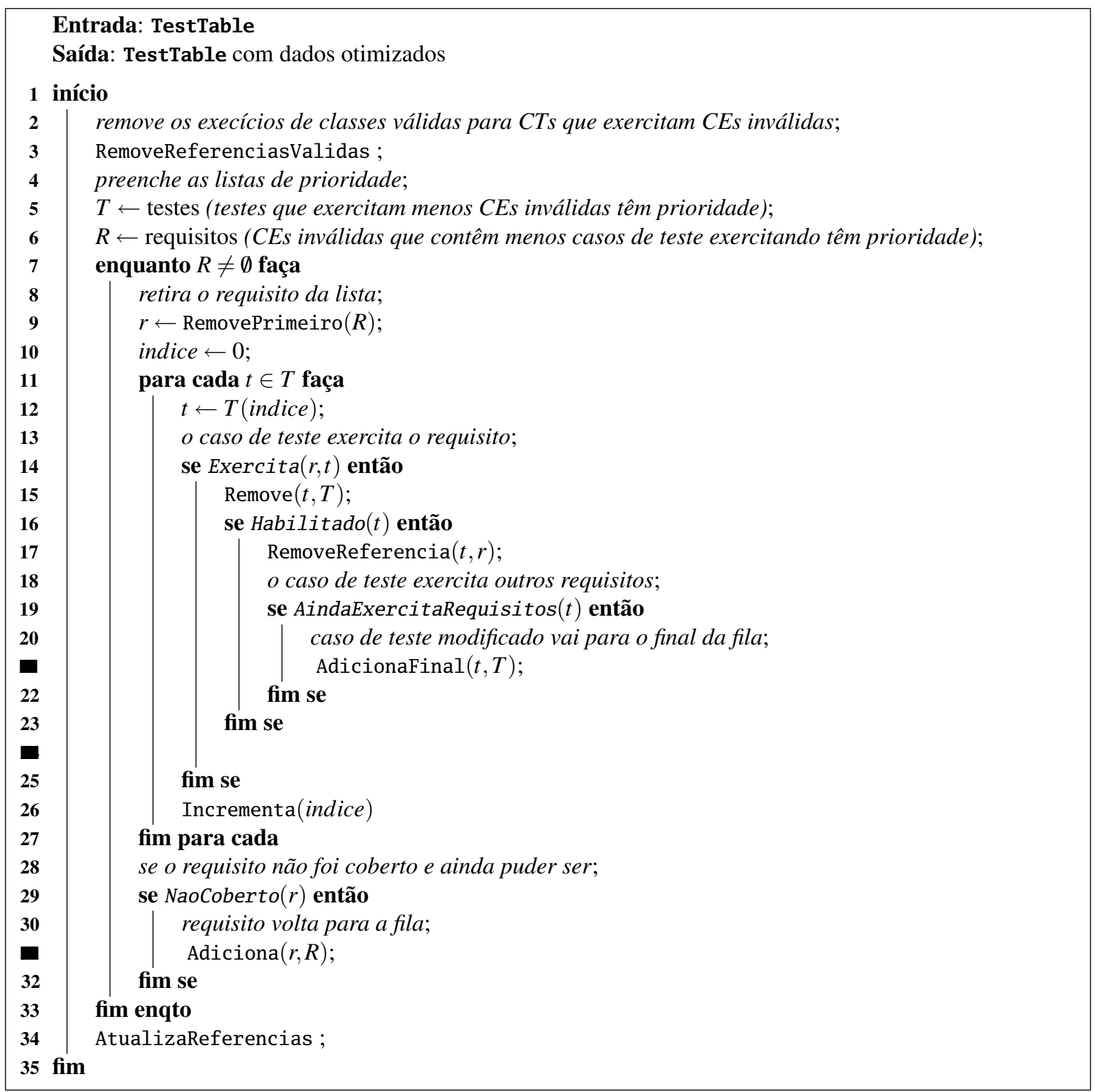

Figura 4.15: Algoritmo para otimização dos requisitos de teste

A estratégia de análise a ser aplicada durante o teste de uma aplicação é escolhida pelo testador durante a sessão de teste. A estratégia padrão utilizada pela ferramenta é a "invalidar casos de teste", a mais conservadora dentre as estratégias presentes. Como essa estratégia invalida os casos de teste que exercitam mais requisitos que o permitido, ela restringe o potencial de atuação dos casos de teste e não permite avaliar a cobertura máxima possível. Se esse tipo de análise for necessário, o testador deve utilizar alguma estratégia mais complexa como, por exemplo, a estratégia "otimizar casos de teste". 


\subsection{Considerações finais}

Neste capítulo foi apresentada a ferramenta J-FuT e seus conceitos principais. Foram descritas a sua arquitetura e modelagem, e a utilização de aspectos para apoio ao teste funcional. Além disso discutiu-se como a J-FuT efetua a análise de cobertura e os algoritmos utilizados para exame dos dados registrados durante o teste.

Para implementação da J-FuT foram programadas aproximadamente seis mil linhas de código, distribuídas em oitenta e seis classes e quatro aspectos, contemplando dezesseis pacotes que estão organizados segundo a sua funcionalidade. Distinguem-se pacotes referentes à interface gráfica, instrumentação e critérios de teste, além de pacotes utilitários.

No próximo capítulo apresentam-se os exemplos utilizados durante o projeto da J-FuT, com o objetivo de validar a ferramenta e demonstrar como o teste de uma aplicação é realizado. 


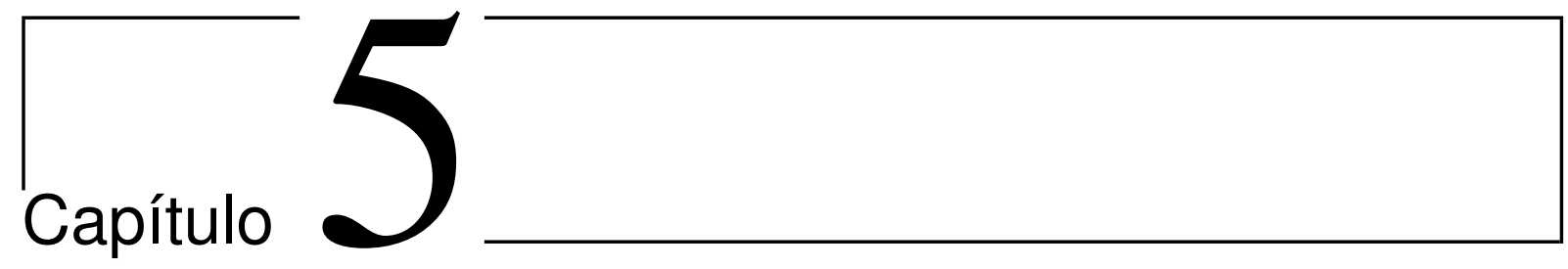

\section{Validação e uso da ferramenta J-FuT}

\subsection{Considerações iniciais}

$\mathrm{N}$ este capítulo são apresentados os testes da ferramenta J-FuT e um exemplo de uso. São descritos de forma breve os exemplos utilizados durante o desenvolvimento da ferramenta e atenção especial é dada ao teste da aplicação VendingMachine, que é apresentado em detalhes. Este capítulo encontra-se organizado da seguinte forma: inicialmente, na Seção 5.2, são descritos os exemplos utilizados durante o desenvolvimento da ferramenta J-FuT. Na Seção 5.3 é apresentada a aplicação VendingMachine, contemplando sua especificação, implementação e requisitos de teste. Por fim, na Seção 5.4 são apresentadas as etapas do processo utilizado para o teste dessa aplicação, utilizando a J-FuT.

\subsection{Testes executados durante o desenvolvimento da ferramenta J-FuT}

Durante a implementação da ferramenta J-FuT foram testados alguns programas simples e outros com maior complexidade. O principal programa utilizado durante o desenvolvimento da J-FuT foi o Ponto de Venda (PDV), proposto por Larman (2000), sobre o qual foi aplicado o critério Particionamento de Equivalência (ROCHA et al., 2004). Além disso foram efetuados alguns testes do pacote gnu. regexp (BIGGS, 2001), uma implementação gratuita de expressões regulares para a linguagem Java, visando a analisar o comportamento da ferramenta em um exemplo real.

Além dos exemplos descritos anteriormente, um exemplo didático foi elaborado e aplicado com os alunos da disciplina Tópicos Avançados em Engenharia de Software do curso de pós- 
graduação do ICMC/USP. O sistema VendingMachine foi implementado e testado pelos alunos utilizando a J-FuT. O exercício aplicado apontou diversas sugestões para a ferramenta, tanto no que se refere à interface quanto à análise dos dados de teste. Essas sugestões foram incorporadas à ferramenta e um novo teste foi executado, a partir da nova versão da J-FuT.

\subsection{A aplicação VendingMachine}

A aplicação VendingMachine simula o funcionamento de uma máquina de venda que permite a compra de diversos produtos por meio de uma sequiência de interação. Sua especificação e implementação são descritas nas próximas seções.

\subsubsection{Especificação da aplicação VendingMachine}

A companhia Tabajara possui em sua sala de lazer uma máquina de café para seus funcionários. Todos os dias pela manhã a máquina é abastecida com todos os ingredientes necessários para preparar os diversos tipos de café. A máquina aceita apenas moedas de $\mathrm{R} \$ 0,25, \mathrm{R} \$ 0,50$ e $\mathrm{R} \$ 1,00$, dispõe de quatro ingredientes (Ingredient) e prepara quatro tipos de café (Recipe). No Quadro 5.1 encontram-se os ingredientes disponíveis na VendingMachine e no Quadro 5.2 suas receitas.

Quadro 5.1: Ingredientes disponíveis na VendingMachine

\begin{tabular}{|l|c|}
\hline Nome & Quantidade inicial diária (unidade) \\
\hline Pó de café & 2000 \\
\hline Água & 4000 \\
\hline Açúcar & 500 \\
\hline Leite em pó & 1000 \\
\hline
\end{tabular}

Quadro 5.2: Receitas disponíveis na VendingMachine

\begin{tabular}{|l|c|l|}
\hline Receita & \multicolumn{1}{|c|}{ Valor (R\$) } & \multicolumn{1}{l|}{ Ingredientes (unidade) } \\
\hline Café Preto sem açúcar & 0,50 & Café: 20; água: 50 \\
\hline Café Preto com açúcar & 0,75 & Café: 20; água: 50; açúcar: 5 \\
\hline Café com leite sem açúcar & 0,75 & Café: 20; água: 30; leite: 20 \\
\hline Café com leite com açúcar & 1,00 & Café: 20; água: 30; leite: 20; açúcar: 5 \\
\hline
\end{tabular}

O funcionamento da máquina é descrito a seguir:

1. O usuário coloca as moedas uma a uma (método void insertCoin(int)). Não há restrição da quantidade de moedas a serem depositadas;

2. A máquina exibe o menu com o que é possível comprar de acordo com o total de dinheiro fornecido e com os ingredientes disponíveis (método Vector getRecipes()); 
3. O usuário escolhe a receita. A máquina prepara a receita, diminuindo os ingredientes do estoque e recalculando o saldo (método Recipe makeRecipe(String)).

4. Após entregar a receita, o menu é atualizado de acordo com o saldo restante e com os ingredientes disponíveis. Neste momento o usuário pode adicionar moedas (método void insertCoin(int)), escolher uma receita (método Recipe makeRecipe(String)) ou retornar o troco disponível (método int returnChange());

5. Se o usuário não desejar mais solicitar receitas, ele deve pressionar o botão "troco" e a máquina devolverá o saldo disponível (método int returnChange()).

Observação: Deve-se considerar que (i) há sempre copos disponíveis para uso e (ii) há sempre moedas suficientes para troco.

\subsubsection{Implementação e requisitos de teste para a aplicação Ven- dingMachine}

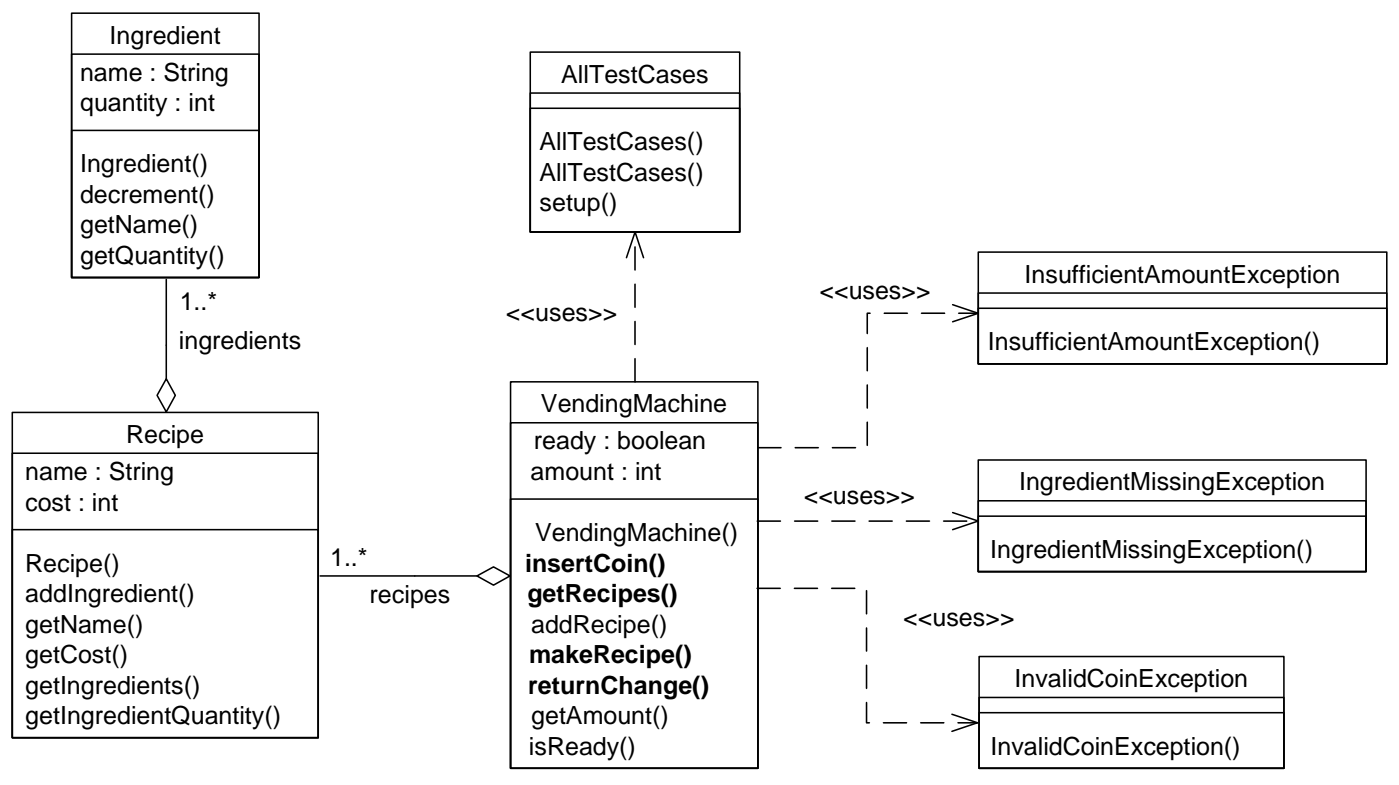

Figura 5.1: Classes da aplicação VendingMachine

No diagrama da Figura 5.1 encontram-se as classes da aplicação VendingMachine, implementada a partir dos esqueletos descritos no Apêndice A. Como as principais funcionalidades estão implementadas na classe VendingMachine e em suas quatro operações, insertCoin, getRecipes, makeRecipe e returnChange, apenas elas foram abordadas no exemplo de uso da ferramenta. A partir da especificação da VendingMachine, foram derivados quarenta e três requisitos de teste, contemplando as quatro operações. Os requisitos de teste para essas operações foram distinguidos em classes de equivalência e valores-limite e são apresentados nos Quadros $5.3,5.4,5.5$ e 5.6 . 
No Quadro 5.3 é possível observar os requisitos de teste para a operação void insertCoin(int). Essa operação possui uma única condição de entrada, referente ao valor da moeda inserida, que deve ser 25, 50 ou 100 centavos. Nesse sentido, esses três valores constituem entradas válidas para a operação (classes de equivalência válidas), enquanto que valores diferentes constituem entradas inválidas (classes de equivalência válidas). Além disso, é importante testar valores próximos aos três valores válidos (valores-limite).

Quadro 5.3: Requisitos de teste para o método void insertCoin(int)

\begin{tabular}{|l|l|l|}
\hline Condições de entrada & Classes de equivalência válidas & Classes de equivalência inválidas \\
\hline \multirow{5}{*}{ Valor da moeda } & Valor $=25$ & \\
\cline { 2 - 2 } & Valor $=50$ & \\
\cline { 2 - 3 } & Valor $=100$ & \\
& Valores-limite & \\
& Valor moeda $=0$ & $\mathrm{e} \neq 100$ \\
\cline { 2 - 3 } & Valor moeda $=24$ & \\
\cline { 2 - 3 } & Valor moeda $=26$ & \\
\cline { 2 - 3 } & Valor moeda $=49$ & \\
\cline { 2 - 3 } & Valor moeda $=51$ & \\
\cline { 2 - 3 } & Valor moeda $=99$ \\
\cline { 2 - 3 } & Valor moeda $=101$ \\
\hline
\end{tabular}

Quadro 5.4: Requisitos de teste para o método Vector getRecipes()

\begin{tabular}{|l|l|l|}
\hline Condições de entrada & Classes de equivalência válidas & Classes de equivalência inválidas \\
\hline \multirow{5}{*}{ Saldo } & Saldo $\geq 50$ & Saldo $<50$ \\
& Valores-limite & \\
\hline & Saldo $=0$ & \\
\cline { 2 - 2 } & Saldo $=25$ & \\
\cline { 2 - 2 } & Saldo $=50$ & \\
\cline { 2 - 2 } & Saldo $=75$ & \\
\cline { 2 - 2 } & Saldo $=100$ & \\
\hline
\end{tabular}

A partir da definição dos requisitos, foi elaborado um conjunto inicial de casos de teste para o teste das operações da classe VendingMachine, contendo vinte e dois casos de teste. Os casos de teste foram codificados na classe AllTestCases, de acordo com o formato do JUnit, e posteriormente utilizada pela ferramenta J-FuT. Na próxima seção aborda-se o teste da VendingMachine utilizando a ferramenta.

\subsection{Teste da aplicação VendingMachine}

\subsubsection{Visão geral do processo de teste utilizando a J-FuT}

O teste utilizando a J-FuT envolve quatro etapas, como mostrado na Figura 5.2. Na primeira etapa é criado o projeto de teste, que contém informações referentes às classes e operações em teste, assim como os requisitos de teste. A seguir procede-se a edição dos aspectos de teste, em que são implementados, em cada aspecto, os predicados referentes aos diversos requisitos 
Quadro 5.5: Requisitos de teste para o método Recipe makeRecipe(String)

\begin{tabular}{|c|c|c|}
\hline Condições de entrada & Classes de equivalência válidas & Classes de equivalência inválidas \\
\hline \multirow{11}{*}{ Estoque } & $\begin{array}{l}\text { Quantidade suficiente para todos } \\
\text { ingredientes }\end{array}$ & $\begin{array}{l}\text { Quantidade insuficiente para algum } \\
\text { ingrediente }\end{array}$ \\
\hline & \multicolumn{2}{|l|}{ Valores-limite } \\
\hline & \multicolumn{2}{|l|}{ Quantidade de café $=0$} \\
\hline & \multicolumn{2}{|l|}{ Quantidade de café $=20$} \\
\hline & \multicolumn{2}{|l|}{ Quantidade de água $=0$} \\
\hline & \multicolumn{2}{|l|}{ Quantidade de água $=30$} \\
\hline & \multicolumn{2}{|l|}{ Quantidade de água $=50$} \\
\hline & \multicolumn{2}{|l|}{ Quantidade de açúcar $=0$} \\
\hline & \multicolumn{2}{|l|}{ Quantidade de açúcar $=5$} \\
\hline & \multicolumn{2}{|l|}{ Quantidade de leite $=0$} \\
\hline & \multicolumn{2}{|l|}{ Quantidade de leite $=20$} \\
\hline \multirow{3}{*}{ Valor da receita } & Valor $\leq$ saldo & Valor $>$ saldo \\
\hline & \multicolumn{2}{|l|}{ Valores-limite } \\
\hline & \multicolumn{2}{|l|}{ Valor $=$ saldo } \\
\hline \multirow{6}{*}{ Nome da receita } & Receita existe & Receita não existe \\
\hline & \multicolumn{2}{|l|}{ Valores-limite } \\
\hline & \multicolumn{2}{|l|}{ Receita = "Café preto sem açúcar" } \\
\hline & \multicolumn{2}{|l|}{ Receita = "Café preto com açúcar" } \\
\hline & \multicolumn{2}{|c|}{ Receita = "Café com leite sem açúcar" } \\
\hline & \multicolumn{2}{|c|}{ Receita = "Café com leite com açúcar" } \\
\hline
\end{tabular}

Quadro 5.6: Requisitos de teste para o método int returnChange()

\begin{tabular}{|l|l|l|}
\hline Condições de entrada & Classes de equivalência válidas & \multicolumn{1}{c|}{ Classes de equivalência inválidas } \\
\hline \multirow{4}{*}{ Troco } & Troco $\geq 0$ & \\
& Valores-limite \\
\cline { 2 - 2 } & Troco $=0$ \\
\cline { 2 - 2 } & Troco $=25$ \\
\cline { 2 - 2 } & Troco $=50$ \\
\cline { 2 - 2 } & Troco $=100$ \\
\hline
\end{tabular}

de teste. Na próxima etapa os casos de teste (criados antes do uso da ferramenta) são executados. Por fim, na última etapa, avalia-se a cobertura alcançada. Se a cobertura alcançada não for suficiente, devem ser elaborados novos casos de teste e as duas últimas etapas devem ser repetidas.

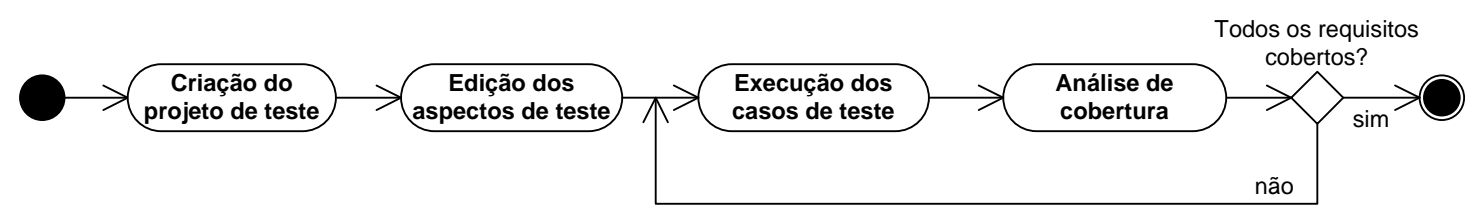

Figura 5.2: Processo de teste utilizando a J-FuT

\subsubsection{Criação do projeto de teste}

Os quarenta e três requisitos derivados anteriormente foram mapeados em seis condições de entrada e, de posse dessas informações, juntamente com os casos de teste, o projeto de teste 
foi criado na J-FuT. A criação de um projeto de teste consiste em três etapas, guiadas por um assistente, nas quais o testador preenche as informações necessárias ao teste da aplicação.

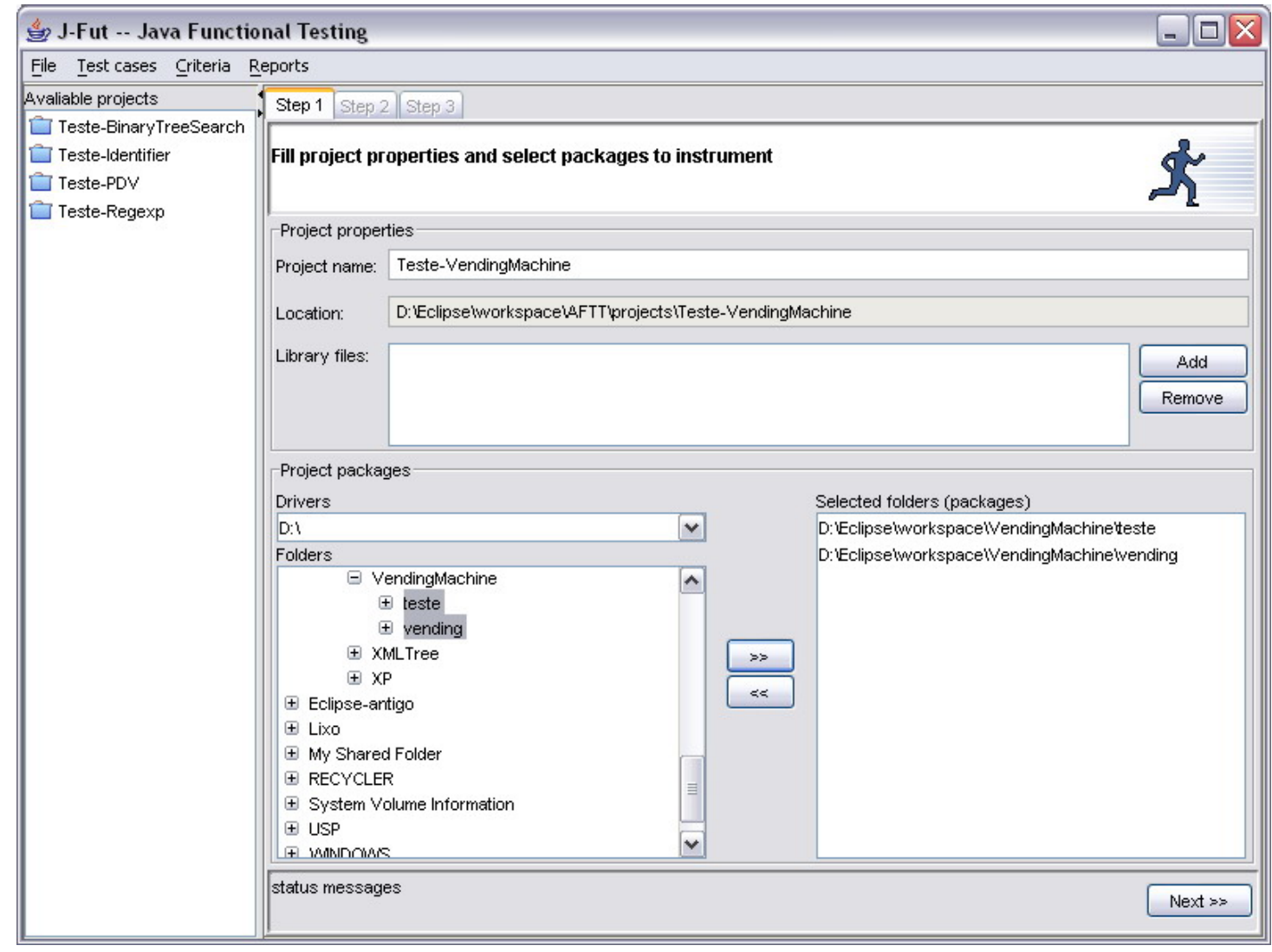

Figura 5.3: Primeira etapa para criação de um projeto de teste

Na Figura 5.3 é exibida a primeira tela do assistente para criação de projetos. Além dos espaços reservados às informações que devem ser preenchidas pelo testador, do lado esquerdo existe uma lista contendo todos os projetos cadastrados, que podem ser abertos a qualquer instante. Nesta etapa o testador deve indicar o nome do projeto, as bibliotecas necessárias para compilá-lo e os pacotes que serão testados (os pacotes são representados por diretórios).

Após preencher as informações necessárias e pressionar o botão "Next", uma nova tela é exibida (Figura 5.4). Nessa etapa devem ser escolhidas as operações que serão testadas e criados os aspectos de teste. Na parte superior dessa tela existe uma caixa de seleção que permite ao testador indicar qual é a classe que contém os casos de teste que serão utilizados (classe AllTestCases). A primeira lista (canto superior esquerdo) contém todas as classes ${ }^{1}$ pertencentes aos pacotes selecionados na primeira etapa (a classe que contém os casos de teste é destacada em negrito). Nesta lista o testador deve selecionar a classe que contém as operações que serão testadas (classe VendingMachine).

Quando uma classe é selecionada, todos os seus métodos são apresentados na lista inferior (métodos públicos são destacados em negrito). O testador deve então selecionar a operação que

\footnotetext{
${ }^{1}$ Classes e métodos são coletados utilizando reflexão e por isso exibidos com sua assinatura completa
} 


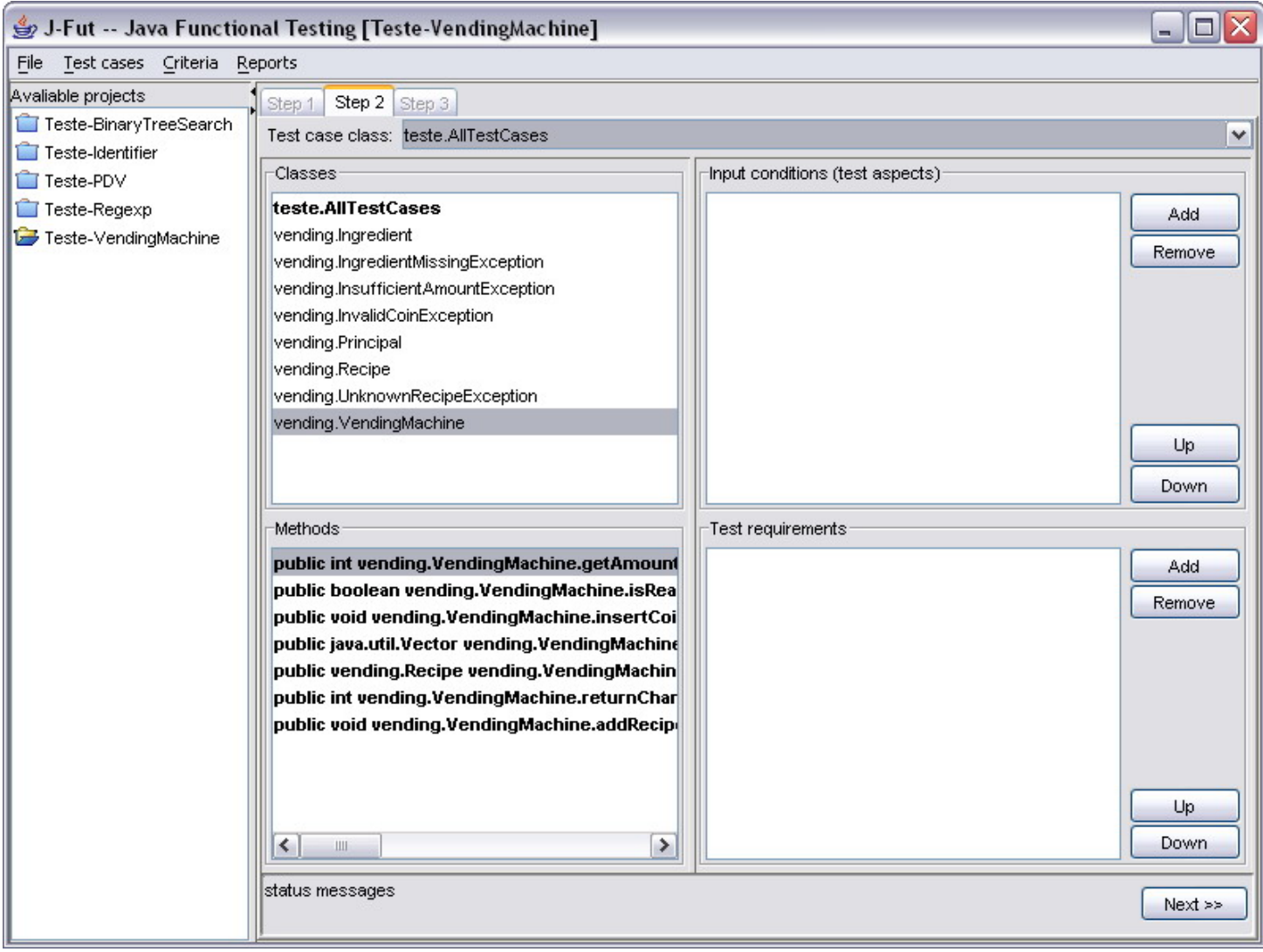

Figura 5.4: Segunda etapa para criação de um projeto de teste

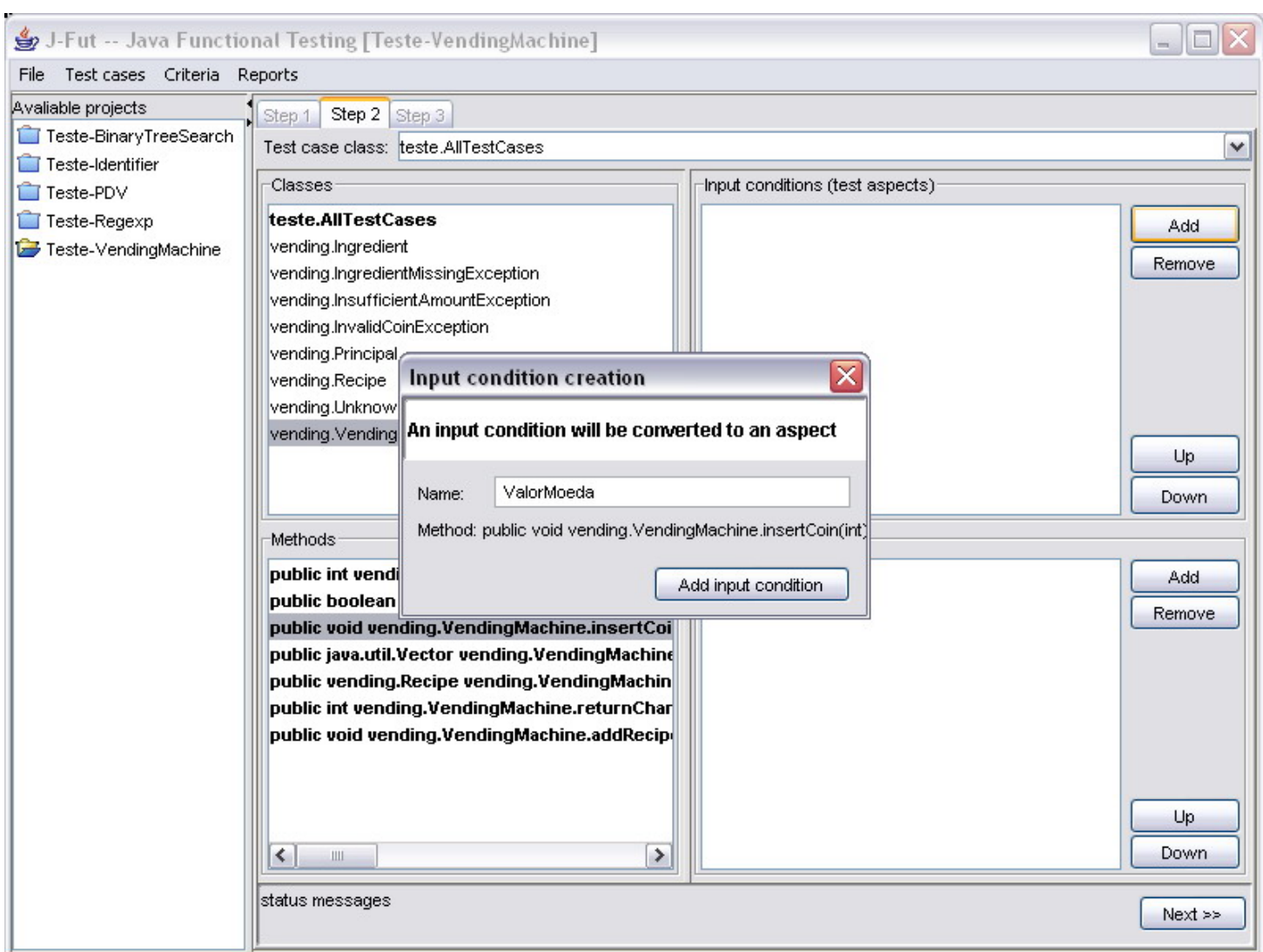

Figura 5.5: Criação de uma condição de entrada 
deseja testar e criar as condições de entrada referentes a ela. A criação das condições de entrada (ou aspectos de teste) é feita por meio do botão "Add" (canto superior direito) que, quando pressionado, exibe uma caixa de diálogo na qual deve ser preenchido o nome da condição de entrada. Na Figura 5.5 observa-se a criação da condição de entrada ValorMoeda, referente à operação insertCoin. Ao se pressionar o botão "Add input condition" a condição de entrada é criada e adicionada à lista correspondente.

Uma vez criada a condição de entrada, é necessária a criação dos requisitos de teste, cujo procedimento é semelhante ao descrito anteriormente. Cada requisito de teste é convertido em um método (predicado) no aspecto correspondente e para sua criação o testador deve selecionar a condição de entrada apropriada e pressionar o botão "Add" no canto inferior direito. Uma nova caixa de diálogo será exibida, como mostrado na Figura 5.6. Nessa caixa o testador deve preencher o nome do requisito e selecionar seu tipo.

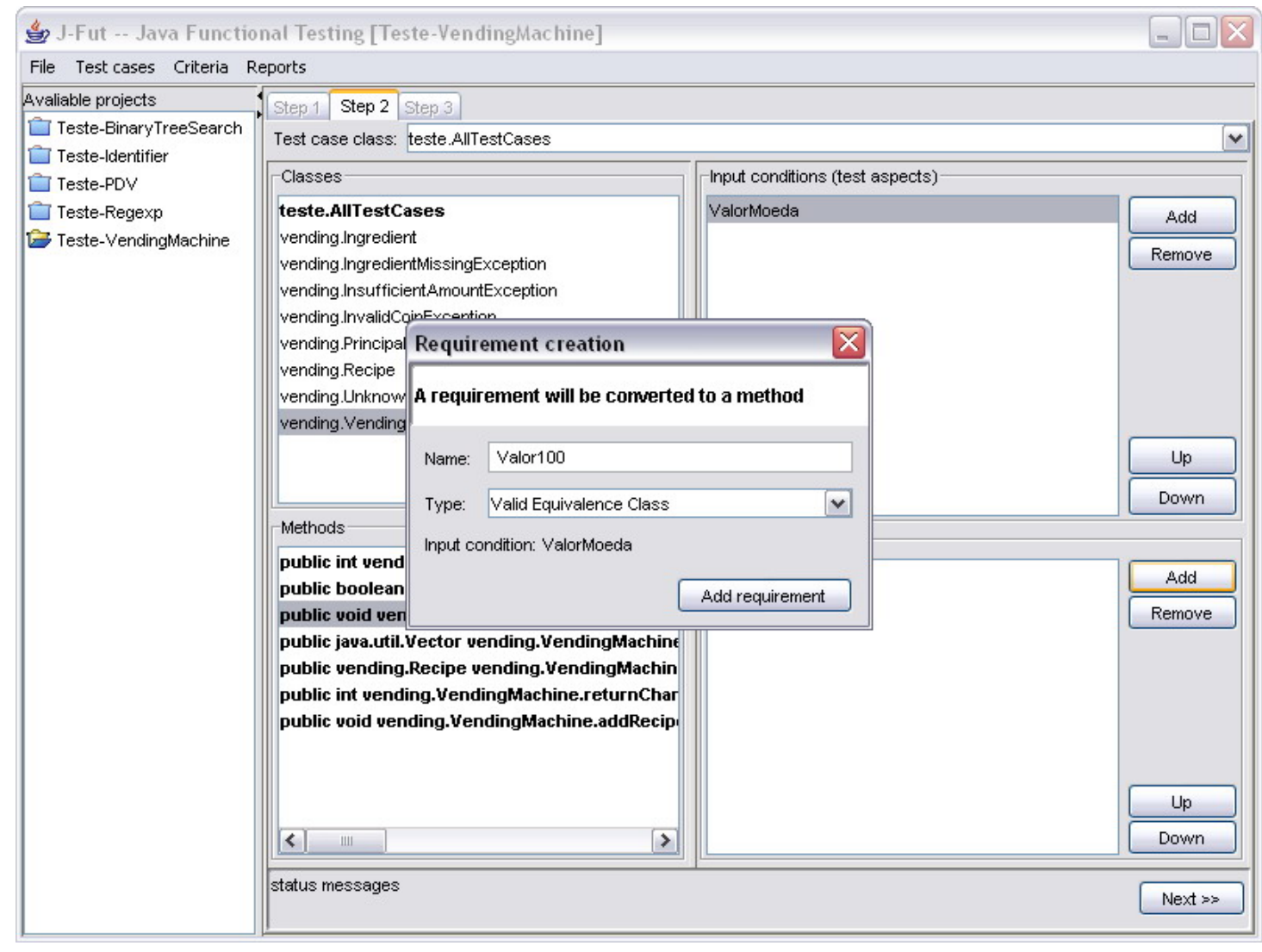

Figura 5.6: Criação de um requisito de teste

Na Figura 5.6 visualiza-se a criação do requisito valid_Valor100, que corresponde a uma classe de equivalência inválida. Não é necessário atribuir o prefixo valid ao nome do requisito, pois a J-FuT faz isso automaticamente, de acordo com o tipo escolhido. Ao pressionar-se o botão "Add requirement" o novo requisito é criado e adicionado à lista correspondente. Cada requisito recebe uma cor de destaque e um prefixo especial de acordo com seu tipo, como exibido na Figura 5.7, o que facilita a localização e distinção dos diversos requisitos de uma condição de entrada. Para detalhes sobre os prefixos dos requisitos de teste vide o Quadro 4.1. 


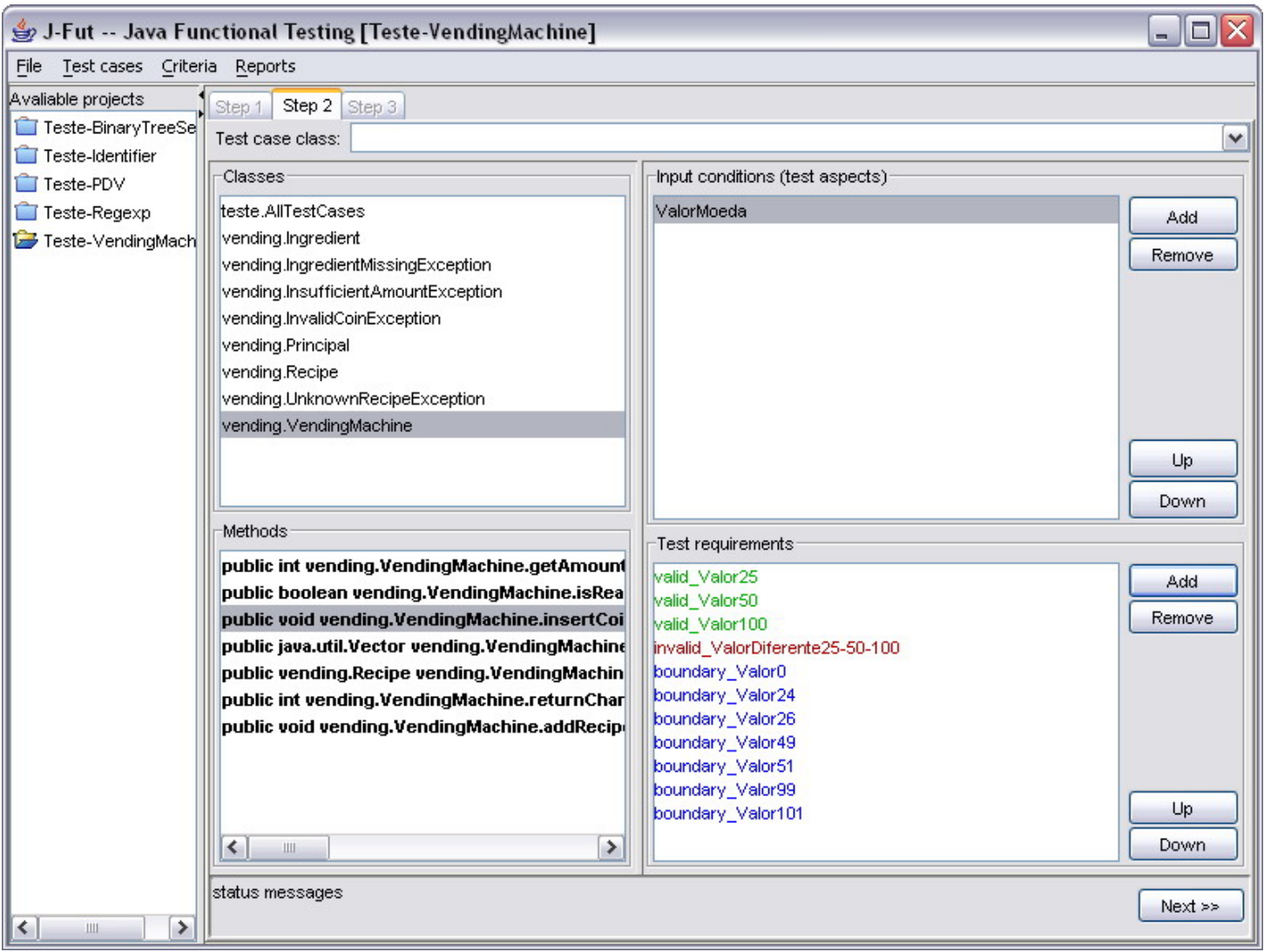

Figura 5.7: Requisitos de teste destacados

A criação de condições de entrada e requisitos de teste deve ser repetida até que todos os requisitos tenham sido informados. Procede-se então para a última etapa: a edição dos aspectos de teste. Na Figura 5.8 é exibida a tela correspondente à última etapa de uso do assistente, contendo todos os aspectos de teste para o teste da aplicação VendingMachine. O esqueleto dos aspectos é criado automaticamente pela J-FuT, a partir dos dados fornecidos na etapa anterior, sendo necessário preencher a lógica que implementa cada predicado (método), o que pode ser feito no proprio editor. Ao pressionar-se o botão "Finish" a aplicação é instrumentada, ou seja, a combinação é executada e os aspectos de teste são introduzidos no programa original, permitindo assim a verificação dos critérios funcionais.

\subsubsection{Edição dos aspectos de teste}

Os aspectos de teste devem ser editados durante a última etapa do assistente, com o objetivo de codificar a lógica dos predicados que representam os requisitos de teste. Por padrão, todos os requisitos criados possuem um implementação mínima, apenas um retorno do tipo false. A J-FuT disponibiliza um editor que permite alterar os aspectos criados automaticamente pelo assistente, mas qualquer editor pode ser utilizado.

Na Figura 5.9 é mostrado um trecho do aspecto Troco, que representa uma condição de entrada da operação returnChange. Nesse código é possível observar a implementação da 


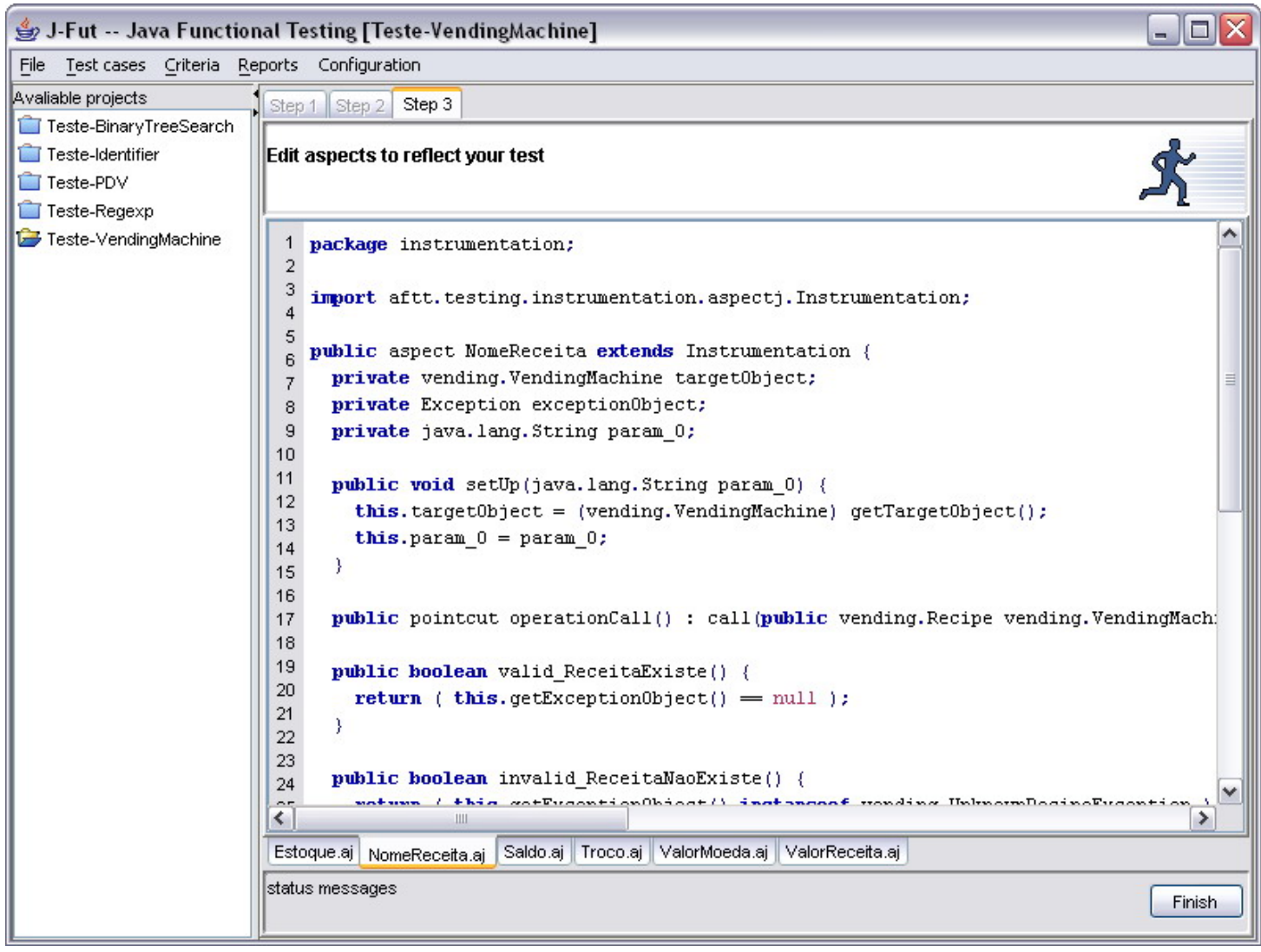

Figura 5.8: Refinamento dos requisitos de teste

classe de equivalência "Troco $\geq 0$ ", especificada anteriormente. Esse requisito é implementado como um método (valid_TrocoMaiorIgua10), e verifica por meio do objeto retornado se o troco é maior ou igual a zero.

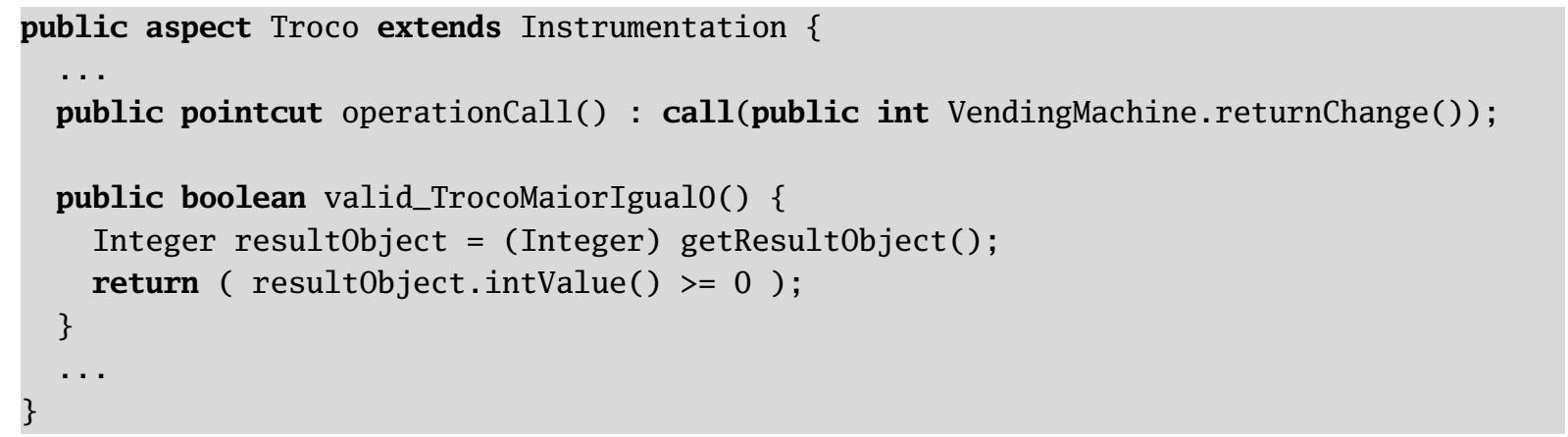

Figura 5.9: Trecho do aspecto Troco

Para o teste da aplicação VendingMachine, além dos aspectos de teste, que são criados automaticamente pela J-FuT e interceptam a execução dos requisitos de teste, foi implementado um aspecto auxiliar para aumentar a testabilidade das classes VendingMachine e Ingredient, de forma semelhante à proposta por Bruel et al. (2003). Essa abordagem foi adotada porque essas classes não possuem métodos para modificar diretamente alguns de seus atributos, como é o caso do saldo (amount) e da quantidade disponível de cada ingrediente (quantity). 
Como descrito na especificação, o saldo (amount) é alterado nas operações insertCoin e makeRecipe, enquanto que a quantidade de cada ingrediente é alterada pela operação makeRecipe. Na Figura 5.10 é mostrado um trecho do caso de teste que testa a insuficiência de ingredientes. A máquina é abastecida com moedas até atingir o saldo de 4050. A seguir são executados diversos pedidos até que falte algum ingrediente. Nota-se que para atingir um determinado saldo ou quantidade de ingrediente é necessário repetir a operação correspondente diversas vezes, o que representa um custo desnecessário.

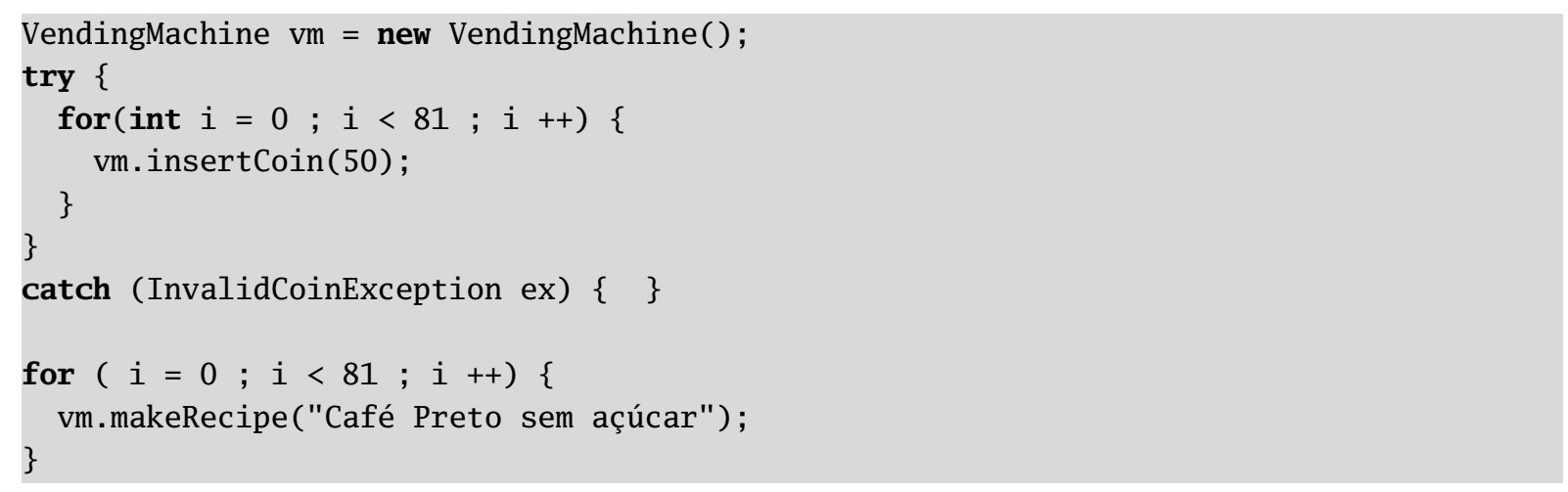

Figura 5.10: Teste da insuficiência de ingredientes

Além disso, sempre que os métodos insertCoin e makeRecipe são chamados, os aspectos correspondentes fazem a interceptação, o que não é desejável nesse momento em que apenas é feita a configuração do caso de teste. Assim, a capacidade de alterar o saldo ou o estoque externamente facilita o teste e melhora o seu desempenho. Na Figura 5.11 é exibido o aspecto MelhoriaTestabilidade. O aspecto define três declarações inter-tipo que adicionam os métodos setAmount e setQuantity à classe VendingMachine e o método setQuantity à classe Ingredient. $\mathrm{O}$ aspecto é do tipo privileged, permitindo o acesso a atributos privados das classes. Após o processo de combinação, os método estarão disponíveis para quaisquer classes que desejem utilizá-los. O novo caso de teste é exibido na Figura 5.12, em que se nota que não são mais necessários os dois laços de repetição para as operações insertCoin e makeRecipe.

\subsubsection{Execução dos casos de teste}

Após a edição dos aspectos de teste, o testador deve executar os casos de teste cadastrados, o que é feito por meio de uma tela específica. Na Figura 5.13 são exibidos os vinte e dois casos de teste elaborados para o teste da aplicação VendingMachine. Nessa tela o testador deve selecionar os casos de teste que deseja executar e marcar se deseja conservar o arquivo de registro original ou sobrescrevê-lo (opção "Override previous trace"). Recomenda-se sobrescrever o arquivo quando todos os testes forem executados de uma única vez e conservá-lo quando executar testes individuais. O testador também poderá optar por armazenar a seqüencia de chamadas a métodos 


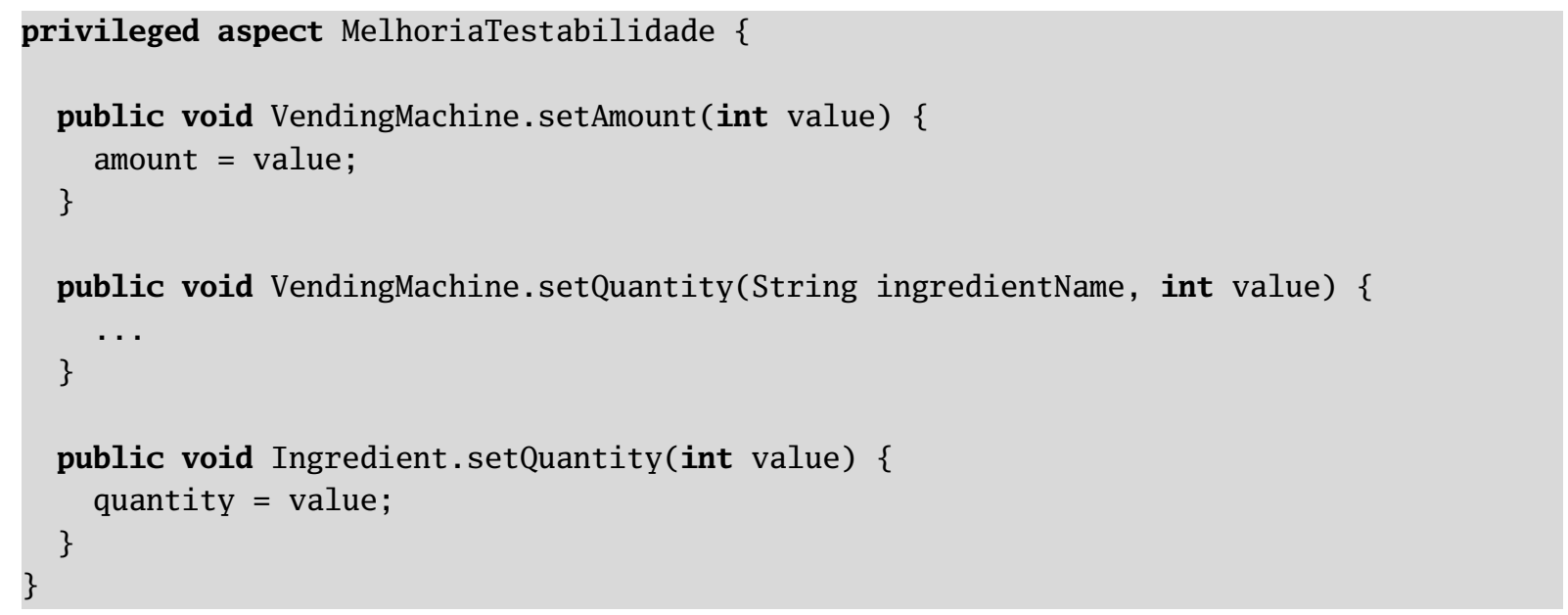

Figura 5.11: Aspecto MelhoriaTestabilidade

VendingMachine $\mathrm{vm}=$ new VendingMachine ();

vm. setAmount (100);

vm. setQuantity("Água", 0);

vm.makeRecipe("Café Preto sem açúcar");

Figura 5.12: Teste da insuficiência de ingredientes (simplificado)

\begin{tabular}{|c|c|c|}
\hline \multicolumn{2}{|c|}{ J-Fut (Java Functional Testing) } & $\square \square x$ \\
\hline \multicolumn{3}{|c|}{ File Iest cases Criteria Reports Configuration } \\
\hline \multirow{4}{*}{$\begin{array}{l}\text { Avaliable projects } \\
\square \text { Teste-BinaryTreeSearch } \\
\square \text { Teste-Identifier } \\
\square \text { Teste-PDV } \\
\square \text { Teste-Regexp }\end{array}$} & Select tests to run & \\
\hline & $\square$ teste.AlltestCases.testCT412010 & $\hat{\imath}$ \\
\hline & $\square$ teste.AlltestCases.testCT41202() & \\
\hline & $\square$ teste.AlltestCases.testCT412030) & \\
\hline \multirow[t]{20}{*}{ E Teste-VendingMachine } & $\square$ teste.AlltestCases.testCT41204() & \\
\hline & $\square$ teste.AlltestCases.$e s t C T 422010$ & \\
\hline & $\square$ teste.AlltestCases.testCT42202() & \\
\hline & $\square$ teste.AlltestCases.testCT2010 & \\
\hline & $\square$ teste.AlltestCases.testCT2020) & \\
\hline & $\square$ teste.AlltestCases.testCT203() & \\
\hline & $\square$ teste.AlltestCases.testCT204() & \\
\hline & $\square$ teste.AlltestCases.testCT205() & \\
\hline & $\square$ teste.AlltestCases.testCT206() & \\
\hline & $\square$ teste.AlltestCases. testCT2070) & \\
\hline & $\square$ teste.AlltestCases.testct2080) & \\
\hline & $\square$ teste.AlltestCases .estCT209() & \\
\hline & $\square$ teste.AlltestCases.testCT2100) & \\
\hline & $\square$ teste.AlltestCases testCT2110 & \\
\hline & $\square$ teste.AlltestCases.testCT2310 & \\
\hline & $\square$ teste.AlltestCases.testCT232() & \\
\hline & $\square$ teste.AlltestCases.testCT2330) & \\
\hline & $\square$ teste.AlltestCases.testCT2340) & 2 \\
\hline & 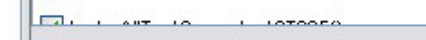 & \\
\hline & $\square$ override previous trace $\square$ call-trace & Run selected \\
\hline
\end{tabular}

Figura 5.13: Seleção e execução dos casos de teste 
que ocorreram durante a execução dos casos de teste ("Call-trace"). Essa informação pode ser utilizada durante a depuração da aplicação.

\subsubsection{Análise de cobertura}

Após a instrumentação da aplicação, a cobertura foi analisada usando os relatórios fornecidos pela J-FuT. Foram utilizados os critérios Particionamento de Equivalência e a estratégia “invalidar casos de teste”, padrão para análise dos dados (vide Seção 4.6). Na Figura 5.14 é exibido o relatório Cobertura de métodos. Neste relatório são mostradas todas as operações da classe em teste (VendingMachine) e suas respectivas coberturas, calculadas em função das suas condições de entrada. Nota-se que os vinte e dois casos de teste implementados não foram suficientes para cobrir todas as condições de entrada, pois alguns requisitos dessas condições de entrada não foram exercitados.

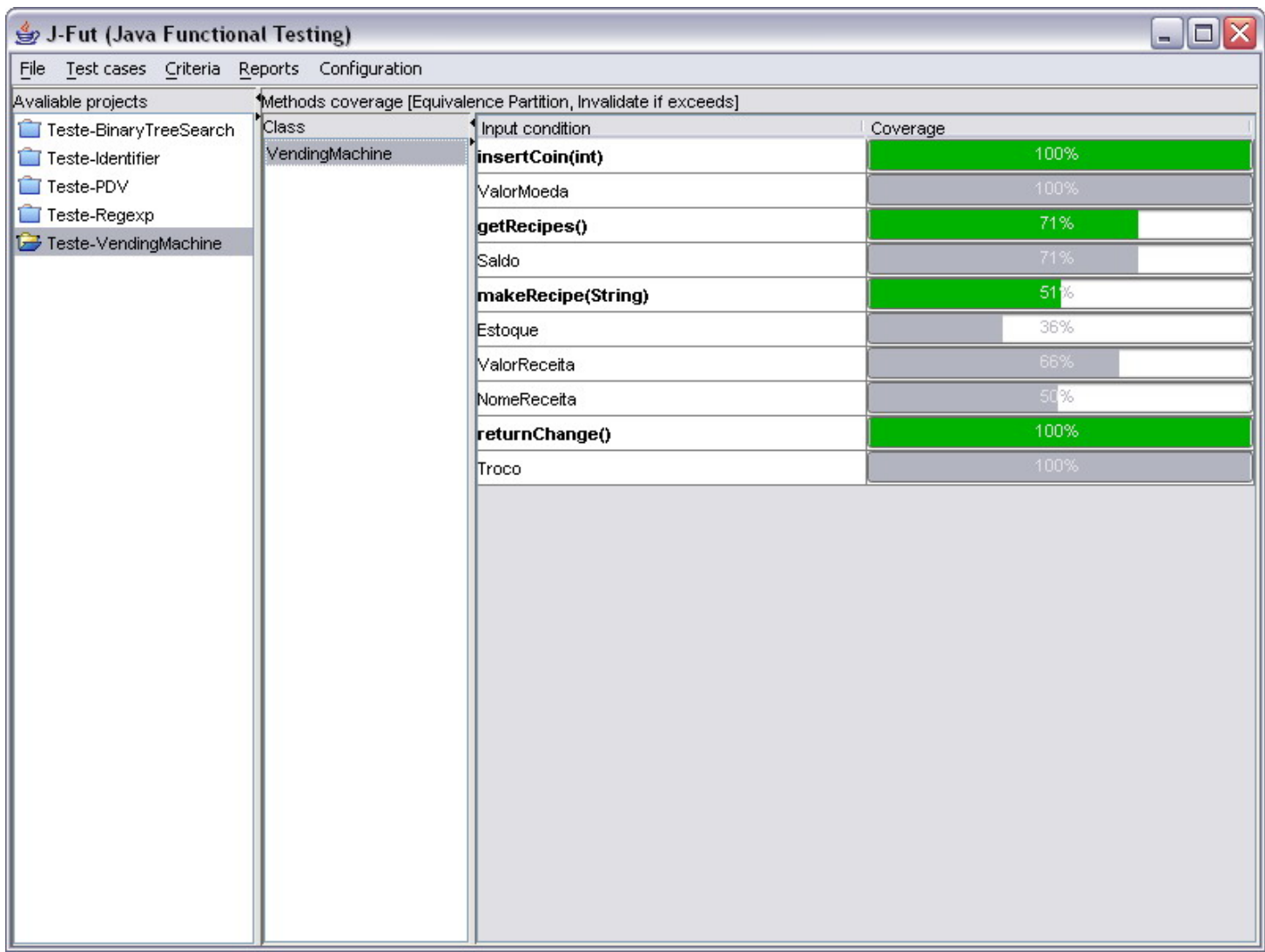

Figura 5.14: Cobertura inicial das operações utilizando o critério Particionamento de Equivalência e a estratégia "invalidar casos de teste"

Para descobrir quais requisitos ainda não foram cobertos pode-se utilizar um outro relatório, que exibe a cobertura das condições de entrada. Na figura 5.15 é exibido o relatório Cobertura de condições de entrada. Selecionando-se a classe e método apropriados (VendingMachine e getRecipes, respectivamente) são exibidas as coberturas das condições de entrada e as informações sobre os requisitos exercitados. Os botões "Equivalence classes", "Pre/pos-conditions" 
e "Boundaries" permitem navegar entre os diversos tipos de requisitos e obter informações sobre suas coberturas. Selecionando a opção "Boundaries", observa-se que o requisitos boundary_SaldoIgual25 e boundary_SaldoIgual75 não foram exercitados e novos casos de teste devem ser elaborados.

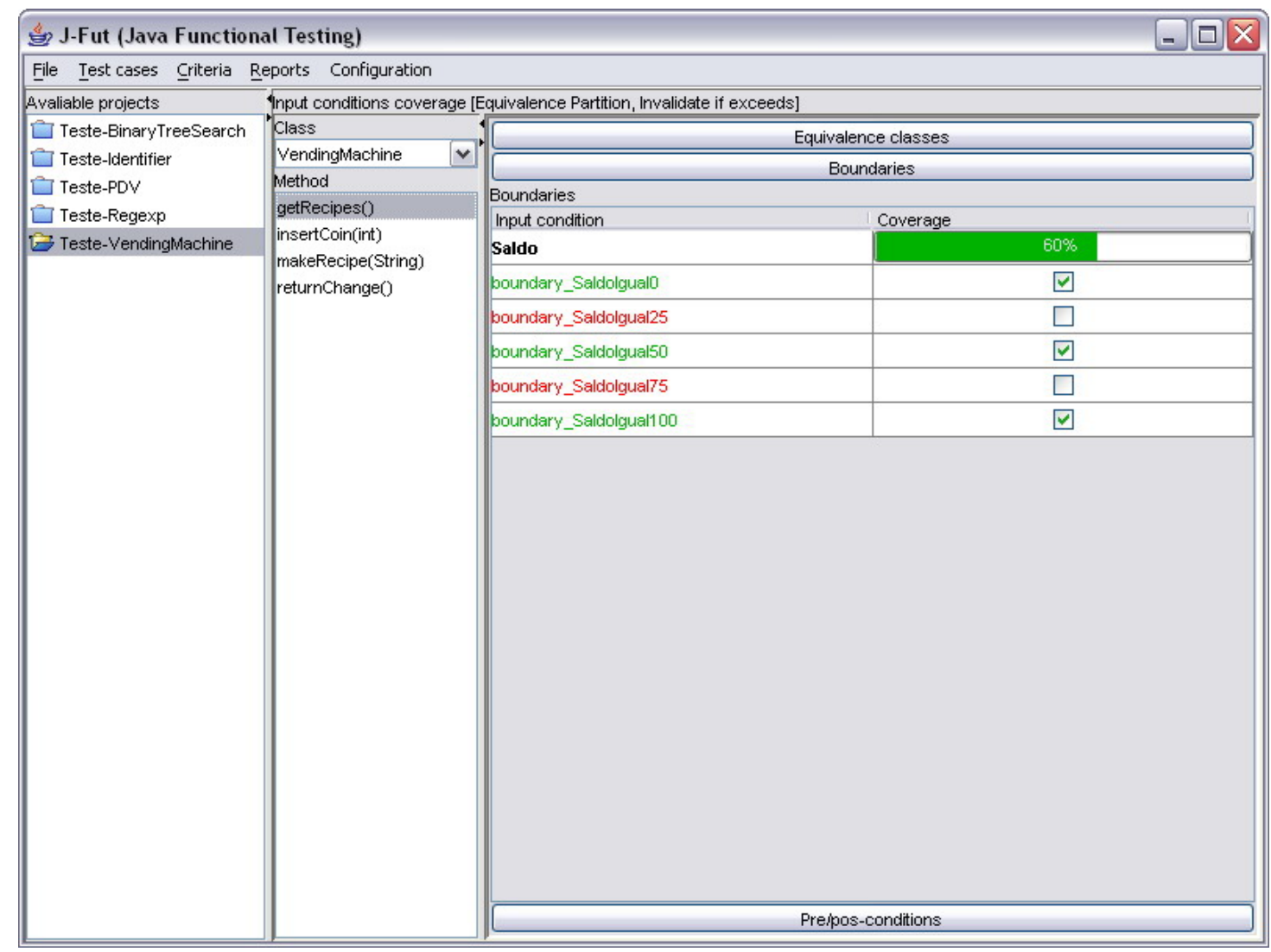

Figura 5.15: Cobertura inicial das condições de entrada da operação getRecipes utilizando o critério Particionamento de Equivalência e a estratégia "invalidar casos de teste"

A análise de cobertura foi feita para todos os requisitos de teste das operações da classe VendingMachine e dezenove novos casos de teste foram implementados, para exercitar os requisitos de teste ainda não exercitados, totalizando quarenta e um. O novo conjunto de casos de teste permitiu atingir $100 \%$ de cobertura em todas as operações, como mostrado na Figura 5.16.

A seguir, a título de ilustração, o critério funcional foi alterado para Teste Funcional Sistemático e o relatório de cobertura foi chamado novamente, conservando a estratégia adotada anteriormente ("invalidar casos de teste"). Em razão desse critério exigir que cada requisito de teste seja exercitado ao menos duas vezes, nenhuma das operações foi coberta, como é possível observar na Figura 5.17. Nesse sentido, foi adotada a estratégia "otimizar requisitos de teste", recomendada para critérios que exigem que cada requisito de teste seja exercitado mais de uma vez.

Na Figura 5.18 observa-se a cobertura dos métodos após a aplicação da estratégia. Nota-se que houve alteração na cobertura das operações getRecipes (de $85 \%$ para $100 \%$ ) e makeRecipe (de 66\% para 77\%), enquanto que as coberturas das operações insertCoin e returnChange 


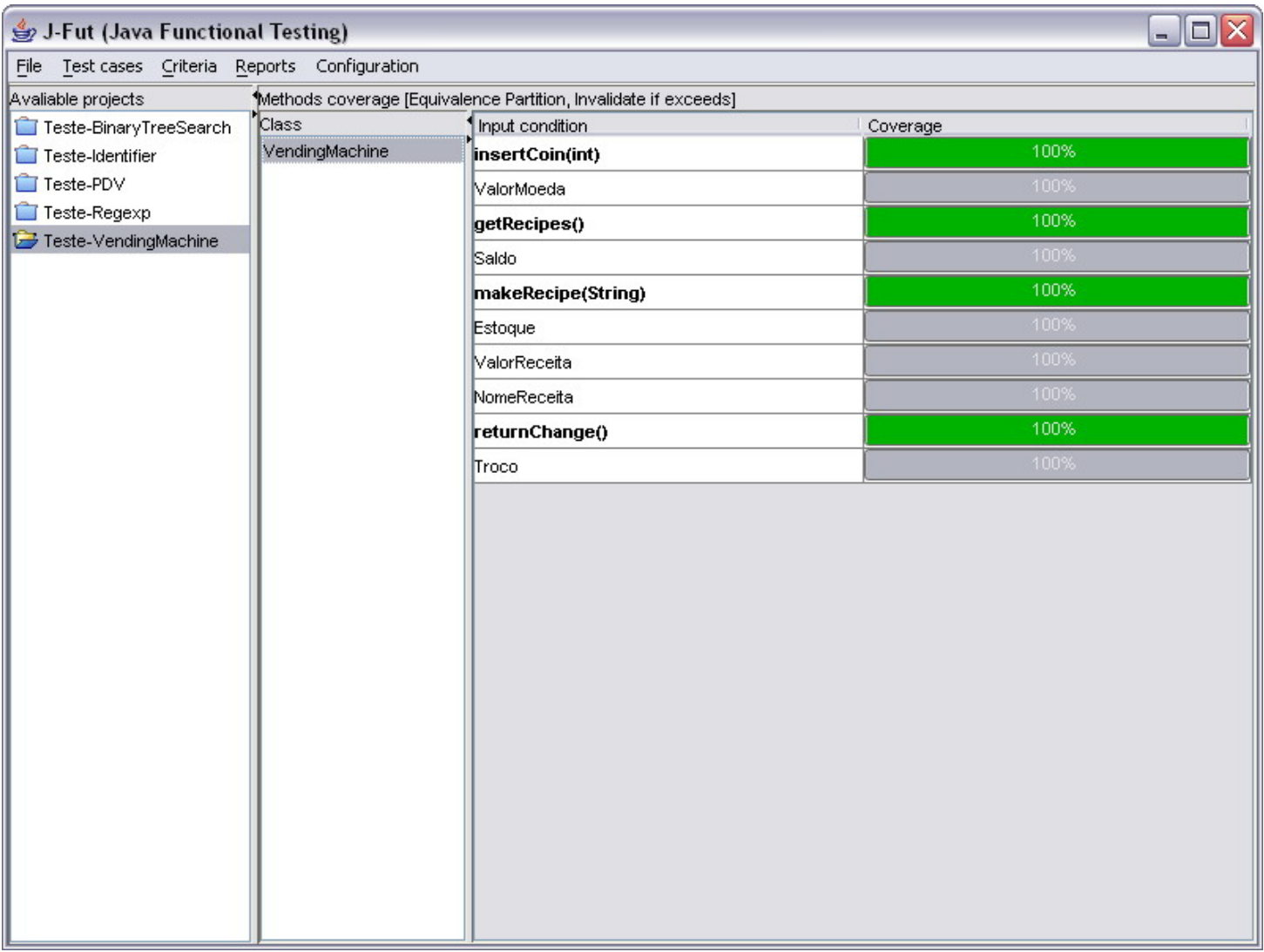

Figura 5.16: Cobertura final das operações utilizando o critério Particionamento de Equivalência e a estratégia "invalidar casos de teste"

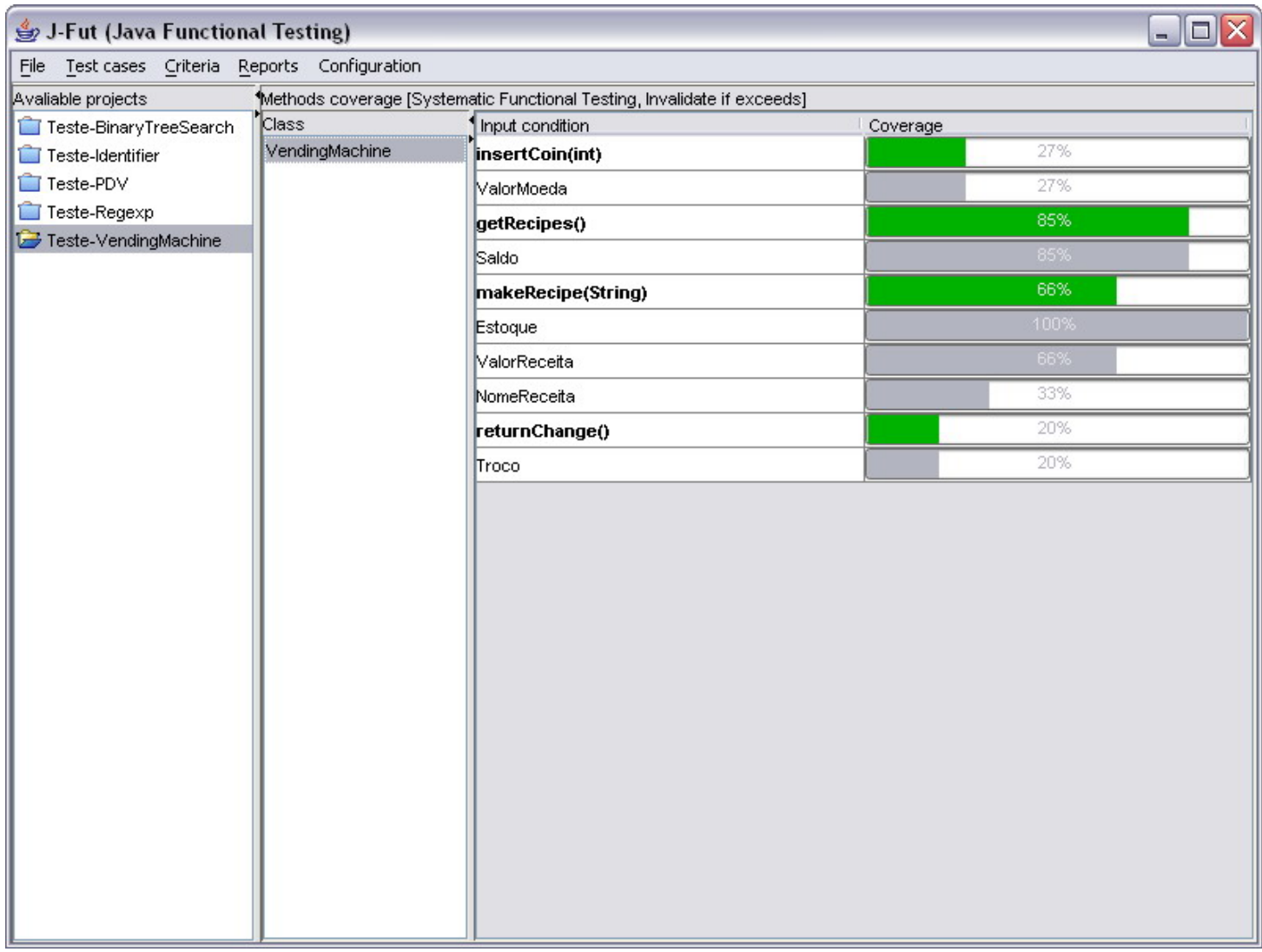

Figura 5.17: Cobertura das operações utilizando o critério Teste Funcional Sistemático e a estratégia "invalidar casos de teste" 


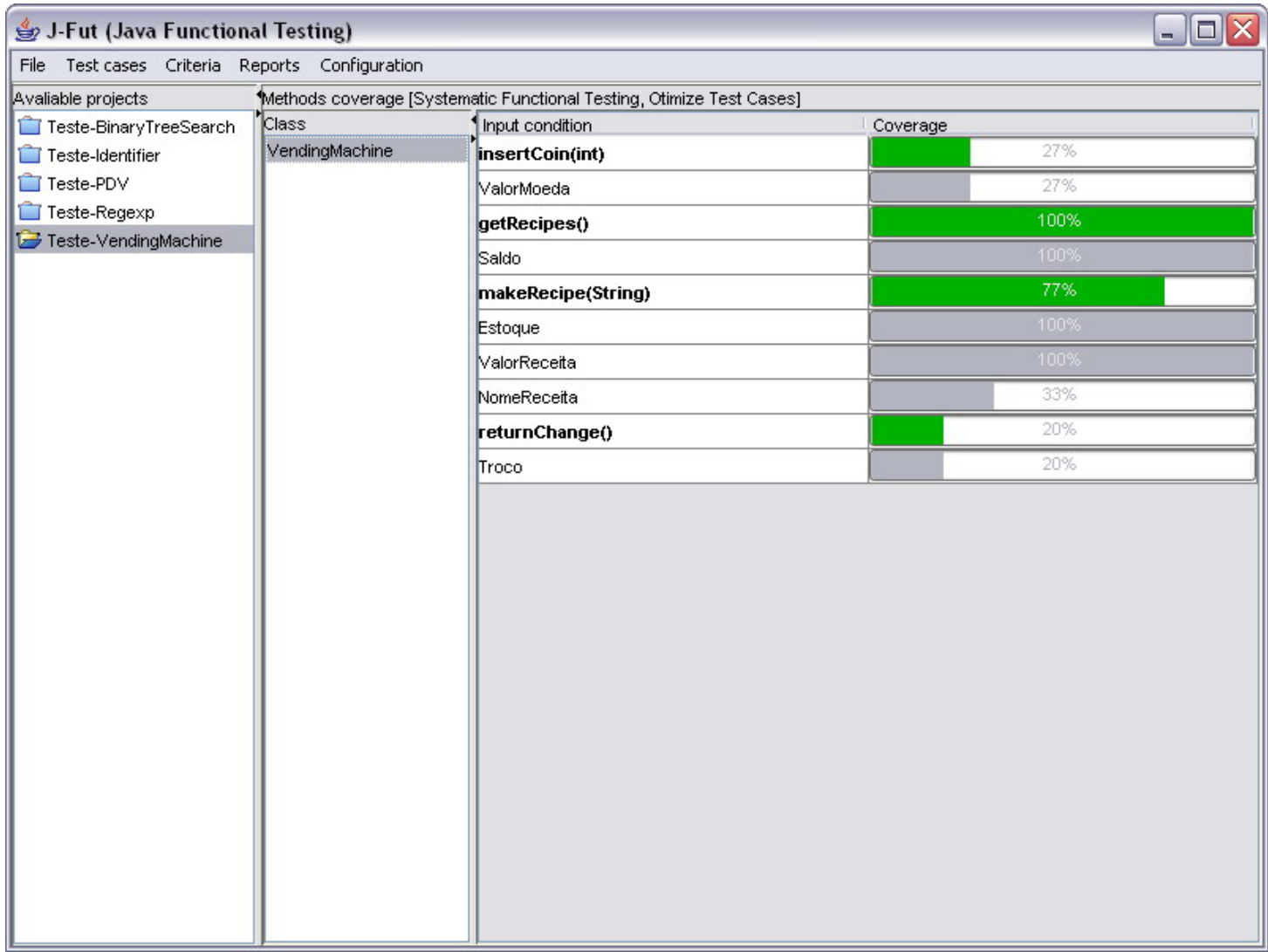

Figura 5.18: Cobertura das operações utilizando o critério Teste Funcional Sistemático e a estratégia "otimizar requisitos de teste"

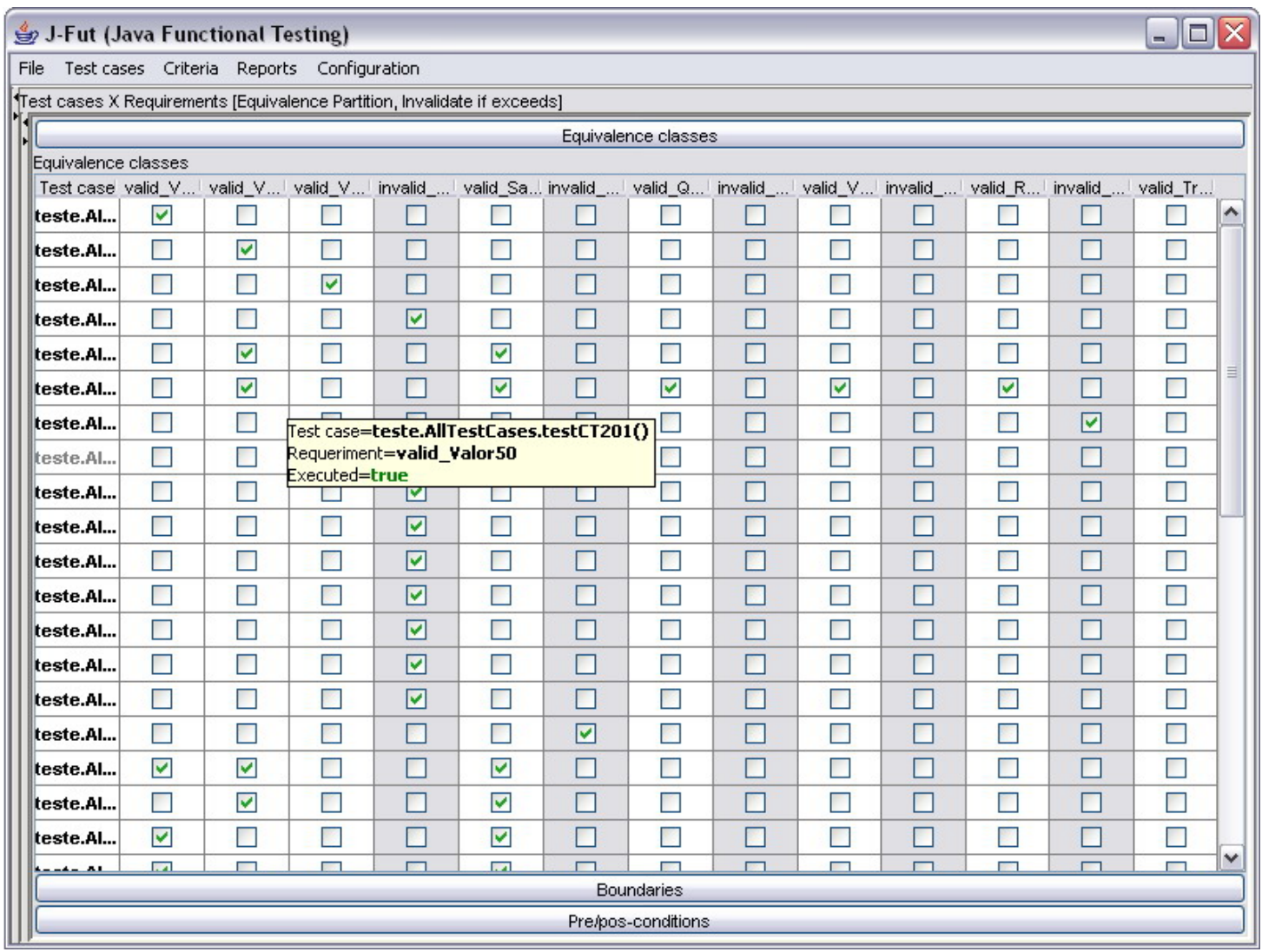

Figura 5.19: Relação entre casos e requisitos de teste 
permaneceram inalteradas. Isso significa que não existem casos de teste suficientes para exercitar mais de uma vez os requisitos que ainda não foram cobertos. A relação entre os casos de teste e os requisitos pode ser visualizada a partir do relatório Casos de teste $\mathbf{X}$ Requisitos, mostrado na Figura 5.19.

Nesse relatório as colunas que representam classes de equivalência inválidas estão destacadas em cinza e, de forma semelhante ao relatório Cobertura de condições de entrada, é possível navegar entre os diversos tipos de requisitos e observar a sua relação com os casos de teste existentes. A movimentação do cursor sobre o relatório exibe as informações relativas a cada célula. Nota-se que, apesar da re-arrumação procedida pelo algoritmo de otimização, diversas classes de equivalência só foram exercitados uma única vez, prejudicando dessa forma a cobertura da condição de entrada correspondente.

\subsection{Considerações finais}

Neste capítulo foram apresentados o uso da ferramenta J-FuT e alguns exemplos utilizados durante o seu desenvolvimento. Um exemplo prático foi detalhado, demonstrando as funcionalidades presentes na ferramenta. O uso da J-FuT permite quantificar o teste funcional e oferece medidas de satisfação que podem ser utilizadas para decidir quando essa atividade deve ser encerrada.

A utilização da ferramenta em diversos exemplos mostrou a sua validade para aplicações simples, nas quais os predicados para avaliação dos requisitos de teste são geralmente pequenos. No entanto, o seu uso em aplicações de maior complexidade ainda apresenta limitações, como foi observado durante o teste do pacote gnu.regexp, que exigiu a codificação de predicados grandes e de métodos auxiliares. 


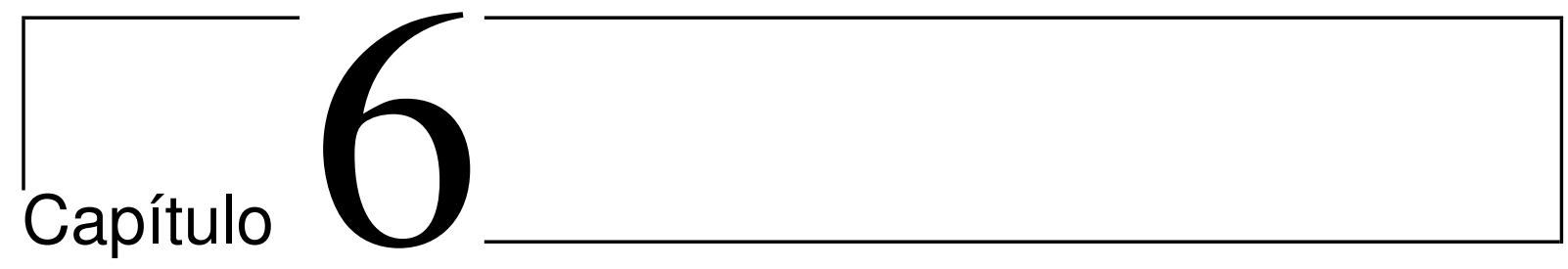

\section{Conclusão}

\subsection{Considerações finais}

Foi apresentada neste trabalho uma ferramenta para apoio ao teste funcional de programas Java, que implementa os critérios mais importantes da técnica funcional. A ferramenta, denominada J-FuT (Java Functional Testing), também oferece análise de cobertura de acordo com os requisitos funcionais, uma característica normalmente não encontrada em ferramentas dessa categoria.

No projeto e implementação da ferramenta foi utilizada a POA, com o intuito de auxiliar o processo de instrumentação e execução dos critérios funcionais. Essa abordagem mostrou-se bastante útil, pois o uso de aspectos permite separar o código de teste do código da aplicação, facilitando o teste. Além disso, aspectos podem ser introduzidos e retirados facilmente da aplicação, conservando intacto o programa original.

O projeto da ferramenta baseia-se em predicados que representam requisitos de teste (classes de equivalência e valores-limite) e são utilizados internamente para o teste de satisfação. O uso de predicados facilita a construção e manutenção do teste, no entanto, a representação dos requisitos sob a forma de predicados nem sempre é uma tarefa trivial e pode requerer a implementação de diversas funções auxiliares. Assim, predicados complexos, cujos custos de elaboração sejam altos, podem dificultar o uso da J-FuT.

\subsection{Contribuições}

Como principais contribuições deste trabalho, pode-se citar o projeto e implementação de uma ferramenta que apóia o teste de unidade e de sistema de programas Java, automatizando a 
verificação dos principais critérios funcionais existentes na literatura. A automatização desses critérios permitiu a definição e implementação da análise de cobertura de acordo com os requisitos dessa técnica, característica não encontrada em nenhuma das ferramentas pesquisadas na literatura.

Outra contribuição refere-se ao uso de POA para apoio a uma técnica específica de teste, a técnica funcional. A POA é utilizada com sucesso nas etapas de instrumentação e execução dos critérios funcionais e essa abordagem permite que os usuários efetuem o teste de uma aplicação sem conhecer detalhes de sua implementação, ao passo que o seu comportamento interno pode ser analisado, incluindo métodos executados, parâmetros e resultados.

\subsection{Trabalhos futuros}

Como continuidade deste trabalho, pretende-se analisar o auxílio da POA em outras fases de teste, nas quais acredita-se que essa técnica possa trazer benefícios como, por exemplo, o teste de regressão. Além disso, em relação à ferramenta, pretende-se executar testes de exemplos mais complexos e testes exaustivos de todas as estratégias de análise dos dados, visando a corrigir eventuais falhas e tornar a ferramenta mais robusta.

Outro tópico que deve ser analisado refere-se ao uso da ferramenta para o teste de programas escritos em AspectJ. O teste funcional de programas escritos nessa linguagem parece ser possível pois o bytecode gerado pelo AspectJ é compatível com Java. No entanto, ainda é necessário um estudo mais aprofundado para verificar se essa linguagem permite a instrumentação de suas próprias construções.

Algumas características também são propostas para a próxima versão da J-FuT: implementação de uma versão script, que permita seu uso sem a interface gráfica Swing e torne-a portável para a web; derivação dos requisitos de teste a partir de especificações OCL e geração automática dos aspectos de teste, que ainda são implementados manualmente e, por fim, implementação do suporte à depuração, que apesar de previsto no projeto da ferramenta, ainda não está implementado. 


\section{Referências}

AKSIT, M.; TEKINERDOGAN, B. Solving the modeling problems of object-oriented languages by composing multiple aspects using composition filters. In: Proceedings of the Workshop on Aspect Oriented Programming (ECOOP 1998). Brussels - Belgium: Springer-Verlag, 1998.

AKSIT, M. et al. Abstracting Object Interactions Using Composition Filters. In: GUERRAOUI, R.; NIERSTRASZ, O.; RIVEILL, M. (Ed.). Proceedings of the ECOOP'93 Workshop on Object-Based Distributed Programming. Kaiserslautern - Germany: Springer-Verlag, 1994. v. 791, p. 152-184.

ANDRIOLE, S. J. Software Validation, Verification, Testing and Documentation. 1. ed. New Jersey: Petrocelli Books, 1986. 389 p.

AspectJ Team. The AspectJ Programming Guide. 2003. Disponível em: <http://dev.eclipse.org/ viewcvs/indextech.cgi/ checkout $\sim$ /aspectj-home/doc/progguide/index.html $>$. Acesso em: $17 / 12 / 2004$.

AutomatedQA Corp. TestComplete. 1999. Disponível em: < http://www.automatedqa.com/ products/testcomplete/index.asp $>$. Acesso em: 07/12/2004.

BANIASSAD, E.; CLARKE, S. Theme: An Approach for Aspect-Oriented Analysis and Design. In: Proceedings of the 26th International Conference on Software Engineering (ICSE'04). Edinburgh - United Kingdom: IEEE Computer Society Press, 2004. p. 158-167.

BARBEY, S.; STROHMEIER, A. The Problematics of Testing Object-Oriented Software. In: ROSS, M. et al. (Ed.). Proceedings of the SQM'94 Second Conference on Software Quality Management. Edinburgh: [s.n.], 1994. v. 2, p. 411-426.

BARBOSA, D. L. et al. SPACES - Uma Ferramenta para Teste Funcional de Componentes. Anais da XI Sessão de Ferramentas - XVIII Simpósio Brasileiro de Engenharia de Software, p. 55-60, Outubro 2004.

BECK, K. et al. Manifesto for Agile Software Development. 2001. Disponível em: $<$ http://agilemanifesto.org/>. Acesso em: 26/11/2004.

BECKER, U. D ${ }^{2}$ AL: A design-based aspect language for distribution control. In: Proceedings of the International Workshop on Aspect-Oriented Programming at ECOOP. Brussels - Belgium: Springer-Verlag, 1998. 
BIGGS, W. Regular Expressions for Java. October 2001. Disponível em: $<$ http://www.cacas.org/java/gnu/regexp/>. Acesso em: 11/12/2004.

BINDER, R. V. Modal testing strategies for OO software. Computer Magazine, v. 9, n. 11, p. 97-99, 1996.

BINDER, R. V. Testing Object-Oriented Systems: Models, Patterns, and Tools. 1. ed. Massachusetts: Addison Wesley, 1999. 1191 p.

BONÉR, J.; VASSEUR, A. AspectWerkz. 2002. Disponível em: <http://aspectwerkz. codehaus.org/>. Acesso em: 10/12/2004.

BRUEL, J.-M. et al. Using Aspects to Develop Built-In Tests for Components. In: AKKAWI, F. et al. (Ed.). Proceedings of the 4th AOSD Modeling With UML Workshop. San Francisco CA: [s.n.], 2003.

BURKE, B. JBoss Aspect Oriented Programming. 2003. Disponível em: $<\mathrm{http}: / / \mathrm{www} . j b o s s . o r g /$ products/aop $>$. Acesso em: 12/11/2004.

CALDER, M. PGUIRobot Java Test \& Replay. 2000. Disponível em: $<$ http://sourceforge.net/projects/pguirobot/>. Acesso em: 05/11/2004.

CASWELL, M.; ARAVAMUDHAN, V.; WILSON, K. jfcUnit. 2002. Disponível em: $<$ http://jfcunit.sourceforge.net/>. Acesso em: 05/11/2004.

CHAVEZ, C. von F. G. A Model-Driven Approach for Aspect-Oriented Design. Tese (Doutorado) - Pontifícia Universidade Católica, Departamento de Informática, Rio de Janeiro Brasil, Abril 2004.

CHIBA, S. Javassist: Java bytecode manipulation made simple. March 2004. Disponível em: $<$ http://www.jboss.org/developers/projects/javassist.html>. Acesso em: 05/09/2004.

COHEN, G.; CHASE, J.; KAMINSKY, D. The Java Object Instrumentation Environment (JOIE). 2003. Disponível em: <http://www.cs.duke.edu/ari/joie/>. Acesso em: 04/11/2004.

DAHM, M. Byte Code Engineering Library. December 2002. Disponível em: $<$ http://bcel.sourceforge.net/>. Acesso em: 05/09/2004.

DEBUSMANN, M.; GEIHS, K. Efficient and Transparent Instrumentation of Application Components using an Aspect-oriented Approach. In: 14th IFIP/IEEE Workshop on Distributed Systems: Operations and Management (DSOM 2003). Heidelberg - Germany: Springer, 2003. (Lecture Notes in Computer Science (LNCS), v. 2867), p. 209-220.

DELAMARO, M. E. Proteum: Um ambiente de teste baseado na análise de mutantes. Dissertação (Mestrado) - Universidade de São Paulo - ICMC/USP, São Carlos - SP, Outubro 1993.

DEMILLO, R. A. et al. Software Testing and Evaluation. 1. ed. Menlo Park: Benjamin Cummings, 1987. $537 \mathrm{p}$.

DETERS, M.; CYTRON, R. K. Introduction of Program Instrumentation using Aspects. In: ACM. Proceedings of the OOPSLA 2001 Workshop on Advanced Separation of Concerns in Object-Oriented Systems. Tampa - FL, 2001. 
DIJKSTRA, E. W. A Discipline of Programming. 1. ed. New Jersey - USA: Prentice-Hall, 1976. $217 \mathrm{p}$.

DIOTALEVI, F. Contract enforcement with AOP: Apply Design by Contract to Java software development with AspectJ. 2004. Disponível em: <http://www106.ibm.com/developerworks/library/j-ceaop/>. Acesso em: 25/08/2004.

EICHBERG, M. et al. Enforcing System-Wide Properties. In: Proceedings of Australian Software Engineering Conference 2004 (ASWEC'04). Melbourne - Australia: IEEE Computer Society Press, 2004. p. 158-167.

ELRAD, T. et al. Discussing Aspects of AOP. Communications of the ACM, v. 44, n. 10, p. 33-38, October 2001.

GAMMA, E.; BECK, K. JUnit, Testing Resources for Extreme Programming. 2002. Disponível em: <http://www.junit.org/>. Acesso em: 16/11/2004.

GAMMA, E. et al. Padrões de Projeto: Soluções Reutilizáveis de Software Orientado a Objetos. Porto Alegre: Bookman, 2000. 364 p.

GEORGE, E. Testing Interface Compliance with Abstract Test. 2002. Disponível em: $<$ http://www.placebosoft.com/abstract-test.html>. Acesso em: 11/11/2004.

GSCHWIND, T.; OBERLEITNER, J. Improving Dynamic Data Analysis with Aspect-Oriented Programming. In: Proceedings of the 7th European Conference on Software Maintenance and Reengineering (CSMR 2003). Benevento - Italy: IEEE Computer Society, 2003. p. 259-268.

HANENBERG, S.; SCHMIDMEIER, A. Idioms for Building Software Frameworks in AspectJ. In: COADY, Y.; EIDE, E.; LORENZ, D. H. (Ed.). The Second AOSD Workshop on Aspects, Components, and Patterns for Infrastructure Software (ACP4IS). Boston - USA: [s.n.], 2003.

HARRISON, W.; OSSHER, H. Subject-oriented programming: a critique of pure objects. In: Proceedings of the eighth annual conference on Object-oriented programming systems, languages, and applications. Washington - USA: ACM Press, 1993. p. 411-428.

HARROLD, M.; SOFFA, M. Interprocedual data flow testing. In: Proceedings of the ACM SIGSOFT'89 third symposium on Software testing, analysis, and verification. Florida - USA: ACM Press, 1989. p. 158-167.

HARROLD, M. J. Testing: A Roadmap. In: Proceedings of the 22th International Conference on Software Engineering - Future of SE Track. Limerick - Ireland: ACM Press, 2000. p. 61-72.

HARROLD, M. J.; ROTHERMEL, G. Performing Dataflow Testing on Classes. In: Proceedings of the SIGSOFT '94 Symposium on the Foundations of Software Engineering. New Orleans - USA: ACM Press, 1994. p. 154-163.

HELlESOY, A.; QUIROZ, C. iContract Plus. 2001. Disponível em: $<$ http://sourceforge.net/projects/icplus/>. Acesso em: 05/11/2004.

HETZEL, B. The Complete Guide to Software Testing. 2. ed. Massachusetts: QED Information Sciences, 1988. 284 p.

HILSDALE, E.; HUGUNIN, J. Advice Weaving in AspectJ. (submetido à 3rd International Conference on Aspect-Oriented Software Development - AOSD). April 2004. 
HIRSCHFELD, R. AspectS - Aspect-Oriented Programming with Squeak. In: Revised Papers from the International Conference NetObjectDays on Objects, Components, Architectures, Services, and Applications for a Networked World. Erfurt - Germany: Springer-Verlag, 2003. (Lecture Notes in Computer Science, v. 2591), p. 216-232.

HOWDEN, W. E. Functional Program Testing and Analysis. New York: McGrall-Hill, 1987.

IBM et al. Eclipse.org. 2001. Disponível em: <http://www.eclipse.org/>. Acesso em: 05/01/2005.

IEEE Standards Board. IEEE Standard Glossary of Software Engineering Terminology. New York, 1990.

ISBERG, W. Get Test-Inoculated! 2002. Software Development Article. Disponível em: $<$ http://www.sdmagazine.com/documents/s=7360/sdm0205b/ $>$. Acesso em: 26/10/2004.

KAELI, D. R. et al. Aspectual Comprehension: Program Understanding Using Aspects. Northeastern University. 2001.

KARAORMAN, M.; ABERCROMBIE, P. jContractor. 2002. Disponível em: $<$ http://sourceforge.net/projects/jcontractor/>. Acesso em: 05/11/2004.

KICZALES, G. et al. An Overview of AspectJ. Lecture Notes in Computer Science, v. 2072, p. 327-355, 2001.

KICZALES, G. et al. Getting Started with AspectJ. Communications of the ACM, v. 44, n. 10, p. 59-65, October 2001.

KICZALES, G. et al. Aspect-Oriented Programming. In: AKSIT, M.; MATSUOKA, S. (Ed.). Proceedings of the European Conference on Object-Oriented Programming. Berlin, Heidelberg, and New York: Springer-Verlag, 1997. v. 1241, p. 220-242.

KIM, H. AspectC\#: An AOSD implementation for C\#. Dissertação (Mestrado) — Trinity College, Dublin - Ireland, November 2002.

LADDAD, R. AspectJ in Action: Practical Aspect-Oriented Programming. 1. ed. Connecticut - USA: Manning Publications Company, 2003. 512 p.

LARMAN, C. Utilizando UML e Padrões: Uma Introdução à Análise e Projeto Orientados a Objetos. 1. ed. Porto Alegre: Bookman, 2000. 492 p.

LESIECKI, N. Test flexibly with AspectJ and mock objects. 2002. IBM developerWorks. Disponível em: <http://www-106.ibm.com/developerworks/java/library/j-aspectj2/?loc=j $>$. Acesso em: 26/10/2004.

LINKMAN, S.; VINCENZI, A. M. R.; MALDONADO, J. C. An Evaluation of Systematic Functional Testing Using Mutation Testing. In: Proceedings of 7th International Conference on Empirical Assessment in Software Engineering. Staffordshire - UK: [s.n.], 2003. v. 1, p. 1-15.

LOPES, C. V. D: A Language Framework for Distributed Programming. Tese (Doutorado) College of Computer Science - Northeastern University, November 1997. 
MAHRENHOLZ, D.; SPINCZYK, O.; SCHRODER-PREIKSCHAT, W. Program Instrumentation for Debugging and Monitoring with AspectC++. In: Proceedings of the The 5th International Symposium on Object-oriented Real-time Distributed Computing. Crystal City - USA: IEEE Press, 2002. p. 249-256.

MALDONADO, J. C. et al. Teste de Software: Teoria e prática. In: Minicurso - XVII Simpósio Brasileiro de Engenharia de Software (SBES 2003). Manaus - AM: [s.n.], 2003.

MALDONADO, J. C.; FABBRI, S. C. P. F. Teste de Software. In: ROCHA, A. R. C. da; MALDONADO, J. C.; WEBER, K. C. (Ed.). Qualidade de Software - Teoria e Prática. 1. ed. São Paulo: Prentice Hall, 2001. p. 73-84.

MAO, X.; MAY, J. A Framework of Integration Testing Using AspectJ. International Workshop on Aspect-Oriented Software Development (WAOSD 2004), Beijing - China, September 2004.

MASSOL, V. et al. PatternTesting. 2002. Disponível em: <http://patterntesting. sourceforge.net/>. Acesso em: 18/11/2004.

MEYER, B. Applying "Design by Contract". Computer, IEEE Computer Society Press, v. 25, n. 10, p. 40-51, 1992.

MEYER, B. Object-Oriented Software Construction. 2. ed. Santa Barbara - USA: Prentice Hall, 1997. $1296 \mathrm{p}$.

MOLNÁR, B.; BERÉNYI, I.; SIKLÓSI, B. Function Call Trap of Java Codes with the Help of AspectJ and XML. In: CSMR '02: Proceedings of the 6th European Conference on Software Maintenance and Reengineering. Budapest - Hungary: IEEE Computer Society, 2002. p. 207210.

MONK, S.; HALL, S. Virtual Mock Objects using AspectJ with JUnit. 2002. XProgramming.com. Disponível em: <http://xprogramming.com/xpmag/virtualMockObjects.htm $>$. Acesso em: 20/11/2004.

MYERS, G. J. The Art of Software Testing. 1. ed. New York: Wiley, 1979. 177 p.

NTAFOS, S. C. A Comparison of Some Structural Testing Strategies. IEEE Transactions on Software Engineering, v. 14, n. 6, p. 868-873, June 1988.

NURSIMULU, K.; PROBERT, R. L. Cause-effect Graphing Analysis and Validation of Requirements. In: Proceedings of the 1995 conference of the Centre for Advanced Studies on Collaborative research. Toronto - CA: IBM Press, 1995. p. 46.

OFFUTT, J.; IRVINE, A. Testing Object-Oriented Software Using the Category-Partition Method. In: Proceedings of the 17th International Conference on Technology of ObjectOriented Languages and Systems (TOOLS USA '95). Santa Barbara - CA: Prentice-Hall, 1995. p. 293-304.

OLIVA, A. Guaraná: Uma Arquitetura de Software para Reflexão Computacional Implementada em Java. Dissertação (Mestrado) — Universidade Estadual de Campinas, Campinas - SP, Agosto 1998.

OSSHER, H.; TARR, P. Multi-Dimensional Separation of Concerns and The Hyperspace Approach. In: Proceedings of the Symposium on Software Architectures and Component Technology: The State of the Art in Research and Practice. Enschede - Netherlands: Kluwer, 2000. 
OSSHER, H.; TARR, P. Hyper/J: Multi-dimensional separation of concerns for Java. In: Proceedinds of 23rd International Conference on Software Engineering. Toronto - Canada: IEEE Computer Society, 2001. p. 729-730.

OSTRAND, T. J.; BALCER, M. J. The category-partition method for specifying and generating fuctional tests. Communications of the ACM, v. 31, n. 6, p. 676-686, June 1988.

PARADKAR, A. M.; TAI, K.-C.; VOUK, M. A. Specification-Based Testing Using CauseEffect Graphs. Annals of Software Engineering, v. 4, p. 133-157, 1997.

Parasoft Corporation. Jtest. 1997. Disponível em: < http://www.parasoft.com/jtest>. Acesso em: 05/11/2004.

PARNAS, D. L. On the Criteria To Be Used in Decomposing Systems into Modules. Communications of the ACM, v. 15, n. 12, p. 1053-1058, December 1972.

PEARSON, C. A Framework for the Aspect-Oriented Dynamic Instrumentation of Java Programs. London - France, June 2003.

PRESSMAN, R. S. Engenharia de Software. 5. ed. Rio de Janeiro: McGraw-Hill, 2002. 843 p.

RAJAN, H.; SULLIVAN, K. Generalizing AOP for Aspect-Oriented Testing. Virginia - USA, September 2004.

RAPPS, S.; WEYUKER, E. J. Selecting software test data using data flow information. IEEE Transactions on Software Engineering, IEEE Press, v. 11, n. 4, p. 367-375, 1985.

RASHID, A. et al. Early Aspects: A Model for Aspect-Oriented Requirements Engineering. In: Proceedings of the 10th Anniversary IEEE Joint International Conference on Requirements Engineering. Essen - Germany: IEEE Computer Society, 2002. p. 199-202.

Rational Corp. IBM Rational XDE Tester. 2002. Disponível em: <http://www136.ibm.com/developerworks/rational/products/xdetester >. Acesso em: 12/12/2004.

ROCHA, A. D.; CAMARGO, V. V. de; MASIERO, P. C. Uso de Aspectos para Verificar Regras de Instanciação de Frameworks. I Workshop Brasileiro de Desenvolvimento de Software Orientado a Aspectos - WASP'04, Outubro 2004.

ROCHA, A. D. et al. Teste Funcional: Uma abordagem Auxiliada por Aspectos. I Workshop Brasileiro de Desenvolvimento de Software Orientado a Aspectos - WASP'04, Outubro 2004.

SIMÃO, A. S. Proteum-RS/PN: Uma ferramenta para a validação de redes de petri baseada na análise de mutantes. Dissertação (Mestrado) - Universidade de São Paulo - ICMC/USP, São Carlos - SP, Fevereiro 2000.

SPINCZYK, O.; GAL, A.; SCHRODER-PREIKSCHAT, W. AspectC++: An Aspect-Oriented Extension to the $\mathrm{C}++$ Programming Language. In: Proceedings of the 14th International Conference on Technology of Object-Oriented Languages AND Systems (TOOLS Pacific 2002). Sydney - Australia: Australian Computer Society, Inc., 2002. (Conferences in Research and Practice in Information Technology, v. 10), p. 53-60.

STEIN, D.; HANENBERG, S.; UNLAND, R. A UML-based Aspect-Oriented Design Notation. In: Proceedings of the 1st International Conference on Aspect-Oriented Software Development. Enschede - Netherlands: ACM Press, 2002. 
SUGETA, T. Proteum-RS/ST : Uma ferramenta para apoiar a validação de especificações statecharts baseada na análise de mutantes. Dissertação (Mestrado) — Universidade de São Paulo - ICMC/USP, São Carlos - SP, Novembro 1999.

Sun Microsystems. Project Swing (Java Foundation Classes) Software. 2002. Disponível em: $<$ http://java.sun.com/j2se/1.4.2/docs/guide/swing/>. Acesso em: 14/11/2004.

SUZUKI, J.; YAMAMOTO, Y. Extending UML with Aspects: Aspect Support in the Design Phase. In: Proceedings of the Workshop on Object-Oriented Technology. Lisbon - Portugal: Springer-Verlag, 1999. p. 299-300.

TARR, P. et al. N Degrees of Separation: Multi-Dimensional Separation of Concerns. In: Proceedings of the 21st international conference on Software engineering. Los Angeles - CA: IEEE Press, 1999. p. 107-119.

TROMER, E. Java Instrumentation Engine (JIE). 1999. Disponível em: $<$ http://www.forum2.org/eran/jie/>. Acesso em: 06/09/2004.

VINCENZI, A. M. R. Orientação a Objetos: Definição, Implementação e Análise de Recursos de Teste e Validação. Tese (Doutorado) — Universidade de São Paulo - ICMC/USP, São Carlos - SP, Março 2004.

VINCENZI, A. M. R. et al. Java Bytecode Static Analysis: Deriving Structural Testing Requirements. In: Proceedings of the 2nd UK Software Testing Workshop - UK-Softest'2003. York: University of York Press, 2003.

VINCENZI, A. M. R. et al. JaBUTi: A Coverage Analysis Tool for Java Programs. In: Anais da Sessão de Ferramentas do XVII Simpósio Brasileiro de Engenharia de Software. Manaus AM: [s.n.], 2003.

VOAS, J. M.; MILLER, K. W. Software Testability: The New Verification. IEEE Software, v. 12, n. 3, p. 17-28, May 1995.

WALEND, D. Cricket Cage. 2002. Disponível em: < http://sourceforge.net/projects/cricketcage>. Acesso em: 18/12/2004.

WALL, T. Abbot framework for automated testing of Java GUI components and programs. 2002. Disponível em: <http://abbot.sourceforge.net/>. Acesso em: 05/11/2004.

WENNER, R. Abstract Test Aspect: Testing with AOP. Lecture Notes in Computer Science, v. 3092, p. 237-241, May 2004.

WOOLLEY, C. VirtualMock. 2003. Disponível em: < http://www.virtualmock.org/>. Acesso em: 18/12/2004. 


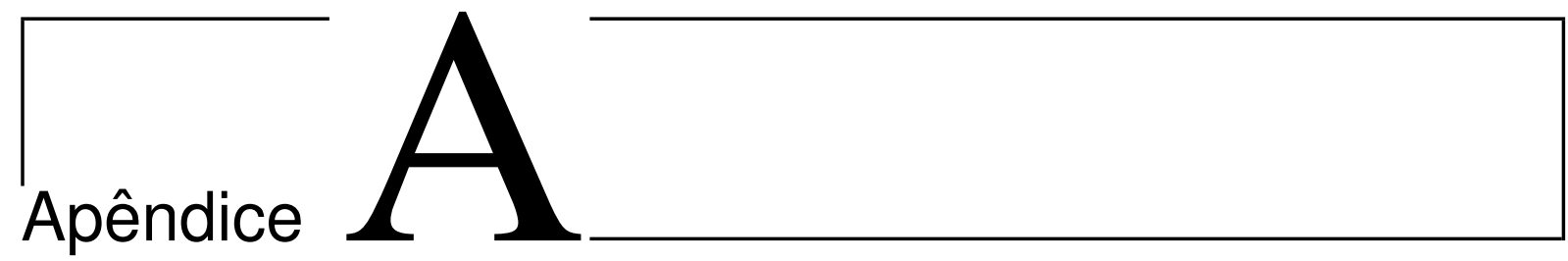

\section{Classes da aplicação VendingMachine}

Neste apêndice encontram-se as estruturas das classes da aplicação VendingMachine, utilizadas para a sua implementação.

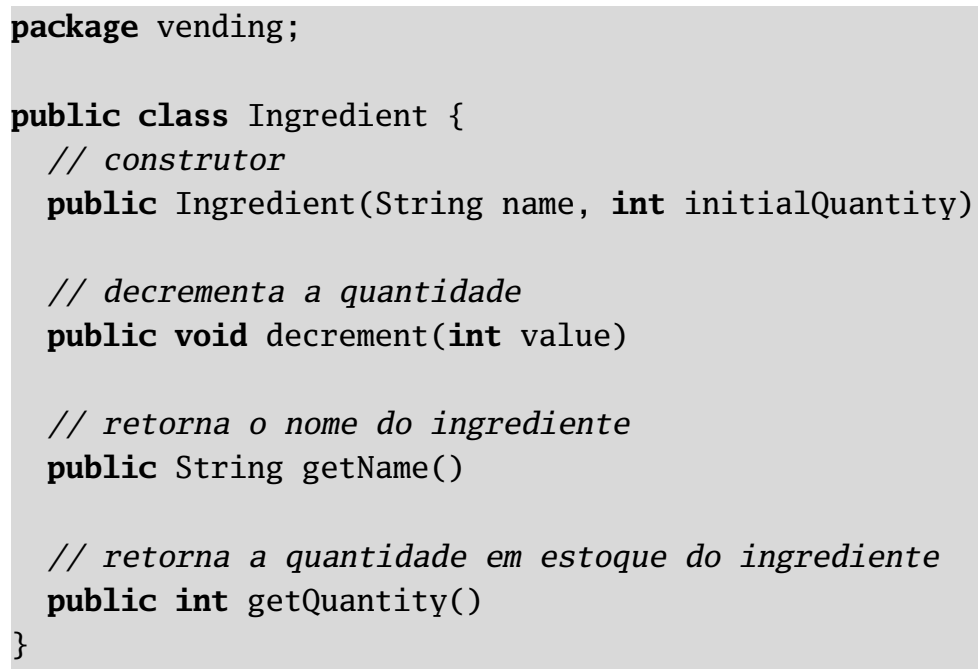

Figura A.1: Classe Ingredient 


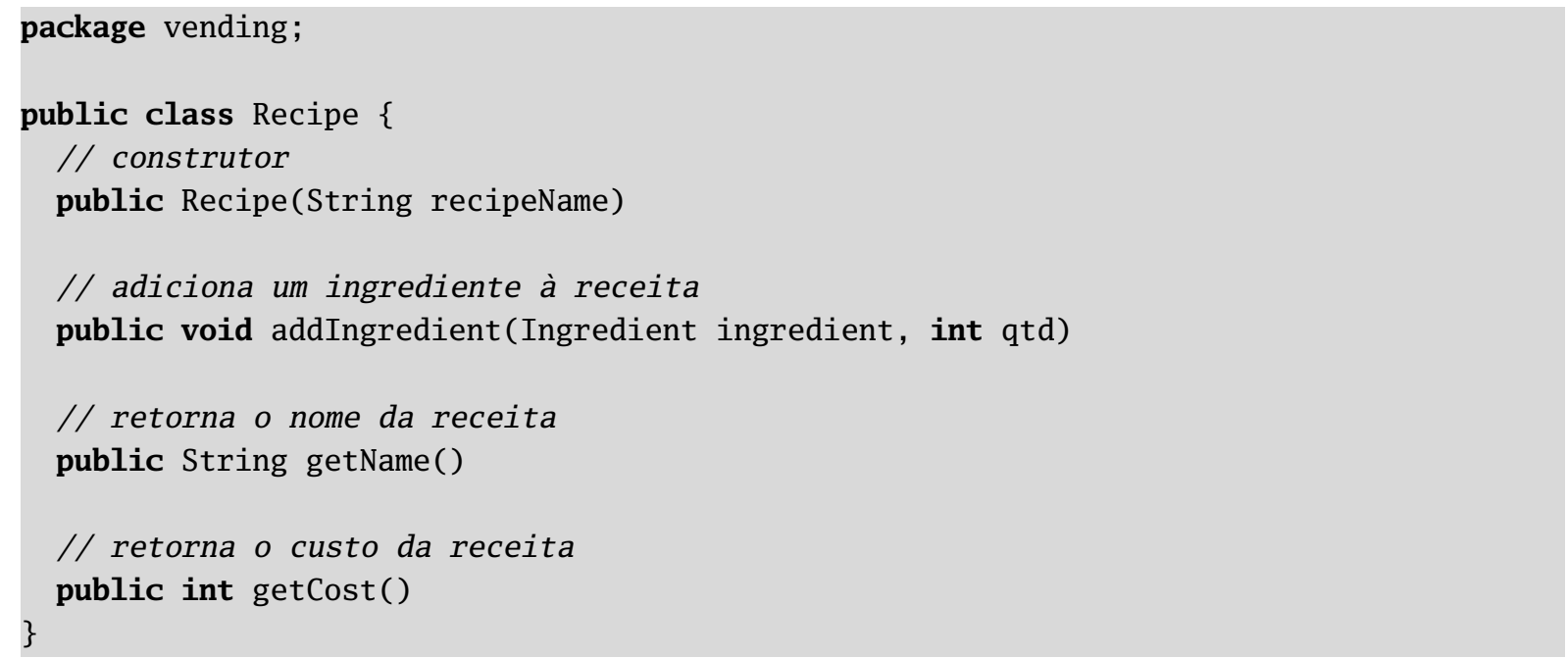

Figura A.2: Classe Recipe

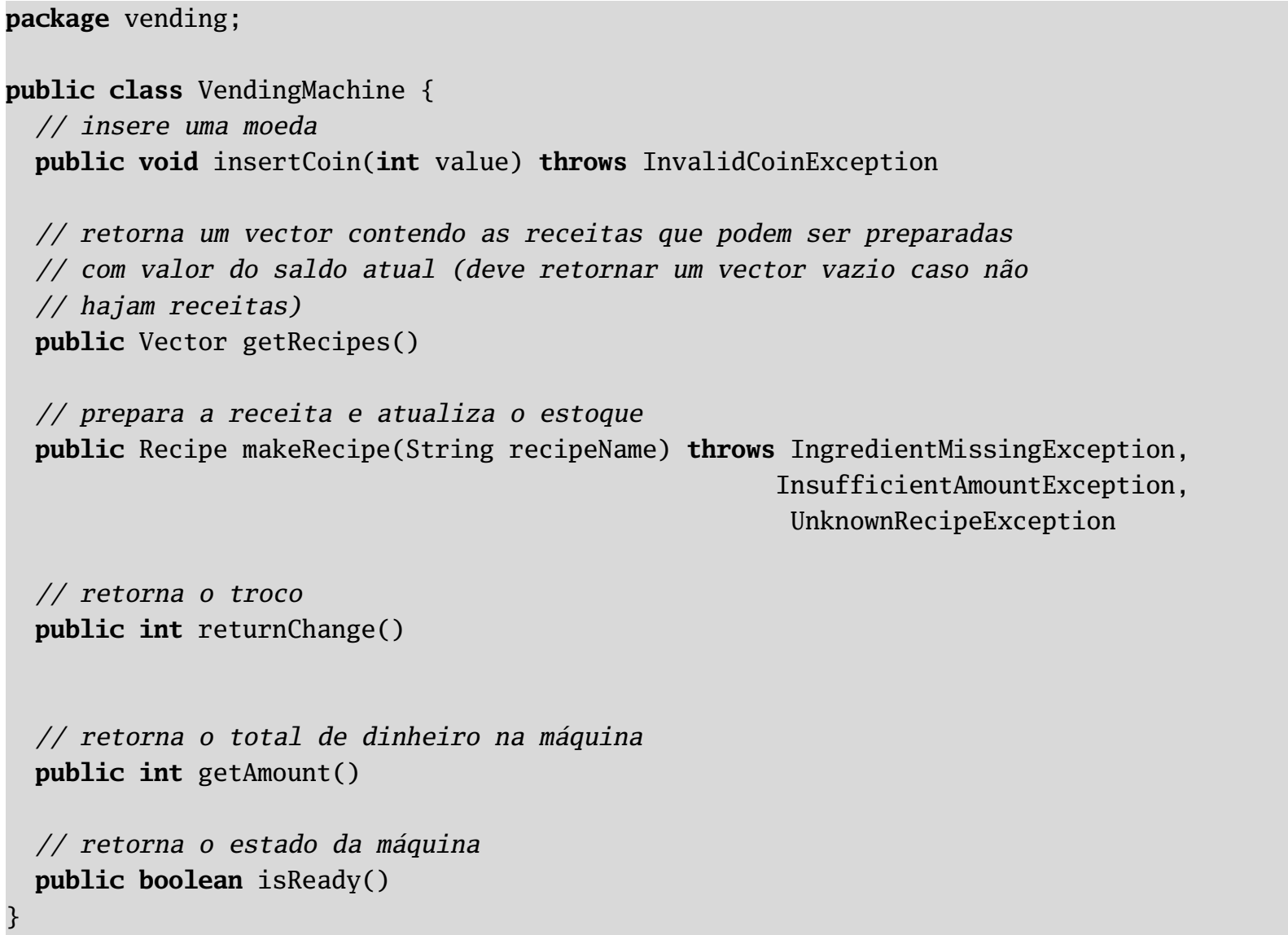

Figura A.3: Classe VendingMachine 


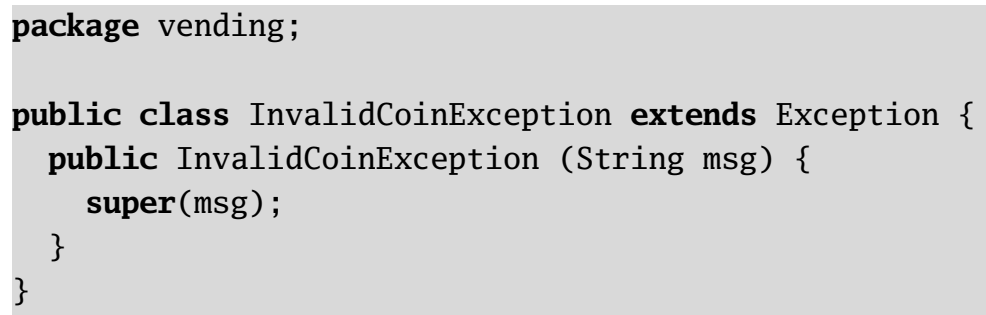

Figura A.4: Classe InvalidCoinException

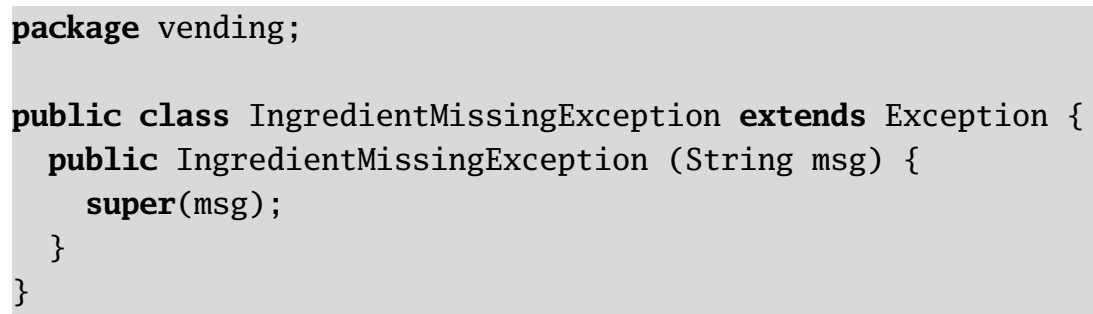

Figura A.5: Classe IngredientMissingException

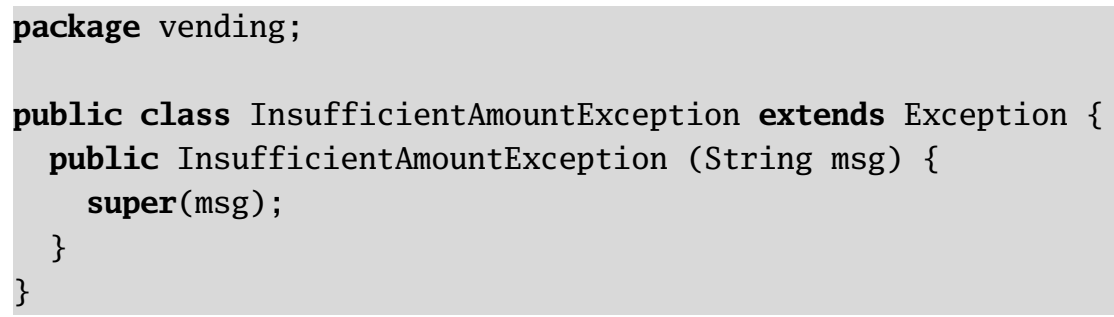

Figura A.6: Classe InsufficientAmountException

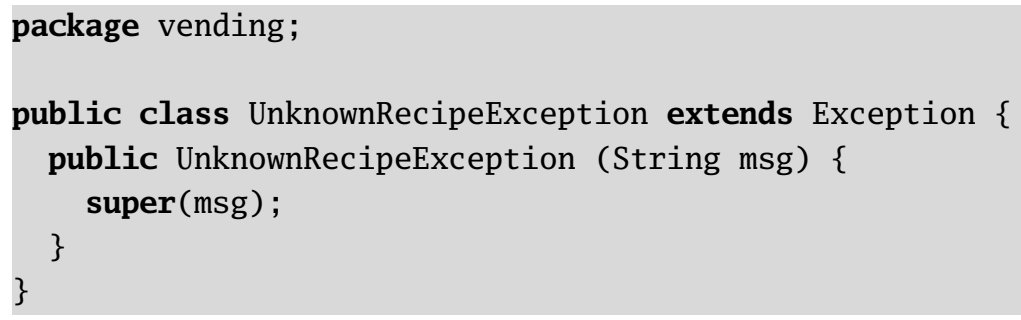

Figura A.7: Classe UnknownRecipeException 


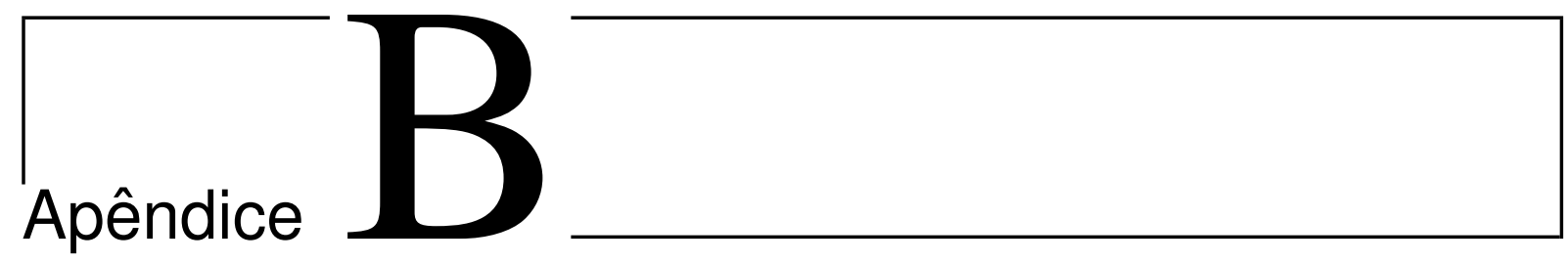

\section{Classes e pacotes da ferramenta}

\section{J-FuT}

\begin{tabular}{|l|}
\hline jfut.core \\
\hline JFUT \\
Project \\
ProjectManager \\
\hline jfut.testing \\
\hline Boundary \\
Criterion \\
FunctionalTestCase \\
InputCondition \\
InvalidEquivalence \\
Invariant \\
Operation \\
PosCondition \\
PreCondition \\
Requirement \\
RequirementFactory \\
ValidEquivalence \\
\hline jfut.testing.instrumentation \\
\hline AspectJCodeGenerator \\
CodeGenerator \\
JBossCodeGenerator \\
\hline
\end{tabular}


jfut . testing . instrumentation . aspect $\mathbf{j}$

ActionsLogger

ImplementationException

Instrumentation

PolicyEnforcement

Tracing

jfut . testing . instrumentation. jboss

Instrumentation

TestCaseInterceptor

WeavingGenerator

jfut . testing . runner

CustomTestCase

CustomTestRunner

\section{jfut . testing . table}

TestTable

TestTableStrategy

TestTableStrategyFirstValid

TestTableStrategyInvalidate

TestTableStrategy0ptimizeReqs

TestTableStrategy0ptimizeTests

jfut.ui

DebuggingTree

JavaEditor

JavaEditorLineNumber

MainWindow

ProjectManagerPanel

ProjectRenderer

Splash

TestCaseEditor

TestCaseEnabler

TestCaseSelector

jfut .ui.renderers

BoldListCellRenderer

CheckBoxListCellRenderer

ColoredListCellRenderer

DebuggingTreeRenderer

FunctionalTestTableCellRenderer

InputConditionTableCellRenderer

MethodListCellRenderer

MethodTableCellRenderer

TestEnablerTableCellRenderer

jfut.ui.report

InputConditionTableModel

ReportInputConditionsCoverage

ReportInputConditionsCoverageContainer

ReportMethodsCoverage

ReportMethodsCoverageContainer

ReportTestsXClasses

ReportTestsXClassesContainer 


\section{jfut.ui.wizard}

CustomFile

FileTreeModel

InputConditionDialog

RequirementDialog

SourceEditor

StepMethodSelection

StepPackageSelection

StepPanel

StepSourceVisualizer

Wizard

\section{jut.util}

AspectUtils

FileUtils

ListUtils

UiUtils

\section{jfut.util.ant}

AntRunner

AspectJRunner

CustomUnitTask

JBossRunner

WeaverRunner

\section{jfut.util.classes}

ClassInfo

ClassPathHacker

SimpleClassLoader

CustomFileFilter

\section{jfut.util.structures}

PriorityQueue

PriorityVector

\section{jfut.xml}

CallManager

ConfigManager

TraceManager

XMLManager

XMLValidator 